Marina Lúcia Bulla Zanetti

\title{
Mortalidade no longo prazo de pacientes ambulatoriais do Sistema Único de Saúde com suspeita diagnóstica ou diagnóstico de doença cardiovascular atendidos em ambulatório de serviço médico acadêmico com alto volume de atendimentos
}

Tese apresentada à Faculdade de Medicina da Universidade de São Paulo para obtenção do título de Doutor em Ciências

Programa de Cardiologia

Orientador: Prof. Dr. Alfredo José Mansur

SÃO PAULO 
Dados Internacionais de Catalogação na Publicação (CIP)

Preparada pela Biblioteca da

Faculdade de Medicina da Universidade de São Paulo

Creprodução autorizada pelo autor

\section{Zanetti, Marina Lúcia Bulla}

Mortalidade no longo prazo de pacientes ambulatoriais do Sistema Único de Saúde com suspeita diagnóstica ou diagnóstico de doença cardiovascular atendidos em ambulatório de serviço médico acadêmico com alto volume de atendimentos / Marina Lúcia Bulla Zanetti -- São Paulo, 2019.

Tese(doutorado)--Faculdade de Medicina da Universidade de São Paulo. Programa de Cardiologia.

Orientador: Alfredo José Mansur.

Descritores: Doenças cardiovasculares/diagnóstico 2.Assistência ambulatorial 3.Análise de sobrevida 4.Prognóstico 5.Mortalidade

\section{USP/FM/DBD-397/19}

Responsável: Erinalva da Conceição Batista, CRB-8 6755 
Ao Vitor, esposo, por sua presença em todos os momentos. Aos meus filhos, Lucas e André, pelo grande estímulo. Aos meus pais, Jurandir e Margareth, que nos ensinaram a família. 


\section{AGRADECIMENTOS}

À Sra. Carmen Mohamad Rida Saleh, Diretora Técnica de Saúde do Instituto Central do HC FMUSP, pelo incentivo ao desenvolvimento da prática da Enfermagem fundamentada na pesquisa científica.

Ao orientador Prof. Dr. Alfredo José Mansur, Diretor da Unidade Clínica de Ambulatório Geral do Instituto do Coração do HC FMUSP, pela orientação e estímulo a ricas interações multidisciplinares suscitadas e cultivadas no decorrer da presente investigação.

À Dra. Bernadette Cunha Waldvogel, Gerente de Indicadores e Estudos Populacionais, à Sra. Monica La Porte Teixeira, Chefe de Divisão de Produção de Indicadores Demográficos e Analista de Projetos, e à Sra. Lilian Cristina Correia Morais, Analista de Projetos - pesquisadores da Fundação Sistema Estadual de Análise de Dados (Fundação SEADE) pela experiência compartilhada no planejamento, coleta e análise de dados do presente trabalho.

À Profa. Dra. Lucia Pereira Barroso, Professora Livre-Docente do Instituto do Matemática e Estatística da USP, pela dedicada, competente e formadora orientação para análise e interpretação dos dados.

Ao Prof. Dr. Antonio Carlos Pedroso de Lima, Professor Associado do Instituto de Matermática e Estatística da USP, pelas contribuições na análise e e interpretação dos dados.

Aos acadêmicos Rodrigo Marques da Cruz e Valdecir Marvulle pelo dedicado trabalho inicial de análise de dados como parte do programa desenvolvido no Centro de Estatística Aplicada do Instituto do Matemática e Estatística da USP.

À Secretaria da Comissão de Pós-Graduação do Instituto do Coração e da Disciplina de Cardiologia nas pessoas da Sra. Neusa Rodrigues Dini e sua equipe de assessoras pelo empenho receptivo nos encaminhamentos que foram necessários em um projeto desta natureza.

À Profa. Barbara Rzyski pela revisão e correção ortográfica deste trabalho. 
À Sra. Sandra Miranda Souza, assistente administrativa da Unidade Clínica de Ambulatório Geral do Instituto do Coração do HC FMUSP pela contribuição cotidiana durante o desenvolvimento do trabalho.

À Sra. Juliana Nogueira Franco Buani, Gerente de Enfermagem do Hospital Regional de São José dos Campos, pelo apoio na etapa de conclusão deste trabalho. 
"To understand God's thoughts we must study statistics, for these are the measure of His purpose."

Florence Nightingale

"A filosofia é conhecimento da verdade e o conhecimento da verdade é o conhecimento das causas."

Aristóteles - Metafísica

"[...] Queria entender do medo e da coragem, e da gã que empurra a gente para fazer tantos atos, dar corpo ao suceder."

João Guimarães Rosa - Grande Sertão: Veredas 
Esta tese está de acordo com as seguintes normas, em vigor no momento de sua publicação:

Referências: adaptado de International Committee of Medical Journals Editors (Vancouver).

Universidade de São Paulo. Faculdade de Medicina. Divisão de Biblioteca e Documentação. Guia de apresentação de dissertações, teses e monografias. Elaborado por Anneliese Carneiro da Cunha, Maria Julia de A.L.Freddi, Maria F.Crestana, Marinalva de Souza Aragão, Suely Campos Cardoso, Valéria Vilhena. 3ํㅗㄹ ed. São Paulo: Divisão de Biblioteca e Documentação; 2011.

Abreviatura dos títulos e periódicos de acordo com List of Journals Indexed in Index Medicus. 


\section{SUMÁRIO}

Lista de figuras

Listas de tabelas

Lista de símbolos

Resumo

Abstract

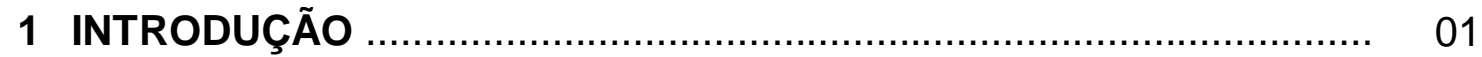

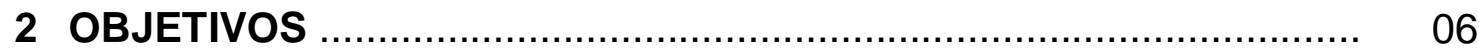

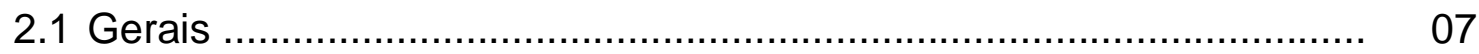

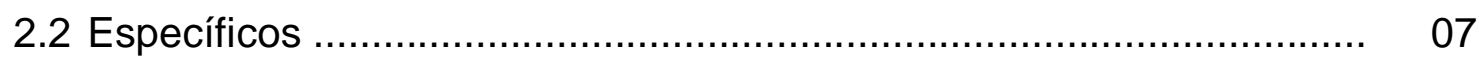

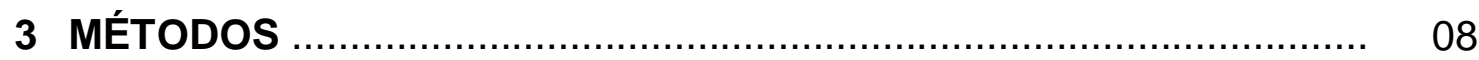

3.1 Local do estudo ................................................................. 09

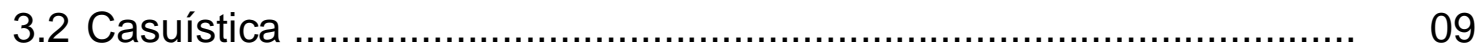

3.2.1 Critérios de inclusão ............................................................. 10

3.2.2 Critérios de exclusão .................................................................. 10

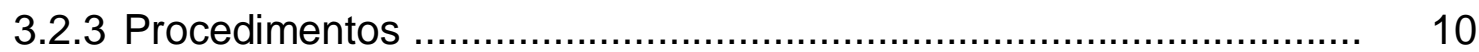

3.2.3.1 Identificação da casuística dos atendimentos médicos ................ 10

3.2.3.2 Pesquisa da casuística na Fundação SEADE ............................. 10

3.2.3.3 Vinculação dados InCor e Fundação SEADE ............................. 11

3.2.4 Variáveis estudadas .............................................................. 12

3.3 Análise Estatística .................................................................. 12

3.3.1 Verificação da consistência dos dados .......................................... 12

3.3.2 Análise descritiva ................................................................... 12

3.3.3 Análise de sobrevivência ........................................................... 13

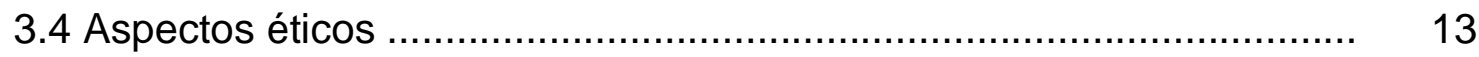

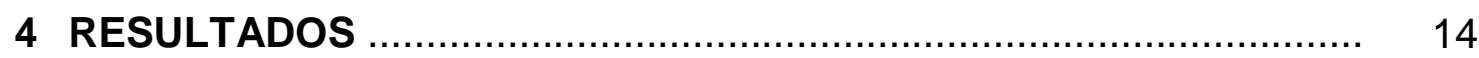

4.1 Características demográficas dos pacientes .................................... 15

4.2 Número de consultas ............................................................... 15

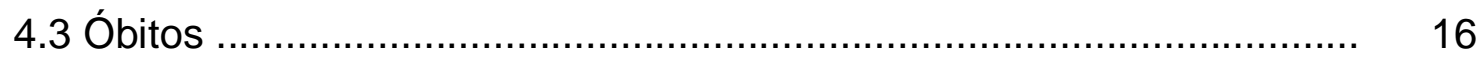

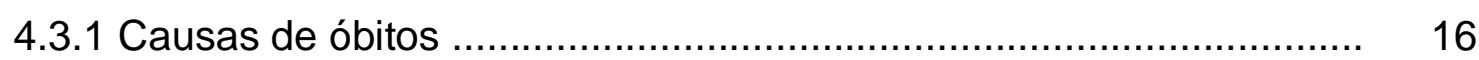

4.3.1.1 Causa básica ......................................................................... 16 
4.3.1.2 Causa imediata de óbito (linha A) e associações com outras causas

4.3.1.3 Relação entre causa básica e outras causas/outras linhas/listadas.

4.3.2 Associações da idade com regiões da cidade, com óbitos e causas de óbito .............................................................................. 23

4.4 Tempo de sobrevida estimada .................................................. 24

4.4.1 Tempo de sobrevida com base nos pacientes que morreram ............ 24

4.4.2 Tempo de sobrevida estimada com base em todos os pacientes da casuística

4.5 Riscos competitivos

5 DISCUSSÃO

5.1 Características demográficas dos pacientes ................................... 27

5.2 Número de consultas ........................................................... 29

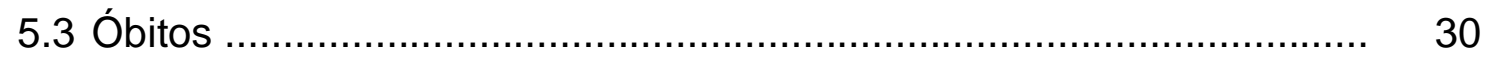

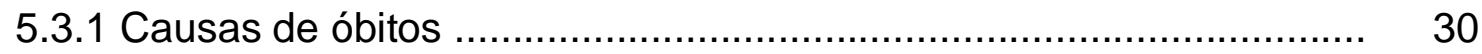

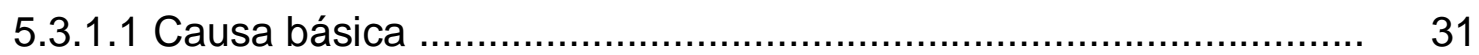

5.3.1.2 Causa imediata de óbito (linha A) e associações com outras causas

5.3.1.3 Relação entre causa básica e outras causas/outras linhas/listadas

5.3.2 Associações da idade com regiões da cidade, com óbitos e causas de óbito

5.4 Tempo de sobrevida estimada

5.4.1Tempo de sobrevida estimada com base nos pacientes que morreram

5.4.2 Tempo de sobrevida estimada com base em todos os pacientes da casuística

5.5 Riscos Competitivos

5.6 Implicações clínicas

5.7 Limitações do estudo 36

6 CONCLUSÕES 


\section{LISTA DE FIGURAS}

Figura 1 Histograma de idade à primeira consulta (2002-2013) ............. 40

Figura 2 Idade à primeira consulta (por ano) .................................... 40

Figura 3 Idade à primeira consulta e da idade ao óbito ......................... 41

Figura 4 Tempo da primeira consulta até o óbito ............................... 41

Figura 5 Distribuição de frequências do local de residência ................... 42

Figura 6 Análise de correspondência da população anual média por faixa etária, segundo região da cidade de São Paulo

Figura 7 Análise de correspondência da idade ao óbito e do local de residência

Figura 8 Análise de correspondência da idade ao óbito e da causa básica do óbito

Figura 9 Análise de correspondência da causa básica e da causa associada de óbito (agrupamento 1)

Figura 10 Análise de correspondência da causa básica e da causa associada de óbito (agrupamento 2)

Figura 11 Probabilidade de sobrevida estimada (Kaplan-Meier) para tempo de acompanhamento agrupado por número de consultas (somente para os pacientes que faleceram)

Figura 12 Probabilidade de sobrevida estimada (Kaplan-Meier) para tempo de acompanhamento de idade ao óbito, agrupado por número de consultas (somente para os pacientes que vieram a óbito)

Figura 13 Probabilidade de sobrevida estimada (Kaplan-Meier) para tempo de acompanhamento agrupado por sexo (somente para os pacientes que vieram a óbito)

Figura 14 Probabilidade de sobrevida estimada (Kaplan-Meier) para idade ao óbito agrupado por sexo (somente para os pacientes que vieram a óbito) 
Figura 15 Probabilidade de sobrevida estimada (Kaplan-Meier) para tempo de acompanhamento agrupado por idade à primeira consulta (somente para os pacientes que vieram a óbito)

Figura 16 Probabilidade de sobrevida estimada (Kaplan-Meier) para idade ao óbito agrupado por idade à primeira consulta (somente para os pacientes que vieram a óbito)

Figura 17 Probabilidade de sobrevida estimada (Kaplan-Meier) para tempo de acompanhamento agrupado por causa básica de óbito (somente para os pacientes que vieram a óbito)

Figura 18 Probabilidade de sobrevida estimada (Kaplan-Meier) para idade ao óbito agrupado por causa básica de óbito (somente para os pacientes que vieram a óbito)

Figura 19 Probabilidade de sobrevida estimada (Kaplan-Meier) para tempo de acompanhamento agrupado por causa básica de óbito (somente para os pacientes que vieram a óbito)

Figura 20 Probabilidade de sobrevida estimada (Kaplan-Meier) para idade ao óbito agrupado por causa básica de óbito (somente para os pacientes que vieram a óbito)

Figura 21 Probabilidade de sobrevida estimada (Kaplan-Meier) para tempo de acompanhamento agrupado por sexo (para todos os pacientes que passaram em consulta

Figura 22 Probabilidade de sobrevida estimada (Kaplan-Meier) para idade ao óbito agrupado por sexo (para todos os pacientes que passaram em consulta)

Figura 23 Função de Incidência Acumulada (FIA) para idade ao óbito modelado por risco competitivo de acordo com a causa básica de óbito (para todos os pacientes que passaram em consulta) .. 


\section{LISTA DE TABELAS}

Tabela 1 Medidas-resumo de idade por sexo na primeira consulta (2002 -2013)

Tabela 2 Distribuição de frequências do número de consultas por paciente, segundo o sexo

Tabela 3 Distribuição de frequências de consultas por unidade federativa de residência

Tabela 4 Distribuição de frequências de consultas por município de residência

Tabela 5 Distribuição de frequências de consultas por região de residência na cidade de São Paulo (2002 - 2013)

Tabela 6 População anual média e número de visitas anual médio ao InCor por 100.000 habitantes (de 2002 a 2013) por região da cidade de São Paulo

Tabela 7 Distribuição de frequências de consultas por distrito de residência na cidade de São Paulo

Tabela 8 Distribuição de frequências do ano de óbito ................................. 57

Tabela 9 Distribuição de frequências de óbito por sexo ….......................... 57

Tabela 10 Medidas-resumo de idade ao óbito ............................................. 57

Tabela 11 Medidas-resumo da Idade ao óbito por número de consultas ..... 58

Tabela 12 Medidas-resumo de idade ao óbito e medidas-resumo do tempo da primeira consulta até o óbito

Tabela 13 Distribuição de frequências de causa básica de óbito (por tipo de doença de acordo com CID 10)

Tabela 14 Contagem de causa básica por letra do CID 10

Tabela 15 Distribuição de frequências de causa básica de óbito (por grupo de doença do aparelho circulatório)

Tabela 16 Distribuição de frequências do número de consultas por causa básica de óbito (doenças do aparelho circulatório $x$ outras doenças) 
Tabela 17 Distribuição de frequências do número de consultas por causa básica de óbito (tipo de doença agrupado)

Tabela 18 Distribuição de frequências da causa básica de óbito por ano de óbito

Tabela 19 Medidas-resumo da Idade à primeira consulta por causa básica de óbito (doenças do aparelho circulatório x outras doenças) ....

Tabela 20 Distribuição de frequências da causa básica de óbito (doenças do aparelho circulatório $x$ outras doenças) por sexo

Tabela 21 Contagem de causa básica por agrupamento . 65

Tabela 22 Contagem de causa imediata por letra do CID10

Tabela 23 Porcentagens com relação a causa básica por letra do CID 10 (linha causa básica $x$ coluna causa imediata

Tabela 24 Porcentagens com relação a causa imediata por letra do CID 10 (linha causa imediata x coluna linhas B, C, D e II)

Tabela 25 Contagem de causa imediata por agrupamento

Tabela 26 Porcentagens com relação a causa imediata por agrupamento (linha causa imediata $x$ coluna causa básica)

Tabela 27 Porcentagens com relação a causa imediata por agrupamento (linha causa imediata x coluna B, C, D e II)

Tabela 28 Todas as causas de óbitos listadas nas cinco linhas do atestado (causa imediata $(A)$, causa básica, e outros diagnósticos das linhas B, C, D e II)

Tabela 29 Distribuição de causa imediata por agrupamento por ano do óbito

Tabela 30 Porcentagens com relação a causa básica por agrupamento (linha causa básica $x$ coluna causa imediata)

Tabela 31 Porcentagens com relação a causa básica por agrupamento (linha causa básica x coluna linhas B, C, D e II)

Tabela 32 Porcentagens com relação a causa básica por letra do CID 10 (linha causa básica $x$ coluna linhas B, C, D e II)

Tabela 33 Medidas-resumo da idade ao óbito por ano de óbito 
Tabela 34 Sobrevida estimada (Kaplan-Meier) para tempo de acompanhamento por número de consultas realizadas (apenas para os pacientes que vieram a óbito)

Tabela 35 Estatísticas calculadas pelo método de Kaplan-Meier para idade ao óbito por número de consultas realizadas (apenas para os pacientes que vieram a óbito)

Tabela 36 Estatísticas calculadas pelo método de Kaplan-Meier para tempo de acompanhamento por sexo (apenas para os pacientes que vieram a óbito)

Tabela 37 Estatísticas calculadas pelo método de Kaplan-Meier para idade ao óbito por sexo (apenas para os pacientes que vieram a óbito)

Tabela 38 Estatísticas calculadas pelo método de Kaplan-Meier para tempo de acompanhamento por faixa etária à primeira consulta (apenas para os pacientes que vieram a óbito)

Tabela 39 Estatísticas calculadas pelo método de Kaplan-Meier para idade ao óbito por faixa etária à primeira consulta (apenas para os pacientes que vieram a óbito)

Tabela 40 Estatísticas calculadas pelo método de Kaplan-Meier para tempo de acompanhamento por causa básica de óbito (grandes grupos de doenças e apenas para os pacientes que vieram a óbito)

Tabela 41 Estatísticas calculadas pelo método de Kaplan-Meier para idade ao óbito por causa básica de óbito (grandes grupos de doenças e apenas para os pacientes que vieram a óbito)

Tabela 42 Estatísticas calculadas pelo método de Kaplan-Meier para tempo de acompanhamento por causa básica de óbito (por grupos

Tabela 43 Estatísticas calculadas pelo método de Kaplan-Meier para idade ao óbito por causa básica de óbito (por grupos de doenças cardíacas e apenas para os pacientes que vieram a óbito) 


\section{LISTA DE SÌMBOLOS}

$\begin{array}{ll}\mathrm{km}^{2} & \text { quilômetro quadrado } \\ \% & \text { por cento } \\ > & \text { maior que } \\ \geq & \text { maior ou igual a } \\ < & \text { menor que } \\ \leq & \text { menor ou igual a }\end{array}$




\section{RESUMO}

Zanetti MLB. Mortalidade no longo prazo de pacientes ambulatoriais do Sistema Único de Saúde com suspeita diagnóstica ou diagnóstico de doença cardiovascular atendidos em ambulatório de serviço médico acadêmico com alto volume de atendimentos [tese]. São Paulo: Faculdade de Medicina, Universidade de São Paulo; 2019.

Fundamentos: o conhecimento da evolução de pacientes com diagnóstico ou suspeita diagnóstica de doença cardiovascular após 0 atendimento médico, particularmente a mortalidade, é de interesse para diferentes aspectos da atenção à saúde cardiovascular. Objetivos: analisar a mortalidade no longo prazo de pacientes ambulatoriais atendidos em razão de suspeita diagnóstica ou com diagnóstico de doença cardiovascular, investigar as causas de morte, a mortalidade no longo prazo de acordo e estimar o tempo decorrido entre a primeira consulta médica e o óbito. Delineamento: vinculação de base de dados assistencial com dados de mortalidade disponíveis nos atestados de óbito disponibilizados através de registros seguros pela Fundação SEADE. As causas atribuídas de óbito foram categorizadas segundo o CID 10. Local: ambulatório cardiológico com alto volume de atendimentos voltado para pacientes do Sistema Único de Saúde (SUS) em hospital acadêmico de referência terciário. Participantes: 180.929 pacientes atendidos em 244.828 consultas entre 2002 e 2013. Desfecho: óbito por qualquer causa. Análise dos Dados: Vinculação determinística, formando pares com identidade, dúvidas dirimidas por análise individualizada: análise de sobrevivência, análise de correspondência e de riscos competitivos. Resultados: ocorreram 31956 (17,7\%) óbitos entre os 180.929 pacientes atendidos entre 2002 a 2013. O tempo médio decorrido entre a primeira consulta e o óbito foi 3,3 anos (desvio padrão 2,9 anos); a média de idade por ocasião do óbito foi 69,3 anos (desvio padrão 13,8 anos). Predominaram homens nos pacientes que faleceram (17.241, $54 \%$ homens vs. $14.711,46 \%$ mulheres). As causas básicas de óbito foram doenças do aparelho circulatório em $15.676(49,1 \%)$ pacientes, neoplasias em 4559 (14,3\%), doenças do aparelho respiratório em $3615(11,3 \%)$. As causas imediatas de óbitos mais comuns foram: 8.669 (25,6\%) por exames laboratoriais alterados, $7.381(21,8 \%)$ causas por doenças do aparelho respiratório, $7.336(21,6 \%)$ causas por doenças do aparelho circulatório, $4.748(14 \%)$ por doenças infecciosas ou parasitárias e o restante 5.748 (17\%) outros diagnósticos (frequências $<8 \%$ ). A idade dos pacientes por ocasião do óbito foi maior nas mulheres (média 70,5 anos) do que para os homens (média 68,3 anos) $(P<0,001)$. A função de incidência acumulada revelou que a taxa de incidência de óbito foi aproximadamente $42 \%$ nos portadores de doença cardíaca, cerca de $15 \%$ para os portadores de doença pulmonar, $12 \%$ para os portadores de neoplasia e $25 \%$ para outras doenças. Conclusões: Percentagem significativa de pacientes vem a falecer em até 3,3 anos depois de atendimento médico cardiológico ambulatorial de referência. O óbito foi 
atribuído a causas não cardíacas em aproximadamente metade dos pacientes. A função de incidência acumulada revelou que a taxa de incidência de óbito foi maior nos portadores de doença cardíaca.

Descritores: Doenças cardiovasculares, diagnóstico, assistência ambulatorial, análise de sobrevida, prognóstico, mortalidade. 


\begin{abstract}
Zanetti MLB. Mortality in the long-term follow-up of outpatients of Sistema Único de Saúde with suspected or diagnosed cardiovascular disease of an outpatient clinics of an academic referral center [thesis]. "São Paulo: Faculdade de Medicina, Universidade de São Paulo"; 2019.

Background: knowledge of outcome of outpatients diagnosed or with suspected diagnosis of cardiovascular disease after medical consultation is evolution after medical attendance, in particular mortality rate, is of interest to different aspects of the cardiovascular health. Objectives: to analyze the long-term mortality rate of ambulatorial outpatients attended by reason of suspected diagnosis or with diagnosis for cardiovascular diseases, investigate the cause of death, the long-term mortality and estimate the time between the first medical attendance to the death. Design: crossing of ambulatorial outpatients' database with mortality data available in the death certificates from secure registers of SEADE foundation. The death causes were categorized by CID 10 categories. Setting: outpatient clinic from an academic tertiary cardiology center. Participants: 180,929 outpatients in 244,828 ambulatorial attendances between 2002 and 2013. Outcomes: death by any cause. Data analysis: Deterministic binding, forming identity pairs, doubts solved by individual analysis: survival analysis, correspondence analysis and competitive risks analysis. Results: $31.956(17.7 \%)$ of the 180.929 outpatients, between 2002 and 2013 . The average time between first attendances and death was 3.3 years, (standard deviation of 2.9 years); the average age of death was 69.3 years (standard deviation of 13.8 years). The majority of deaths occurred among men (17,241, 54\% of men vs $14,711,46 \%$ of women). The more common immediate cause of death were: alterations in laboratorial exams, 8,669 (25,6\%); respiratory system diseases, 7.381 (21,8\%); circulatory system diseases, 7,336 (21,6\%); infectious or parasitary diseases, 4.748 (14\%); and 5,748 other diagnosis (frequencies $<8 \%$ ). The average age at death was higher between the women (70.5 years) then between men (68.3 years) $(p<0,001)$. The cumulative incidence function for deaths was approximately $42 \%$ in persons with cardiac diseases, circa $15 \%$ in persons with pulmonary diseases, $12 \%$ to people with neoplasia and circa $25 \%$ of other diseases. Conclusions: Significative percentage of the outpatients die in 3,3 years from the first attendance in the academic tertiary cardiology center. The death was attributed to non-cardiac diseases in approximately half of the outpatients. The cumulative incidence function revealed that the death incidence were higher on the outpatients with cardiac diseases.
\end{abstract}

Descriptors: cardiovascular diseases, diagnosis, ambulatory care, survival analysis, prognosis, mortality. 
1 INTRODUÇÃO 


\section{INTRODUÇÃO}

As doenças cardiovasculares são definidas como o conjunto de moléstias que afetam o coração e os vasos sanguíneos. Entre essas doenças estão os acidentes vasculares cerebrais, as doenças arteriais coronárias como anginas, infartos, miocardiopatias, arritmias, trombose, valvulopatias, entre outras. É importante ressaltar, que elas representam um problema de saúde pública importante por causa de suas complexidades e magnitude (OPAS, 2017).

De acordo com a Organização Pan-Americada de Saúde (OPAS, 2017) as doenças cardiovasculares são a causa principal de morte no mundo, e mais de três quartos dos óbitos por doenças cardiovasculares ocorrem em países de renda baixa e média, pois a população tem menos acesso aos serviços de saúde e é diagnosticada tardiamente. A maioria dessas doenças pode ser prevenida por meio de abordagem de fatores de risco como obesidade, sedentarismo, dieta não saudável.

As taxas de mortalidade por doença cardiovascular no mundo aumentaram 12,5\% entre 2005 e 2015 (IC 95\% 10,6 - 14,4), entretanto houve uma queda de 15,6\% (IC 95\% 14,2 - 16,9) referente à idade média das mortes por doenças cardiovasculares (Ribeiro et al., 2016).

De acordo com dados da World Heart Federation (2017), as doenças cardiovasculares constituem o maior ônus para a saúde no mundo, e correspondem a mais de 17 milhões de mortes a cada ano.

Segundo dados estatísticos da American Heart Association, a doença cardiovascular é a principal causa de morte no mundo. Em 2016, ocorreram 274.4248 mortes nos EUA, ultrapassando os óbitos por diversas causas como câncer, doenças respiratórias, acidente vascular cerebral e suicídios (Benjamim et al., 2019).

No Brasil, as doenças cardiovasculares têm sido a principal causa de morte desde o final da década de 1960. Nas últimas décadas, têm contribuído as mudanças no estilo de vida como ingestão calórica mais elevada, vida sedentária e o envelhecimento da população (Monteiro et al., 2011; Schmidt et al., 2011; MS, 2012; Ribeiro et al., 2016).

A atenção à saúde no Brasil segue os padrões determinados pela Organização Mundial de Saúde (OMS), segundo os quais os serviços de saúde devem ser 
agrupados de acordo com a complexidade das ações necessárias para promover, restaurar ou manter a saúde da população. Existem três níveis de atenção à saúde, sendo eles: primário, que concentra as ações relacionadas à diminuição do risco de doenças e à proteção da saúde - prevenção; secundário, que é formado pelos hospitais e ambulatórios responsáveis por oferecer tratamento especializado à população; e, terciário, referente aos serviços de alta complexidade, representados pelos grandes hospitais e clínicas (MS, 2013).

O ambulatório tem a responsabilidade de avaliar e distinguir pacientes com maior necessidade clínica para receber tratamento que utilize as competências e tecnologias disponíveis em hospital de referência.

No atendimento de pacientes com suspeita ou diagnóstico de doenças cardíacas, o encaminhamento destes é um processo reconhecido como o início de uma série de ações que merecem investigação contínua (Shurlock, 2009). Após a consulta médica, diagnóstico e recomendações para o tratamento em longo prazo, novas linhas de resultados são abertas, que dependem de características da população, das instalações locais e do acesso ao tratamento.

Investigações sobre a evolução dos pacientes, após o atendimento médico recebido, foram publicadas na literatura internacional para grupos específicos de pacientes (Czarnecki et al., 2013).

Estudo feito em hospitais dos Estados Unidos, permitiu avaliar o risco médio de readmissão por causa de diferentes tipos de internações e foram encontrados os resultados seguintes: em 590.809 internações por infarto do miocárdio, em 4.506 hospitais, o risco foi de 19,9\% (desvio padrão = 1,05); em 1.161.179 internações por insuficiência cardíaca, em 4.767 hospitais, esse risco foi de $24,6 \%$ (desvio padrão = 1,95); em 1.225.366 internações por pneumonia, em 4.811 hospitais, foi de 18,2\% (desvio padrão $=1,63$ ). Os autores mostraram, por meio de dados de mortalidade e reinternações, que o seguimento de pacientes apresentou informações distintas e potencialmente úteis para o entendimento do processo, e para o melhor cuidado dos pacientes (Krumholz et al., 2013).

Em outro estudo desenvolvido por Czarnecki et al. (2013), foram acompanhados 56.767 pacientes para identificar as diferentes formas seguidas de tratamentos após a primeira consulta. Os resultados mostraram que $17 \%$ dos pacientes foram tratados por cardiologistas; $58 \%$ por generalistas; e, $25 \%$ não receberam ou não tiveram acompanhamento médico. O resultado foi diferente de 
acordo com o tipo de acompanhamento recebido; os pacientes que tiveram acompanhamento apresentaram prognóstico melhor.

Estudo publicado por Stevens et al. (2018), evidenciou que, no Brasil, as doenças cardíacas exerceram impacto financeiro significativo com um custo de $R \$$ 56,2 bilhões, apenas em 2015, para doenças como: insuficiência cardíaca, infarto do miocárdio, hipertensão arterial e fibrilação atrial. Conhecer a população, para melhor prevenir e melhorar o manejo das doenças cardíacas poderia resultar em benefícios significativos, bem-estar e preservação da economia.

É preciso, destarte, conhecer e investigar o seguimento desses pacientes. A Fundação SEADE (Sistema Estadual de Análise de Dados) no Estado de São Paulo é responsável pelo Sistema de Estatísticas do Registro Civil. As bases de dados produzidas pela SEADE, integram o Sistema Nacional de Estatísticas Vitais do IBGE (Instituto Brasileiro de Geografia e Estatística). A produção dos dados de mortalidade na Fundação SEADE considera dois tipos de instrumentos de coleta: formulários de informações específicas dos registros legais e cópias das declarações de óbito. $O$ processamento desses eventos gera bancos de mortalidade por sexo, idade, causas de morte e uma série de outras variáveis que estão desagregadas, para todos os municípios paulistas e distritos da capital, o que permite estudos minuciosos da população (Waldvogel et al., 2019).

No Brasil, a Fundação SEADE tem sido uma das organizações pioneiras na utilização da vinculação determinística de dados, por meio de convênios, acordos de cooperação e contratos com outras instituições. Dessa forma, o Estado de São Paulo é o único estado brasileiro que desenvolveu um sistema próprio de produção de estatísticas vitais relacionadas aos registro civil e dados epidemiológicos das declarações de óbito, e de nascido vivo, potencializando a geração de informações e acompanhamento clínico de pacientes, por exemplo, com doenças cardiovasculares (Waldvogel et al., 2019).

Várias são as hipóteses suscitadas pelos pesquisadores. Pode-se citar entre elas: pacientes que procuram atendimento médico cardiológico podem morrer em curto prazo; pacientes que procuram atendimento médico cardiológico morrem, predominantemente, em decorrência de doença cardiovascular; pacientes que procuram atendimento médico cardiológico e tratamento podem não morrer de doença cardiovascular. 
Estudos são necessários para conhecer melhor a população de pacientes ambulatoriais que demandam e recebem cuidados de saúde e atendimento médico em hospitais acadêmicos de referência terciária, inseridos na rede do Sistema Único de Saúde (SUS). Particularmente, a sobrevida e o desfecho óbito em longo prazo depois do atendimento recebido. Esse conhecimento pode contribuir significativamente para o entendimento de aspectos múltiplos da atenção à saúde desses pacientes. 
2 OBJETIVOS 


\section{OBJETIVOS}

\subsection{Gerais}

Analisar o desfecho óbito no longo prazo em pacientes de hospital de referência terciário, que integra a rede do Sistema Único de Saúde, que foram atendidos com suspeita diagnóstica ou com diagnóstico de doença cardiovascular, após a primeira consulta médica, em unidade ambulatorial com alto volume de atendimentos.

\subsection{Específicos}

Investigar as causas básicas e múltiplas de morte dos pacientes atendidos com suspeita diagnóstica ou com diagnóstico de doenças cardiovasculares, agrupadas segundo a Classificação Internacional de Doenças.

Analisar a mortalidade no longo prazo de acordo com as características demográficas e comorbidades relacionadas aos pacientes.

Estimar o tempo decorrido entre a primeira consulta médica e o óbito. 
3 MÉTODOS 


\section{MÉTODOS}

\subsection{Local do estudo}

O estudo foi realizado na Unidade Clínica de Ambulatório Geral do Instituto do Coração (InCor) do Hospital das Clínicas da Faculdade de Medicina da Universidade de São Paulo (HC FMUSP), que é um serviço voltado para o atendimento ambulatorial de pacientes do Sistema Único de Saúde, encaminhados para avaliação médica cardiológica, predominantemente em primeira consulta ambulatorial. O Serviço tem entre as suas características: a) atuar como parte da rede do Sistema Único de Saúde em um hospital acadêmico; b) realizar alto volume de atendimentos e possui alcance assistencial importante; c) os atendimentos, além da alta qualidade médica, são resolutivos, isto é, o diagnóstico e o encaminhamento terapêutico são decididos, em geral, em até três consultas médicas. Nesse Serviço, entre 1988 e 2017, foram realizadas 940.048 consultas de pacientes provenientes de diversos estados brasileiros. Do total, 50\% a 73\% dos pacientes, depois do diagnóstico e da orientação terapêutica, foram reencaminhados para tratamento em serviços médicos da comunidade de origem. Os demais pacientes demandaram tratamento de maior complexidade e assim foram orientados.

Durante a análise estatística optou-se por subdividir a cidade de São Paulo em oito regiões: Central, Centro-Sul, Leste, Nordeste, Noroeste, Oeste, Sudeste e Sul.

\subsection{Casuística}

Foram estudados os dados de pacientes de 244.828 consultas médicas realizadas na Unidade Clínica de Ambulatório Geral, no período de 2002 a 2013. Dessas consultas, após retirar os dados duplicados (número de consultas), restaram 243.091 consultas que correspondiam a 180.929 pacientes, pois alguns passaram em mais de uma consulta por isso foram contados uma única vez. Dos 180.929 pacientes, 159.413 eram provenientes do Estado de São Paulo.

As pessoas foram identificadas pelo nome, nome da mãe e data de nascimento para quantificar as consultas por pessoa. Dificilmente duas pessoas com as mesmas 
características e que houvessem passado por tratamento no InCor, seriam consideradas as mesmas para efeito do estudo.

\subsubsection{Critérios de inclusão}

Foram incluídos no estudo pacientes com idade superior a 18 anos, atendidos entre 01 de janeiro de 2002 a 31 de dezembro de 2013.

\subsubsection{Critérios de exclusão}

Foram excluídos pacientes não residentes no Estado de São Paulo, pois a Fundação Estadual de Análise de Dados (SEADE) dispõe apenas das informações sobre a mortalidade da população paulista.

\subsubsection{Procedimentos}

\subsubsection{Identificação da casuística dos atendimentos médicos}

Os dados dos pacientes atendidos em consulta médica foram obtidos nos registros hospitalares administrativos.

\subsubsection{Pesquisa da casuística na Fundação SEADE}

Os dados dos atendimentos na Unidade Clínica de Ambulatório Geral foram cotejados com os dados das bases de dados da Fundação SEADE: a) base de mortalidade registrada no SEADE, que contém os óbitos ocorridos entre 01 de janeiro de 2002 a 31 de dezembro de 2013, provenientes da produção regular das estatísticas vitais do Estado de São Paulo, realizada a partir dos eventos registrados nos Cartórios de Registro Civil de todos os municípios paulistas; b) população projetada e estimada para o Estado de São Paulo, realizada pela Fundação SEADE. A Fundação SEDAE dispõe das informações sobre a mortalidade da população paulista (Waldvogel et al., 2019). 


\subsubsection{Vinculação dados InCor e Fundação SEADE}

Para aperfeiçoar os processos de produção de informações e maximizar sua utilização, o processo de vinculação determinística tem sido aprimorado. A base de dados resultante é gerada a partir de identificação e análises comparativas de variáveis comuns presentes nas duas bases consideradas. Várias são as vantagens de utilizar essa metodologia, entre elas, destaca-se: o enriquecimento de detalhes e qualidade dos dados, integração e racionalização do uso das bases já existentes, atualizações e complementações de campos diferentes relacionados, e melhor categorização da população estudada (Waldvogel et al., 2019).

A técnica de vinculação pressupõe a existência de diferentes bases de dados com informações individualizadas, que possibilitem a formação de pares somente com a certeza de se tratar de registros da mesma pessoa. Esse procedimento procura maximizar a utilização de registros administrativos existentes, permitindo compatibilizar as informações disponíveis, enriquecendo o detalhamento dos dados coletados e ampliando o universo de casos (Waldvogel et al., 2019).

Foram utilizados 31 critérios de seleção (isolados e combinados) da base de mortalidade originária de uma pesquisa tradicional realizada pela Fundação SEADE nos Cartórios de Registro Civil de todos os municípios do Estado de São Paulo, em que são coletadas informações sobre o registro legal dos eventos vitais: nascimentos, óbitos e casamentos. As variáveis "nome", "nome da mãe" e "data de nascimento" foram fundamentais.

Os critérios utilizados para vinculação dos dados da Fundação SEADE com os do InCor foram: nome completo, nome completo da mãe, nome completo do pai, data de nascimento, sexo, idade, data do óbito, local do óbito, endereço de residência, bairro, município, documento de identidade.

A vinculação adotada foi determinística, formando pares e relacionando variáveis somente com a certeza de identidade. A validação dos pares foi realizada em duas etapas: automática; e, os pares selecionados que apresentaram alguma divergência, passaram por uma análise visual, comparando-se outras informações adicionais contidas nas bases. As vinculações com divergências foram examinadas individualmente por dois observadores independentes, que reduziu a possibilidade de erro na validação dos pares, e as inconsistências resolvidas por consenso. Quando surgiram dúvidas, os casos passaram por análise individualizada, contando com 
informações adicionais que melhor identificassem o par, por exemplo, cidade, município e logradouro de residência, além do nome da mãe e data de nascimento.

Após essa fase, a Fundação SEADE realizou a união dos dados ao comparar as informações das duas análises. Os dados de pacientes que obtiveram aceitação nos dois julgamentos, foram aceitos na pesquisa. As inconsistências que apareceram foram submetidas à análise e decisão por consenso, e para melhor refinamento, cruzadas com informações contidas no cadastro do banco de dados do hospital.

\subsubsection{Variáveis estudadas}

Idade, sexo, local de residência, número de consultas, óbito, data do óbito, causas básicas de óbito (agrupamento de frequências em famílias da Classificação Internacional de Doenças e Problemas Relacionados à Saúde - CID 10), causas associadas e múltiplas de morte - os pacientes foram agrupados conforme as causas básicas de óbito - CID 10, e, tempo estimado de sobrevida.

\subsection{Análise Estatística}

A análise estatística foi conduzida na sequência seguinte:

\subsubsection{Verificação da consistência dos dados}

A consistência de dados apoiou-se na verificação de entradas, semanticamente corretas e condizentes com a definição do campo, homogeneização de padrões de identificação, identificação de duplicidade de registros e harmonização de identificações.

\subsubsection{Análise descritiva}

A análise exploratória do comportamento das variáveis, inclui a análise de correspondência para dados de consultas médicas e dados de óbitos. 
A análise de correspondência é uma técnica descritiva utilizada para representar linhas e colunas de uma matriz (uma tabela de contingência, por exemplo) como pontos em um gráfico, tipicamente em duas dimensões. O objetivo principal da técnica é simplificar a informação contida na tabela e ilustrar possíveis associações existentes entre as categorias das variáveis cruzadas (Greenacre, 1984).

A população de residentes em cada região da cidade de São Paulo foi estimada com base na população anual média, entre 2002 e 2013.

\subsubsection{Análise de sobrevivência}

A análise de sobrevivência foi realizada com o emprego do método de KaplanMeier (Kaplan, Meier, 1958) para os pacientes falecidos e para os sobreviventes, e para a análise de riscos competitivos. $\mathrm{Na}$ análise de riscos competitivos, cada causa de óbito foi considerada como um desfecho competitivo com os demais, para evitar a superestimação que poderia advir do método de Kaplan-Meier. A variável principal utilizada foi a idade do paciente quando ocorreu o óbito.

\subsection{Aspectos éticos}

O projeto foi apreciado e aprovado no Comitê de Ética Institucional (CAAE n. $\left.{ }^{0} 33359414.9 .0000 .0068\right)$. 


\section{RESULTADOS}




\section{RESULTADOS}

\subsection{Características demográficas dos pacientes}

$\mathrm{Na}$ base administrativa ambulatorial de dados foram obtidos 244.828 registros de consultas de pacientes. Os registros iguais, replicados em linhas subsequentes, foram eliminados. Restaram, portanto, 243.091 registros de consultas. Pacientes podem ter tido mais de uma consulta e, neste caso, foram contados uma única vez o que resultou em 180.929 pacientes.

A distribuição das idades dos pacientes na primeira consulta variou de 18 anos a 109 anos (Anexo - Tabela 1). A distribuição da frequência mostra assimetria leve à esquerda; metade dos pacientes tinha idade entre 47 anos e 68 anos (Anexo - Figuras 1 e 2).

Predominaram pacientes do sexo feminino (Anexo - Tabelas 1 e 2) e não houve diferença de idade na primeira consulta dos homens (média = 56,7 anos, desvio padrão $=15,5$ ) com relação à idade das mulheres (média $=56,8$ anos, desvio padrão $=15,5)$.

A procedência principal dos pacientes foi do Estado de São Paulo - 159.413 (97,3\%) (Anexo - Tabela 3) e da cidade de São Paulo - 111.943 (68,8\%) (Anexo Tabelas 3 e 4). A procedência de cidades próximas variou de 0,4\% a 3,3\%; outras cidades compuseram, em conjunto, 11,1\% (Anexo - Tabela 4).

Na cidade de São Paulo, a região de procedência dos pacientes variou de 3.415 $(3,7 \%)$ vindos da zona Sul da cidade até 15.805 (17,3\%) provenientes da zona Leste (Anexo - Tabela 5). A taxa anual de consultas por 100.000 habitantes foi mais alta na região Centro-Sul (163 por 100.000 habitantes) e a menor na região Sul (13 por 100.000 habitantes) (Anexo - Tabela 6).

\subsection{Número de consultas}

A maioria dos pacientes, 139.289 (77\%), foi atendida em uma única consulta. Outros $20,5 \%$ fizeram até três consultas e os demais $2,5 \%$ foram atendidos em quatro a quinze consultas (Anexo - Tabela 2). A frequência de consultas por 100.000 
habitantes com relação à população estimada foi mais alta para residentes na região Centro-Sul da cidade de São Paulo e mais baixa para residentes da região Sul da cidade (Anexo - Tabelas 6 e 7).

\section{3 Óbitos}

Ocorreram 31.956 (17,7\%) óbitos entre os 180.929 pacientes; o número de óbitos aumentou a cada ano do estudo (Anexo - Tabela 8). O número de óbitos foi maior entre os homens (Anexo - Tabela 9). É de se notar que um número maior de mulheres foi atendido em consulta (Anexo - Tabela 1). A média de idade dos pacientes por ocasião do óbito foi 69,3 anos (desvio padrão = 13,8 anos) (Anexo - Tabela 10 e Figura 3). A idade dos pacientes por ocasião do óbito aumentou quando associada com o número de consultas ( 1 a 5 consultas), ainda que o número de pacientes com mais de uma consulta tenha sido menor (Anexo - Tabela 11). O tempo médio decorrido entre a primeira consulta e o óbito foi 3,3 anos (desvio padrão = 2,9 anos) (Anexo Tabela 12 e Figura 4). O município de residência dos pacientes que apresentou maior frequência de óbitos foi São Paulo (64,2\%), seguida por Osasco (3,9\%), Guarulhos $(3,4 \%)$, Taboão da Serra (1,8\%), Carapicuíba (1,6\%), Cotia (1,2\%) e Embu das Artes $(1,2 \%)$. Depois do município de São Paulo, a maior parte dos pacientes era procedente: da região metropolitana de São Paulo (64,2\%); interior (8,9\%); litoral $(1,9 \%)$; e, deoutros estados (0,7\%) (Anexo - Figura 5).

\subsubsection{Causas de óbitos}

\subsubsection{Causa básica}

As doenças do aparelho circulatório foram consideradas as causas básicas de óbito: em 15.676 (49\%) pacientes; neoplasias em 4.560 (14,3\%); doenças do aparelho respiratório em 3.619 (11,3\%); doenças infecciosas e parasitárias em 1.687 (5,3\%); doenças endócrinas e metabólicas em 1.612 (5\%); e, doenças do aparelho digestivo em 1.432 (4,5\%). Outros grupos de doenças apresentaram frequências inferiores a $4,5 \%$ (Anexo - Tabelas 13 e 14). 
As causas básicas dos óbitos informadas no atestado de óbito foram examinadas em cinco grupos, quatro dos quais reuniam causas do aparelho circulatório e um grupo de causas não cardíacas (Anexo - Tabela 15). Os quatro grupos de doenças do aparelho circulatório foram ordenados da forma seguinte:

Grupo 1 - Infarto agudo do miocárdio e outras formas de doença isquêmica do coração; neste grupo ocorreram 4.128 óbitos (12,9\%).

Grupo 2 - Cardiomiopatia dilatada, insuficiência cardíaca congestiva (ICC), cardiomiopatia isquêmica, doença cardíaca hipertensiva com insuficiência cardíaca; neste grupo foram identificados 2.938 óbitos $(9,2 \%)$.

Grupo 3 - Acidente vascular cerebral, outras doenças cerebrovasculares; foram evidenciados 1.269 óbitos (4\%).

Grupo 4 - Doença aterosclerótica do coração, doença cardíaca hipertensiva sem insuficiência cardíaca, outras formas de doenças cardíacas; identificados 7.341 óbitos (23\%)

As doenças não-cardíacas foram a causa básica mais frequente dos óbitos em 16.280 (51\%) pacientes (Anexo - Tabela 15). Não foi feita associação entre a número de consultas e as causas de óbito (Anexo - Tabelas 16 e 17).

As frequências relativas das causas de óbito por doenças do aparelho circulatório, doenças do aparelho respiratório, neoplasias e outras doenças não apresentaram modificações substanciais no período de estudo de 2002 a 2013. De 2002 a 2007 as causas principais de morte foram as doenças cardiovasculares, de 2008 a 2013 essas causas de morte foram causadas por outras doenças (Anexo Tabela 18).

As médias de idade por ocasião da morte por doenças do aparelho circulatório não diferiram das médias de idade da morte por outras doenças (Anexo - Tabela 19).

A frequência relativa de homens e mulheres nos óbitos por doenças do aparelho circulatório não diferiu substancialmente com relação aos óbitos por outras doenças (Anexo - Tabela 20).

Nas causas básicas descritas nos 31.956 atestados de óbito, observou-se: $3.739(11,7 \%)$ óbitos atribuídos ao infarto agudo do miocárdio (IAM); $1.333(4,2 \%)$ diabetes mellitus (DM); 1.119 (3,5\%) insuficiência cardíaca (IC); 1.087 (3,4\%) doença pulmonar obstrutiva crônica (DPOC); 986 (3,1\%) doença de Chagas; 608 (1,9\%) 
neoplasia de pulmão; 365 (1,1\%) neoplasia de próstata; $358(1,1 \%)$ neoplasia de mama; 283 (0,9\%) insuficiência renal crônica (IRC); 257 (0,8\%) hipertensão arterial sistêmica; 63 (0,2\%) dislipidemia; 62 (0,2\%) aterosclerose; 61 (0,2\%) obesidade; $21.635(67,7 \%)$ por causa de outras doenças (Anexo - Tabela 21).

\subsubsection{Causa imediata de óbito (linha A) e associações com outras causas}

Foram consideradas causas imediatas de morte, todas (33.882) descritas nas linhas A dos atestados de óbitos. Sendo assim, as causas imediatas nos 31.956 óbitos, foram: $8.669(25,6 \%)$ atribuídas aos resultados de exames laboratoriais alterados; 7.381 (21,8\%) doenças do aparelho respiratório; $7.336(21,6 \%)$ doenças do aparelho circulatório; 4.748 (14\%) doenças infecciosas ou parasitárias; e, o restante, 5.748 (17\%), por outros diagnósticos menos relevantes (incidência menor que 8\%) (Anexo - Tabela 22).

Alterações nos exames laboratoriais, foram as causas imediatas de óbitos mais frequentes, que representaram 8.669 (25,6\%) dos óbitos, e dessas causas: 4.289 (49,5\%) causas básicas atribuídas a doenças do aparelho circulatório; 1.063 (12,3\%) neoplasias; 772 (9\%) doenças do aparelho respiratório e outras; 2.545 (29,2\%) causas básicas atribuídas a outras doenças com prevalência <5\%. Das 7.381 (21,8\%) causas imediatas, atribuídas às doenças do aparelho respiratório: 3.418 (46,3\%) causas básicas de óbitos relacionadas com as doenças do aparelho circulatório; 1.405 (19\%) causas básicas referentes às doenças do aparelho respiratório; 1.252 (16,9\%) causas básicas atribuídas às neoplasias; e, demais causas básicas com prevalência $<5 \%$ para outras doenças. Das $7.336(21,6 \%)$ causas imediatas de óbitos imputadas às doenças do aparelho circulatório: 5.880 (80,1\%) por causas básicas estavam relacionadas com doenças do aparelho circulatório; 528 (7,2\%) atribuídas às doenças endócrinas/metabólicas; demais causas básicas com prevalência <4\% para demais diagnósticos. Das 4.748 (14\%) causas imediatas de óbitos atribuídas às doenças infecciosas ou parasitárias: 1.250 (26,3\%) doenças do aparelho circulatório; 1.142 $(24,1 \%)$ relacionadas com as doenças do aparelho circulatório; 713 (15\%) neoplasias; 348 (7,3\%) doenças do aparelho circulatório; e, 1.295 (27,3\%) demais causas com prevalência $<5 \%$ para demais doenças (Anexo - Tabela 23).

Ao avaliar a associação da causa imediata de óbito com relação às colunas das linhas B, C, D e II dos atestados de óbitos, obteve-se como resultado 89.743 causas. 
Destas, em primeiro lugar 25.505 causas, referentes aos achados anormais em exames laboratoriais, isto é: 11.243 (44,1\%) imputados a doenças do aparelho circulatório; 2.856 (11,2\%) doenças do aparelho respiratório; 2.021 (7,9\%) doenças geniturinárias; 1.757 (6,9\%) doenças endócrinas/metabólicas; 1.737 (6,8\%) achados alterados em exames laboratoriais; 1.691 (6,6\%) neoplasias; e, 4.200 (16,5\%) com prevalência < $5 \%$ para as demais enfermidades. Em segundo lugar as doenças atribuídas como causa imediata foram as do aparelho respiratório com 20.325 causas. Destas, 8.949 (44\%) relacionadas às doenças do aparelho circulatório; 3.246 (16\%) doenças do aparelho respiratório; 2.052 (10\%) neoplasias; 1.446 (7,1\%) doenças endócrinas/metabólicas; 1.049 (5,1\%) doenças do aparelho geniturinário; e, 3.610 $(17,8 \%)$ causadas por outras moléstias menos relevantes. A terceira causa imediata de óbitos em ordem de frequência foram as doenças do aparelho circulatório, representando 16.180 causas. Destas, com maior destaque: $10.045(62,1 \%)$ causas imputadas às doenças do aparelho circulatório; seguidas por 1.647 (10,2\%) causadas por doenças endócrinas/metabólicas; e, 1.044 (6,4\%) doenças do aparelho circulatório. As demais $3.444(21,3 \%)$ causas, eram atribuídas a outras doenças menos relevantes. A quarta causa imediata de morte somou 14.651 casos, referentes a doenças infecciosas e parasitárias. Destacaram-se $4.053(27,7 \%)$ causas associadas a doenças do aparelho circulatório; 3.724 (25,4\%) doenças do aparelho respiratório; 1.865 (12,7\%) doenças geniturinárias; 1.015 (7\%) doenças endócrinas e metabólicas; 984 (6,7\%) neoplasias; e 3.010 (20,5\%) causas com prevalência <5\% (Anexo - Tabela 24).

Verificou-se que das 33.882 causas imediatas de morte: 2.374 (7\%) óbitos foram atribuídos ao infarto agudo do miocárdio; 857 (2,5\%) insuficiência cardíaca; 79 $(0,2 \%)$ neoplasia de pulmão; 69 (0,2\%) insuficiência renal crônica; 60 (0,2\%) doença pulmonar obstrutiva crônica; 54 (0,2\%) hipertensão arterial; $48(0,1 \%)$ neoplasia de próstata; $46(0,1 \%)$ diabetes mellitus; $44(0,1 \%)$ neoplasia de mama; $37(0,1 \%)$ doença de Chagas; 26 (0,1\%) aterosclerose; 03 (0\%) dislipidemia; $1 \quad(<0,01 \%)$ obesidade; 3.0184 (89,1\%) outras causas (Anexo - Tabela 25).

Das causas imediatas mais relevantes relacionadas com a causa básica, constatou-se 2.374 causas imediatas atribuídas ao infarto agudo do miocárdio e 857 à insuficiência cardíaca. Nas causas imputadas ao infarto, 1.917 (80,7\%) por infarto como causas básicas; 166 (7\%) ao diabetes mellitus e demais associações com prevalência $<2 \%$. Nas mortes imputadas à insuficiência cardíaca observou-se: 104 
(12,1\%) atribuídas à própria insuficiência cardíaca; (8,4\%) infarto; 7.264 (7,5\%) doença de Chagas; e, demais afecções com percentil <5\% (Anexo - Tabela 26).

Ao analisar a Tabela 27, sobre a causa imediata de óbito, com relação às linhas B, C, D e Il dos atestados de óbitos, obteve-se 89.743 causas, e entre elas as mais relevantes: infarto agudo do miocárdio e insuficiência cardíaca. Das 4.781 (5,3\%) causas imediatas atribuídas ao infarto: 808 (16,9\%) associadas à hipertensão arterial; $631(13,2 \%)$ aterosclerose; e, 405 (8,5\%) diabetes mellitus. Demais com prevalência $<5 \%$. O número total de causas imediatas de óbito atribuída à insuficiência cardíaca foi de 1.931 (2,1\%), e destas 119 (6,2\%) associadas à diabetes mellitus e 243 (12,6\%) à hipertensão arterial. As demais com prevalência <5\% (Anexo - Tabela 27).

Ao examinar as causas de óbito informadas nas cinco linhas de óbito (portanto, incluindo causas imediatas, causa básica e outros diagnósticos) foram identificadas 151.038 causas e 652.280 linhas sem preenchimento. A distribuição das frequências foi ampla, de tal forma que os percentis mais prevalentes foram inferiores a $10 \%$. Do total das causas listadas obteve-se os resultados no percentil 5 (7.552 causas): 8375 (5,5\%) causas atribuídas ao infarto agudo do miocárdio; 8.667 (5,7\%) causas de óbitos relacionados a pneumonias; 8.375 (5,5\%) causas de óbitos imputadas ao infarto agudo do miocárdio; e, 8.006 (5,3\%) causas relacionadas à hipertensão arterial (Anexo - Tabela 28).

Das demais causas nas cinco linhas do atestado de óbito, foram listadas, com maior prevalência: 7.410 (4,9\%) causas de óbitos atribuídas à insuficiência cardíaca; 7.272 (4,8\%) com septicemia; 6.773 (4,4\%) com a doença isquêmica crônica do coração; 5.698 (3,7\%) com diabetes mellitus; 4.771 (3,1\%) por causa de choque [3.815 (79,9\%) choque cardiogênico, 4.544 (3,0\%) insuficiência respiratória, 4.228 (2,8\%) cardiomiopatias, 3.142 (2,0\%) doenças pulmonares obstrutivas crônicas]. Das doenças pulmonares: 2.327 (74\%) doença pulmonar obstrutiva crônica; 2.926 (1,9\%) associadas à insuficiência renal crônica; 2.631 (1,7\%) edema pulmonar; 2.253 (1,5\%) doença de Chagas; 2.329 (1,5\%) aterosclerose; 1805 (1,1\%) acidente vascular cerebral; 1.805 (1,1\%) doença cardíaca hipertensiva; 1.694 (1,1\%) doença isquêmica aguda do coração; 1.766 (1,1\%) arritmias cardíacas; 1.697 (1,1\%) doenças cerebrovasculares; e, os 37,07\% restantes, com menor prevalência, outras afecções (Anexo - Tabela 28).

As causas imediatas de óbito, conforme as doenças específicas e ano do óbito, observou-se: no período de 2002 a 2013, como causa principal de morte o infarto 
agudo (2.374 casos), seguida de insuficiência cardíaca (856 casos) e, por último, insuficiência renal crônica (79 casos). A maior incidência de óbitos $(17,4 \%)$ associada ao diabetes mellitus ocorreu no ano de 2009 (Anexo - Tabela 29).

\subsubsection{Relação entre causa básica e outras causas/outras linhas/listadas}

Ao avaliar a relação entre causa básica e causa imediata, obteve-se como resultados 33.882 causas básicas entre os 31.956 óbitos. A primeira causa básica de maior prevalência, foi a doença do aparelho circulatório com 16.496 causas assinaladas nos atestados. Destas, $5.580(33,8 \%)$ associadas à causa imediata de óbito por causa de doenças do aparelho circulatório, $3.418(20,7 \%)$ doenças do aparelho respiratório, 1.270 (7,7\%) traumas/intoxicações (letra T), 1.142 (6,9\%) achados anormais em exames laboratoriais, 5.084 (30,9\%) demais causas com prevalência $<5 \%$ para as demais doenças. A segunda causa básica de morte de maior prevalência foram as neoplasias com 4.677 causas básicas nos atestados de óbito. Destas, $1.252(26,8 \%)$ causas imediatas de óbito atribuídas à doença do aparelho respiratório, $901(19,3 \%)$ às neoplasias, $713(15,2 \%)$ aos achados anormais em exames laboratoriais e o restante, $1.811(38,7 \%)$, com prevalência $<5 \%$ para as demais causas. A terceira maior causa básica de óbito registrada nos atestados, foram as doenças do aparelho respiratório, com 3.656 causas básicas. Destas, 1.405 $(38,4 \%)$ associadas às doenças do aparelho respiratório como causa imediata de morte, seguida de $1.250(34,2 \%)$ causas imediatas de óbito atribuídas às doenças infecciosas/parasitárias, $772(21,1 \%)$ achados nos exames laboratoriais, e demais causas que somaram $229(6,3 \%)$ com percentil $<5$. A quarta causa básica com maior prevalência foram as doenças endócrinas/metabólicas com 1.679 causas básicas. Destas, $528(31,4 \%)$ causas imediatas de óbito imputadas às doenças do aparelho circulatório, $376(22,4 \%)$ às alterações em exames laboratoriais, $312(18,6 \%)$ às doenças do aparelho respiratório como causa de morte imediata, $227(13,5 \%)$ aos achados laboratoriais anormais, e o restante por outras causas com prevalência $<5 \%$. A quinta causa básica de óbito com maior incidência nos atestados de óbito, foram às doenças do aparelho digestivo, com 1.559 causas. Destas, a causa imediata de óbito que foi mais descrita eram as alterações em exames laboratoriais, com $418(26,8 \%)$ casos, seguidos por 348 (22,3\%) com doenças infecciosas e parasitárias, 270 (17,3\%) por causas imediatas motivadas pela própria doença do aparelho digestivo, 210 
(13,5\%) doenças do aparelho respiratório, 193 (12,4\%) traumas/intoxicações (letra T), e $120(7,7 \%)$ com incidência $<10 \%$ por outras causas (Anexo - Tabela 23 ).

Das 33.882 causas básicas de óbito citadas nos atestados dos 31.956 pacientes, foram observadas as relações com causas imediatas de óbito seguintes: das 3.796 causas básicas atribuídas ao infarto agudo do miocárdio, em 1.917 (50,5\%) a causa imediata de morte foi infarto, com nenhuma relação entre aterosclerose, doença de Chagas, neoplasia de mama, próstata, pulmão, dislipidemia, diabetes mellitus ou doença pulmonar obstrutiva crônica. Não houve relevância (prevalência $<2 \%$ ) entre as demais doenças, como: hipertensão arterial, obesidade, insuficiência cardíaca e insuficiência renal crônica. Das 1.376 causas básicas atribuídas ao diabetes mellitus, $166(12,1 \%)$ receberam diagnóstico de infarto agudo do miocárdio como causa de morte imediata. Não foram constatados nos atestados $(0 \%)$ : relação com doença de Chagas; neoplasias; doença pulmonar obstrutiva crônica; e, obesidade. Demais associações com percentil <4\%. Das 1.135 causas básicas imputadas à insuficiência cardíaca: $104(9,2 \%)$ causas imediatas relacionadas à própria doença, não havendo relação $(0 \%)$ com aterosclerose, doença de Chagas, câncer de mama, próstata, pulmão, dislipidemia, diabetes, doença pulmonar obstrutiva crônica, hipertensão arterial, obesidade ou infarto; e, $2(0,2 \%)$ causas imediatas associadas à insuficiência renal crônica. Das 1.017 causas básicas atribuídas à doença de Chagas, 64 (6,3\%) faleceram com insuficiência cardíaca como causa imediata e 42 (4,1\%) infarto (Anexo - Tabela 30).

Ao avaliar a associação da causa básica de óbito por agrupamento com as linhas B, C, D e II dos atestados, foram constatadas 85.199 causas. Dessas, 9.030 $(10,6 \%)$ causas atribuídas ao infarto agudo do miocárdio, 4.441 (5,2\%) ao diabetes mellitus e demais associações com prevalência $<5 \%$. Dos óbitos imputados ao infarto, observamos associações entre: 1.831 (20,3\%) com infarto, 1.330 (14,7\%) hipertensão arterial, $789(8,7 \%)$ aterosclerose, $542(6 \%)$ diabetes mellitus, demais relações com percentil $<5$. Com relação ao diabetes mellitus, observou-se $1.338(30,1 \%)$ causas por diabetes mellitus, 611 (13,7\%) hipertensão, e, 315 (7\%) insuficiência renal crônica. Demais doenças apresentaram prevalência $<5 \%$ (Anexo - Tabela 31).

$\mathrm{Na}$ associação da causa básica investigada por letra do CID 10, com as linhas b, c, d e II dos atestados de óbitos, obteve-se 85.199 causas. Dentre essas, 41.836 causas básicas atribuídas às doenças do aparelho circulatório: 27.781 (66,4\%) doenças do aparelho circulatório; 3.636 (8,7\%) doenças do aparelho respiratório; 
$2.683(6,4 \%)$ doenças endócrinas/metabólicas; e, 7.736 (18,5\%) por causa de outras doenças. Em segunda posição, as neoplasias com 11.318 causas básicas, destas: $5.572(49,2 \%)$ associadas às neoplasias como causa básica; 1.433 (12,7\%) a doenças do aparelho circulatório; 1.202 (10,6\%) a doenças do aparelho respiratório; e, 3.111 $(27,5 \%)$ a outras doenças com percentil <5. As doenças do aparelho respiratório ocuparam a terceira posição com 10.026 causas básicas: $4.581(45,7 \%)$ atribuídas às doenças do aparelho respiratório; 2.434 (24,3\%) doenças do aparelho circulatório; 779 (7,8\%) associadas a doenças do aparelho geniturinário; 684 (6,8\%) achados anormais em exames laboratoriais; 623 (6,2\%) atribuídas às doenças endócrinas/metabólicas; e, $925(9,2 \%)$ causas com prevalência $<5 \%$. Responsáveis pela quarta posição das causas básicas mais frequentes, as doenças endócrinas e metabólicas, representadas por 5.310 causas, e destas, 1.904 (35,8\%) relacionadas às doenças do aparelho circulatório, 1.802 (33,9\%) doenças endócrinas/metabólicas, 534 (10\%) doenças do aparelho geniturinário, 340 (6,4\%) doenças do aparelho respiratório, e demais $730(13,9 \%)$ causas com incidência $<5 \%$. Na quinta posição, responsável por 4.339 causas básicas, as doenças do aparelho digestivo. Destas, 1.891 (43,6\%) associadas a doenças do próprio aparelho digestivo; $840(19,3 \%)$ a doenças do aparelho circulatório; $288(6,7 \%)$ a doenças do aparelho geniturinário; 234 (5,4\%) doenças respiratórias; 224 (5,2\%) doenças endócrinas/metabólicas; e, 862 (19,8\%) causas atribuídas às doenças com percentil <5 (Anexo - Tabela 32).

\subsubsection{Associações da idade com regiões da cidade, com óbitos e causas de óbito}

As associações estudadas com o emprego da análise de correspondência, revelaram que as regiões Central, Centro-Sul e Oeste da cidade de São Paulo estiveram associadas mais fortemente com a faixa etária acima de 64 anos. As regiões Leste, Sul e Noroeste associaram-se com mais intensidade à faixa etária até 19 anos (Anexo - Figura 6).

Idades mais elevadas no óbito foram associadas com maior frequência aos moradores da grande São Paulo e as menos elevadas associadas com maior frequência aos moradores de cidades do interior do Estado de São Paulo (Anexo Figura 7); no período do estudo, em 2002, a média da idade em que ocorreu o óbito foi 64,3 anos e, em 2013, a média de idade foi de 71,1 anos; o aumento verificado foi gradual de ano a ano (Anexo - Tabela 33). 
A doença pulmonar foi a causa de óbito em pacientes com idade mais avançada com relação às outras causas, seguida das neoplasias. As doenças do sistema circulatório, bem como as outras doenças, destacaram-se como as causas de óbito dos pacientes que faleceram com idade menos avançada (Anexo - Figura 8).

As causas secundárias de óbito foram predominantemente da mesma natureza da causa básica registrada (Anexo - Figuras 9 e 10).

\subsection{Tempo de sobrevida estimada}

\subsubsection{Tempo de sobrevida estimada com base nos pacientes que morreram}

O tempo estimado em anos de sobrevida foi o decorrido entre a primeira consulta e a data do óbito ou a idade em que ocorreu o óbito.

Nos 24.118 pacientes que faleceram após a primeira consulta (Anexo - Tabela 34), o óbito se verificou em 50\% dos casos em até 2 anos (Anexo - Figura 11).

As idades por ocasião do óbito com relação ao número de consultas (Anexo Tabela 35) não revelaram diferenças estatisticamente significantes, quando foram comparados com pacientes que fizeram uma ou três consultas $(p=0,139)$, duas e três consultas $(p=0,888)$ e entre quatro e cinco ou mais consultas $(p=0,725)$. As demais comparações múltiplas apresentaram diferenças significantes $(p<0,05)$ (Anexo Figura 12).

O tempo de acompanhamento quanto ao sexo dos pacientes que faleceram, revelou que nas mulheres o tempo de acompanhamento é discretamente maior média = 3,5 anos (IC 95\% [3,45; 3,55]), com relação aos homens - média = 3,2 anos (IC 95\% [3,15; 3,23]) ainda que a diferença (média para ambos os sexos = 3,3 anos) tenha sido significante $(p<0,001)$ (Anexo - Tabela 36 e Figura 13). A idade, por ocasião do óbito, foi aproximada para homens (média = 68,3 anos) e mulheres (média = 70,5 anos), ainda que a diferença (média para ambos os sexos $=69,3$ anos) tenha sido estatisticamente significativo ( $p<0,001)$ (Anexo -Tabela 37 e Figura 14).

Categorizando a idade, por ocasião da primeira consulta, em quartis (idade $\leq 57,3$ anos, $>57,3$ anos e $\leq 67,5$ anos, $>67,5$ e $\leq 76$ anos, $>76$ anos) dos pacientes que faleceram, o tempo de acompanhamento diferiu entre os quartis, exceto entre o primeiro e segundo quartis. A comparação entre o segundo e terceiro quartis teve o 
valor de $\mathrm{p}=0,051$ (Anexo - Tabela 38 e Figura 15). A idade por ocasião do óbito diferiu segundo os quartis de idade na primeira consulta (Anexo - Tabela 39 e Figura 16).

Os tempos de acompanhamento dos pacientes que faleceram com relação aos grupos de causas básicas de óbito (doenças do sistema circulatório, doenças do sistema respiratório, neoplasias, outras doenças) foram significativamente diferentes entre si (Anexo - Tabela 40 e Figura 17), ainda que a diferença seja pequena. A idade por ocasião o óbito não diferiu significativamente entre os pacientes com neoplasias e doenças do aparelho circulatório e portadores de neoplasias em relação a outras doenças (Anexo - Tabela 41 e Figura 18).

A sobrevida de pacientes em grupos de doenças cardíacas e não cardíacas, categorizadas conforme descrito no item 4.3.1.1 Causa básica, revelou diferenças estatisticamente significantes entre si, exceto a comparação entre grupos 1 e 4 (Anexo - Tabela 42 e Figura 19).

As idades de óbito dos pacientes diferiram nos grupos de doenças cardíacas, exceto na comparação entre os grupos 2 e 4 (Anexo - Tabela 43 e Figura 20).

\subsubsection{Tempo de sobrevida estimada com base em todos os pacientes da casuística}

Ao realizar a análise de sobrevida para todos os pacientes da casuística, foi observada uma média de idade do óbito de 85 anos, o que mostra um dado superestimado, pouco fundamentado e impreciso, uma vez que o número de casos censurados foi muito maior do que a de óbitos (cerca de 150.000 versus 30.000).

\subsection{Riscos Competitivos}

A função de incidência acumulada revelou que a taxa de incidência de óbito foi de aproximadamente $42 \%$ nos portadores de doença cardíaca, cerca de $15 \%$ para os portadores de doença pulmonar, $12 \%$ para os portadores de neoplasia e $25 \%$ para outras doenças (Anexo - Figura 23). 
5 DISCUSSÃO 


\section{DISCUSSÃO}

\subsection{Características demográficas dos pacientes}

A distribuição etária mostrou leve assimetria à esquerda para idades inferiores a 60 anos e não revelou mudança expressiva da distribuição no decorrer do período de 2002 a 2013, e a mediana se manteve praticamente estável, aproximando-se dos 60 anos (Anexo - Figura 2). O que é condizente com a natureza crônico-degenerativa das doenças cardiovasculares, no contexto da projeção etária do Estado de São Paulo de população entre 15 e 64 anos no mesmo período, que aumentou de 67,9\% para $70,2 \%$, e acima dos 65 anos de 6,1\% para 8,1\% (IBGE, 2018).

A distribuição etária também revelou que $50 \%$ dos indivíduos que passaram em uma única consulta, tinham idade entre 47 anos e 68 anos. Observa-se maior frequência de doenças crônicas nos idosos, associadas às transformações biológicas e fisiológicas que promovem a variação na necessidade de utilização dos serviços de saúde (Costa, Facchini, 1997; Mendoza-Sassi, Béria, 2001; Pinheiro et al., 2002; Travassos et al., 2002; Gomes, Nascimento, Araújo, 2007; Turci et al., 2010; Thumé et al., 2011; Ribeiro et al., 2016; Dilélio et al., 2014).

Existe equilíbrio entre a frequência de homens e mulheres na casuística estudada, com pequeno predomínio de mulheres. Em comparação com a população brasileira, os dados do IBGE (2018), mostram que a população feminina predomina sobre a população masculina. No presente estudo, em 2002, a população era de 19.656.934 mulheres e 19.178.784 homens e, em 2013 a casuística contava com 22.164.263 mulheres e 21.499.406 homens (IBGE, 2018). Conforme dados da Fundação SEADE, no Estado de São Paulo, no decorrer dos anos, houve uma diferença no predomínio de mais ou menos 1 milhão de mulheres, em 2013, (21.717.731 mulheres vs. 20.586.963 homens) (SEADE, 2013).

Segundo o levantamento realizado no Brasil por Brant et al. (2017) a doença cardiovascular foi mais frequente nos homens do que nas mulheres. Em 1990, a mortalidade foi 524,8 para cada 100.000 habitantes para os homens vs. 358,3 para cada 100.000 habitantes para as mulheres, e, em 2015, 315,8 para cada 100.000 habitantes para os homens vs. 210,7 para cada 100.000 habitantes para as mulheres. 
As mulheres foram, portanto, parte significativa de pacientes com suspeita diagnóstica ou diagnóstico de doença cardíaca. Porém, os sintomas não devem ser negligenciados em mulheres com o pressuposto de menor prevalência de doenças cardiovasculares.

Com a evolução nos contextos cultural, social e econômico no mundo, as mulheres deixaram os espaços domésticos para atuarem em diferentes áreas, sobretudo passando por momentos de pressão e longas jornadas de trabalho, o que sabe-se serem fatores de estresse e, dessa forma, contribuem para as doenças cardiovasculares. Além do trabalho externo para auxiliar na renda do lar, elas continuam sobrecarregadas com as atividades domésticas. (Veloso et al., 2014)

Outros estudos, por outro lado, mostram que as mulheres procuram mais os serviços de saúde do que os homens. Dados na literatura mostram que as mulheres procuram mais os serviços de saúde para exames de rotina e prevenção, enquanto os homens, em geral, procuram por motivo de doença. Isto também ocorre por causa dos pretextos intimamente relacionados com a masculinidade. (Pinheiro et al., 2002; Gomes et al., 2007)

Como hospital de referência, os dados obtidos no presente estudo realizado na Unidade Clínica de Ambulatório Geral do Instituto do Coração (InCor) do HC FMUSP, sobre a procedência dos pacientes, permitem observar a dimensão da natureza e da geografia da demanda de pacientes que o hospital recebe. A maioria dos pacientes do Estado de São Paulo e da cidade de São Paulo e cidades vizinhas, pode contribuir tanto para a melhor orientação médica de tratamento pós atendimento hospitalar, quanto para seguimento em função de projetos de pesquisa institucionais. Apesar dos pacientes referirem ser do Estado de São Paulo, muitos acabam mentindo o endereço para poder passar no serviço de saúde. Pois, segundo o princípio organizacional do SUS, chamado regionalização, é um processo técnico-político relacionado com a definição de recortes de determinadas áreas geográficas, a partir de critérios epidemiológicos e conhecimento da população a ser atendida, para fins de planejamento, organização e gestão de redes de ações e serviços de saúde. Sendo assim, cada paciente deveria passar em consulta no local mais próximo de sua residência (MS, 2019).

Na cidade de São Paulo, à exceção das zonas Sul, mais distante, e zona Central (menos populosa) houve uma certa homogeneidade de distribuição dos locais 
de residência informados pelos pacientes. Portanto, não foi detectada uma zona de concentração de residências.

No período de 2002 a 2013, segundo dados do SEADE, foi observado predomínio da faixa etária de 18 anos até 19 anos na região Sul (34,8\%), de 20 anos a 24 anos na região Central (30\%), de 35 anos a 49 anos (23\%) e de 50 anos a 64 anos (17\%) na região Centro-Sul, e acima de 64 anos (11,8\%) na região Central e Centro-Sul da cidade de São Paulo.

\subsection{Número de consultas}

Uma das características do serviço é predominantemente o atendimento dos pacientes em primeira consulta no ambulatório do InCor, como constatado para a maioria dos pacientes. Curiosamente, ainda assim, 23\% dos pacientes tenha recebido atendimentos múltiplos na Unidade, em decorrência da não absorção por outras unidades de saúde.

Com relação à população da região administrativa da cidade, verificou-se que a frequência de consultas foi maior para as zonas Leste e Centro-Sul, provavelmente por causa da proximidade geográfica. Tal proximidade pode ser relevante para os resultados do tratamento e da orientação. Há de se indagar se a distribuição geográfica com relação ao acesso pode contribuir para diferentes desfechos/ mortalidades relacionados ao local de moradia (Dalton et al., 2017).

Nos resultados, obteve-se a informação de que a maioria dos pacientes (77\%), foi atendida apenas uma única vez em consulta no ambulatório clínico do InCor, o que não significa que eles não passaram por outros atendimentos em demais serviços de saúde. Apesar da recomendação a respeito da regionalização e hierarquização do atendimento médico, de acordo com a sua complexidade, há anos nota-se no InCor que não existe área de concentração das procedências dos pacientes, mesmo em se tratando da cidade de São Paulo (Yamada et al., 1990). 


\section{3 Óbitos}

Considerando que se trata de um serviço médico ambulatorial de um hospital de referência, no qual uma porcentagem elevada de pacientes é reencaminhada para seguimento em recursos da comunidade de níveis primário e secundário, a mortalidade que observada é elevada - quase um quinto dos pacientes veio a falecer no período do presente estudo, e foi mais elevada nos homens. Quando se observa a taxa de mortalidade no Estado de São Paulo, pode-se afirmar que essas taxas nos homens foram substancialmente mais altas do que nas mulheres. Em 1990, a mortalidade no Estado de São Paulo para cada 100.000 habitantes foi de 535,5 nos homens e 349,8 nas mulheres e, em 2015, 281,7 nos homens e 191,1 nas mulheres (Brant et al., 2017).

A média de idade por ocasião do óbito mostrou ser de 69,3 anos. Segundo dados da Fundação SEADE, a expectativa de vida em 2014 era, em geral, de 75,5 anos, e para pessoas com doenças do aparelho circulatório entre 65 anos e 69 anos (Ferreira, Lopes, 2015).

Nota-se que o tempo médio de acompanhamento decorrido até o óbito foi curto - 3,3 anos (Anexo - Tabela 12). Vários fatores podem ser invocados para o entendimento deste achado: a) encaminhamento tardio dos pacientes para tratamentos resolutivos; b) fase avançada de doença; c) dificuldade de acesso, entre outros.

Quanto ao município de residência, São Paulo teve maior número de óbitos, compreensível por ser o maior município com a maior número de pessoas na amostra estudada e de maior frequência entre os locais de proveniência dos doentes.

\subsubsection{Causas de óbitos}

Apesar dos resultados mostrarem que a idade do óbito aumentou, quando associada ao número de consultas (uma a cinco consultas), ainda que o número de pacientes com mais de uma consulta tenha sido menor, não se pode considerar esse dado totalmente preciso, pois foi feito o acompanhamento de número de consultas apenas no InCor. Destarte, mais consultas, talvez possam indicar doenças mais graves em que os pacientes procuraram atendimento repetido no mesmo serviço. 
No decorrer da análise dos resultados, é também digno de nota que não foram encontradas informações de todas as causas das cinco linhas dos atestados de óbito em todas as declarações.

\subsubsection{Causa básica}

No presente estudo constatou-se que a média de idade ao óbito em homens e mulheres esteve entre 56,8 anos e 56,7 anos, e que 50,9\% dos óbitos foram atribuídos às doenças não cardíacas, destes, 14,3\% a neoplasias e 11,3\% causadas por doenças do aparelho respiratório, seguidas por $49,1 \%$ por doenças do aparelho circulatório.

Estudo realizado, em 2014, pela Fundação SEADE revelou taxas de mortalidade maiores em homens $(27 \%)$ do que em mulheres $(11 \%)$ na população de 15 anos a 59 anos, e as causas externas mais prevalentes no Estado de São Paulo, em 2012, foram: em segundo lugar, as doenças cardiovasculares; em terceiro, as neoplasias; em quarto, as doenças do aparelho digestivo; e, em quinto, as doenças do aparelho respiratório (SEADE, 2014). Conforme estatísticas da Fundação SEADE, as doenças do aparelho circulatório ocuparam, durante o período de 35 anos (1980 a 2014) a primeira posição entre as causas de morte do contingente idoso, seguidas por neoplasias e na terceira posição, as doenças do aparelho respiratório (Camargo, 2016).

Estudos mostraram que houve declínio da taxa de mortalidade causada por doença do aparelho circulatório com o passar dos anos para ambos os sexos. $O$ monitoramento da mortalidade reflete sobre a saúde pública, em curto e longo prazos, e dessa forma a proposição de políticas públicas e para avaliação, planejamento e ações de promoção e prevenção. A explicação para isto é o controle dos fatores de risco (prevenção) e os progressos na qualidade do atendimento médico (melhora na sobrevida) (Ceccon et al., 2001; Cesse et al., 2009).

As causas agrupadas dos óbitos do aparelho circulatório revelaram maior frequência da atribuição da causa de óbito a diagnósticos mais abrangentes, o que é compreensível, pois nem sempre há acesso ou possibilidade de avaliação diagnóstica de alta precisão que precede o óbito.

Dos quatro grupos de causas básicas por doenças cardiovasculares, o grupo de doença aterosclerótica do coração, doença cardíaca hipertensiva sem insuficiência 
cardíaca, e outras formas de doenças cardíacas se destacaram com 7.339 óbitos (23\%).

Segundo a Sociedade Brasileira de Cardiologia, a doença aterosclerótica do coração, também conhecida como aterosclerose, é uma doença inflamatória crônica de origem multifatorial que ocorre como resposta à agressão endotelial, que acomete, sobretudo, a camada íntima de artérias de calibre médio e grande (Sposito et al., 2007). Por se tratar de uma doença cardiovascular, com mortalidade elevada, merece destaque. O diagnóstico correto e o tratamento otimizado do colesterol fazem a diferença no desfecho desses pacientes (Xavier et al., 2013).

Maior acesso à atenção em saúde, juntamente com a evolução dos procedimentos de alta complexidade, tais como as cirurgias de revascularização miocárdica e as angioplastias coronarianas, considerando a melhoria da qualidade da informação, podem ter um impacto positivo no declínio da mortalidade cardiovascular ao longo dos anos na cidade de São Paulo (Farias et al., 2009).

\subsubsection{Causa imediata de óbito (linha A) e associações com outras causas}

Nos 31.956 atestados de óbito, foram descritas 33.882 causas imediatas de óbito. Destas, destacaram-se 8.669 (25,6\%) no código R, que significa alterações nos exames laboratoriais. Esse achado é bastante amplo, uma vez que, a CID 10 fornece códigos relativos à classificação de doenças e de uma grande variedade de sinais, sintomas, aspectos anormais, queixas, circunstâncias sociais e causas externas para ferimentos ou doenças. Esses achados podem ser desde tosse até anormalidades nas hemácias. Em segundo lugar, 7.381 (21,8\%) as doenças do aparelho respiratório, em terceiro lugar com $7.336(21,6 \%)$ as doenças do aparelho circulatório, 4.748 (14\%) as doenças parasitárias e/ou infecciosas, e 5.748 (17\%) com outros diagnósticos.

É digno de nota que das causas imediatas de óbitos atribuídas às doenças do aparelho respiratório, que estão em segundo lugar, 46,3\% estavam associadas àquelas do aparelho circulatório. As repercussões das doenças cardiovasculares sobre o sistema respiratório podem variar.

A maior frequência de causa imediata atribuída à doença cardiovascular foi o infarto do miocárdio, que perfez $7 \%$ dos óbitos. Por outro lado, a insuficiência cardíaca aparece como causa primária de óbito em porcentagem $<2,5 \%$. A distribuição das 
outras causas mostra não haver uma concentração nas doenças listadas como causa primária de óbito.

\subsubsection{Relação entre causa básica e outras causas/outras linhas/listadas}

Os cruzamentos observados permitiram verificar que das 3.796 causas básicas atribuídas ao infarto agudo do miocárdio, metade (50,5\%) dos pacientes teve como causa imediata de morte, o diagnóstico de infarto, sem nenhuma associação às demais doenças cardiovasculares, como: aterosclerose, dislipidemia, aterosclerose, doença de Chagas. A prevalência foi <2\% para demais enfermidades, como: hipertensão, obesidade e insuficiência cardíaca.

Das 1.376 causas básicas atribuídas ao diabetes mellitus, 12\% tiveram como causa imediata de morte o infarto agudo, sem nenhuma relação descrita para obesidade.

Apesar dos resultados apresentados, a doença de Chagas foi atribuída a apenas 1.017 causas de óbitos, e dessas, 64 (6,3\%) tiveram diagnóstico de insuficiência cardíaca, uma parcela significativa dos pacientes cardiopatas acaba por evoluir para insuficiência cardíaca (Xavier et al., 2005).

Também é digno de nota, que dentre todas as causas básicas de óbitos descritas, em associação com as demais quatro linhas dos atestados de óbito ( $\mathrm{B}, \mathrm{C}$, D e linha II), aquelas que mais se destacaram foram as doenças do aparelho circulatório. Dessas, destacou-se, com quase 11\% das causas atribuídas, o infarto agudo do miocárdio, importante enfermidade dentro dos grupos das doenças cardiovasculares que apresentam maior taxa de mortalidade.

\subsubsection{Associações da idade com regiões da cidade, com óbitos e causas de óbito}

Idades mais avançadas por ocasião do óbito foram verificadas em habitantes da cidade de São Paulo, e aquelas menos avançadas em cidades do interior do Estado de São Paulo. O aumento da idade, por ocasião do óbito, segue a tendência de aumento da expectativa de vida verificada desde o ano 2000 (Ferreira, Lopes, 2015). De acordo com dados da Fundação SEADE, em 1950, a população paulista 
apresentava esperança de vida ao nascer de 54,2 anos e, em 2017, esse indicador alcançou 76,2 anos - um aumento de 22 anos (SEADE, 2018).

A idade por ocasião do óbito foi mais elevada nos pacientes que faleceram por doenças pulmonares, seguidos daqueles que faleceram em decorrência de neoplasias. As doenças cardiovasculares afetaram os pacientes mais jovens, apesar do ganho de esperança de vida ao nascer no Estado de São Paulo, no período do estudo de Ferreira e Lopes (2015).

\subsection{Tempo de sobrevida estimada}

\subsubsection{Tempo de sobrevida estimada com base nos pacientes que morreram}

Observou-se maior probabilidade de sobrevida estimada nas mulheres, corroborando com o estudo de Lebrão (2007) que refere que são várias as explicações para o fenômeno das mulheres viverem mais que os homens, como: diferenças biológicas (por exemplo: o fator de proteção conferido por hormônios femininos com relação à isquemia coronariana); diferenças de exposição às causas de risco de trabalho; diferenças no consumo de álcool e tabaco, que estão sabidamente associados às causas de mortes mais frequentes na faixa etária acima dos 45 anos, e como neoplasias e doenças do aparelho circulatório. Achado relevante foi que $50 \%$ dos óbitos ocorreram até dois anos decorridos da primeira consulta. O que isto significa?; Eram doenças graves?; Eram doenças em fase avançada de evolução?; Intervenções terapêuticas poderiam modificar essa evolução?

\subsubsection{Tempo de sobrevida estimada com base em todos os pacientes da casuística}

Também é digno de nota que a possibilidade da informação de sobrevida, uma vez incorporada institucionalmente, pode contribuir para estudos adicionais em que haja interesse no conhecimento da evolução de pacientes no longo prazo. 


\subsection{Riscos competitivos}

A função de incidência acumulada, definida como probabilidade acumulada de um evento competitivo ocorrer na presença de outros eventos competitivos (Giordani, 2015), mostrou que a taxa de incidência de óbito foi de aproximadamente $42 \%$ nos portadores de doença cardíaca, cerca de 15\% para os portadores de doença pulmonar, $12 \%$ para os portadores de neoplasia e $25 \%$ para outras doenças. Isso pode ser interpretado, apesar do domínio dos diagnósticos cardíacos atribuídos, de que há outras contribuições diagnósticas, incluindo neoplasia e doença pulmonar crônica. A função da incidência acumulada indicou também aumento da frequência a partir dos 60 anos de idade.

\subsection{Implicações clínicas}

O presente estudo possibilitou uma estimativa da mortalidade de pacientes que procuraram atendimento médico ambulatorial em serviço de referência.

O método de vinculação determinística pode ser útil também para outros estudos nessa área do conhecimento, respeitando os requisitos do trabalho na consistência dos dados.

Frente ao panorama atual de comorbidades, os resultados da pesquisa fazem refletir sobre a relação ou não da causa de óbito com a suspeita diagnóstica inicial, uma vez que mais de $50 \%$ dos pacientes vieram a falecer e a causa de morte atribuída não foi cardíaca, mas entre elas o câncer e as doenças pulmonares.

Tendo em vista o tempo curto observado até o óbito de certo número de pacientes, seria interessante ter identificadores de pacientes sob maior risco de evolução desfavorável em estudos adicionais.

A estimativa do risco de desenvolvimento ou de adoecimento por uma doença ou agravo em uma população, durante um intervalo de tempo determinado, juntamente com as informações de sobrevida, uma vez incorporadas institucionalmente, pode contribuir para estudos adicionais em que haja interesse de conhecimento quanto a evolução de pacientes no longo prazo. 


\subsection{Limitações do estudo}

A Fundação SEADE possui dados de mortalidade do Estado de São Paulo, portanto, óbitos fora do Estado não foram alcançados por essa estatística, ainda que possam ser representados, segundo algumas fontes, por uma porcentagem reduzida. Além disso, os dados referem-se a um período específico, situação que no âmbito epidemiológico pode se modificar a ritmos não necessariamente previsíveis. Para superar esta possibilidade, estudos dessa natureza podem ser repetidos periodicamente.

Outro ponto relevante é a ausência de informações básicas em alguns casos (por exemplo, data de nascimento, nome da mãe) na base original de dados e com consequente dificuldade de pareamento para tomar conhecimento da evolução, desse modo restringindo a casuística, ainda que de forma limitada. 
6 CONCLUSÃO 


\section{CONCLUSÃO}

Porcentagem significativa de pacientes falece em até dois anos depois de receber atendimento médico cardiológico ambulatorial de referência. $O$ óbito foi atribuído a causas não cardíacas em aproximadamente metade dos pacientes.

As três causas básicas principais de óbitos foram: $49 \%$ atribuídas às doenças do aparelho circulatório; $14,3 \%$ às neoplasias; e, $11,3 \%$ às doenças do aparelho respiratório. Já as causas imediatas de óbitos foram: 25,6\% atribuídas aos resultados anormais de exames laboratoriais; $21,8 \%$ às doenças do aparelho respiratório; $21,6 \%$ às doenças do aparelho circulatório; e, 14\% às doenças infecciosas ou parasitárias. As maiores frequências de causas básicas e causas imediatas atribuídas à doença cardiovascular foram o infarto do miocárdio, com $11,7 \%$ e $7 \%$ dos óbitos, respectivamente.

A função de incidência acumulada revelou que a taxa de incidência de óbito foi maior nos portadores de doença cardíaca. Essa estimativa do risco de desenvolvimento ou adoecimento por uma doença ou agravo em uma população, durante um intervalo de tempo determinado, juntamente com as informações de sobrevida, uma vez incorporadas institucionalmente, podem contribuir para estudos adicionais com base no conhecimento da evolução de pacientes no longo prazo. Novos estudos epidemiológicos podem adicionar experiência, ampliar e aprofundar os resultados ora apresentados. 


\section{ANEXOS}




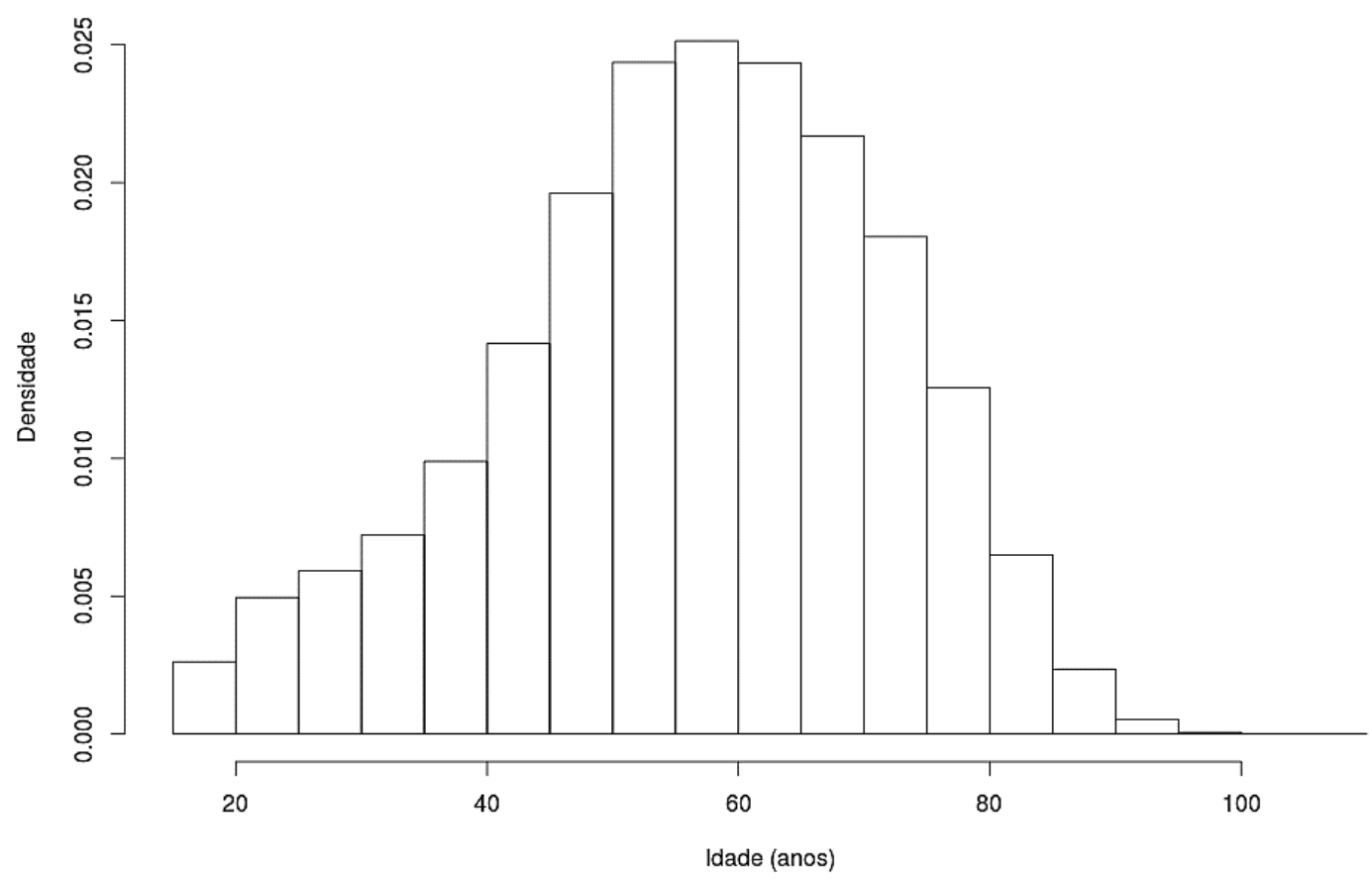

Figura 1. Histograma de idade à primeira consulta (2002-2013)

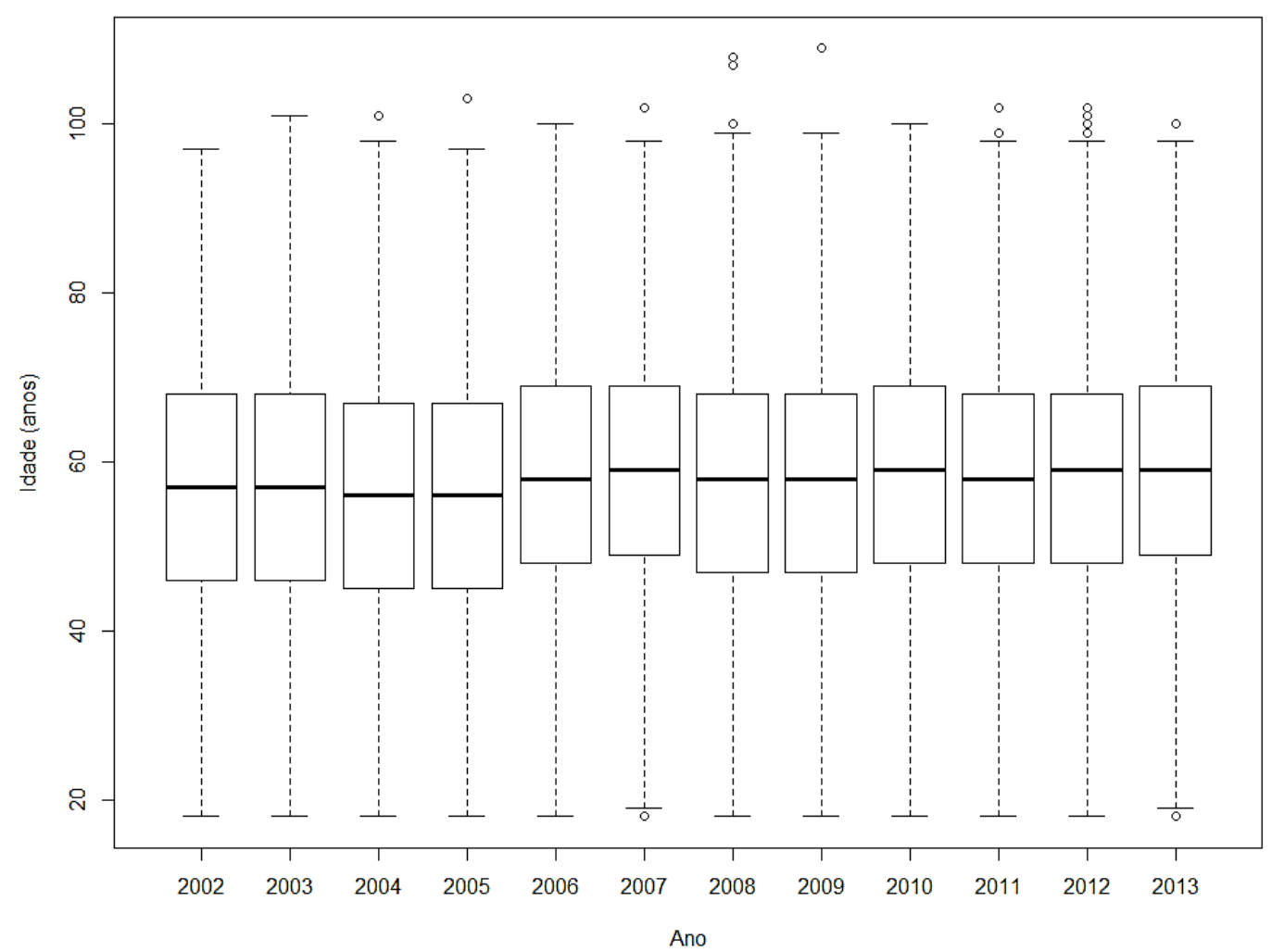

Figura 2. Idade à primeira consulta (por ano) 


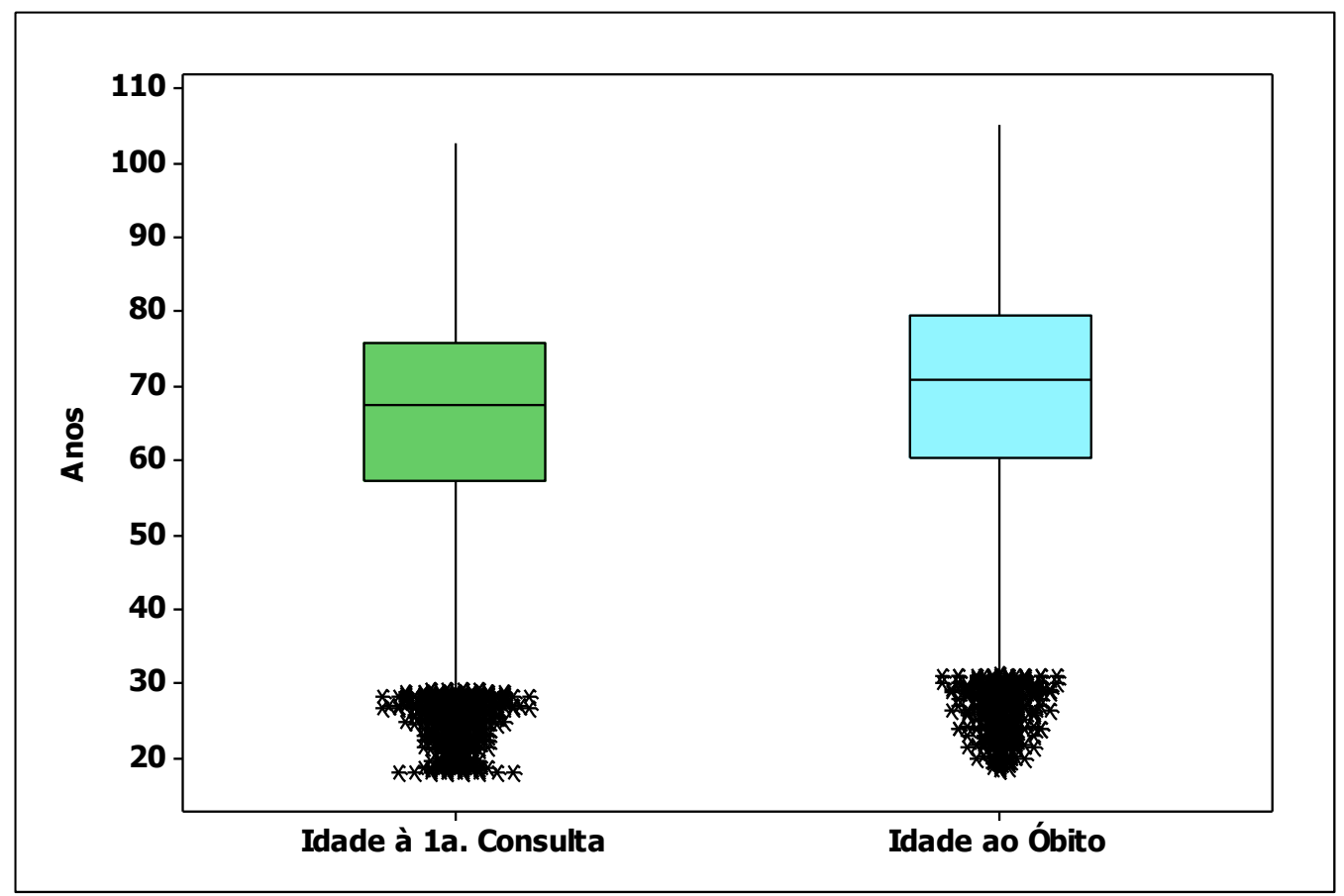

Figura 3. Idade à primeira consulta e da idade ao óbito

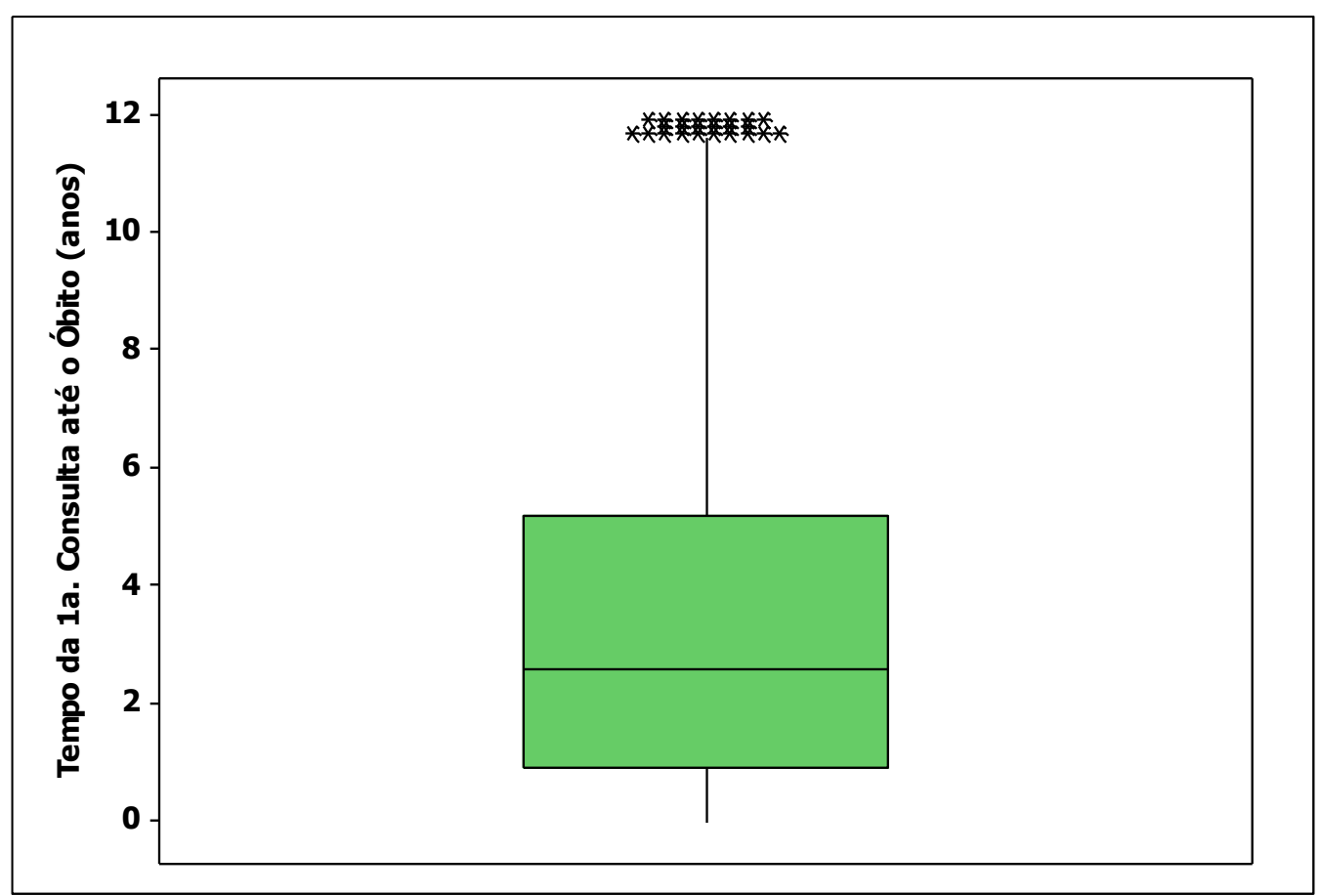

Figura 4. Tempo da primeira consulta até o óbito 


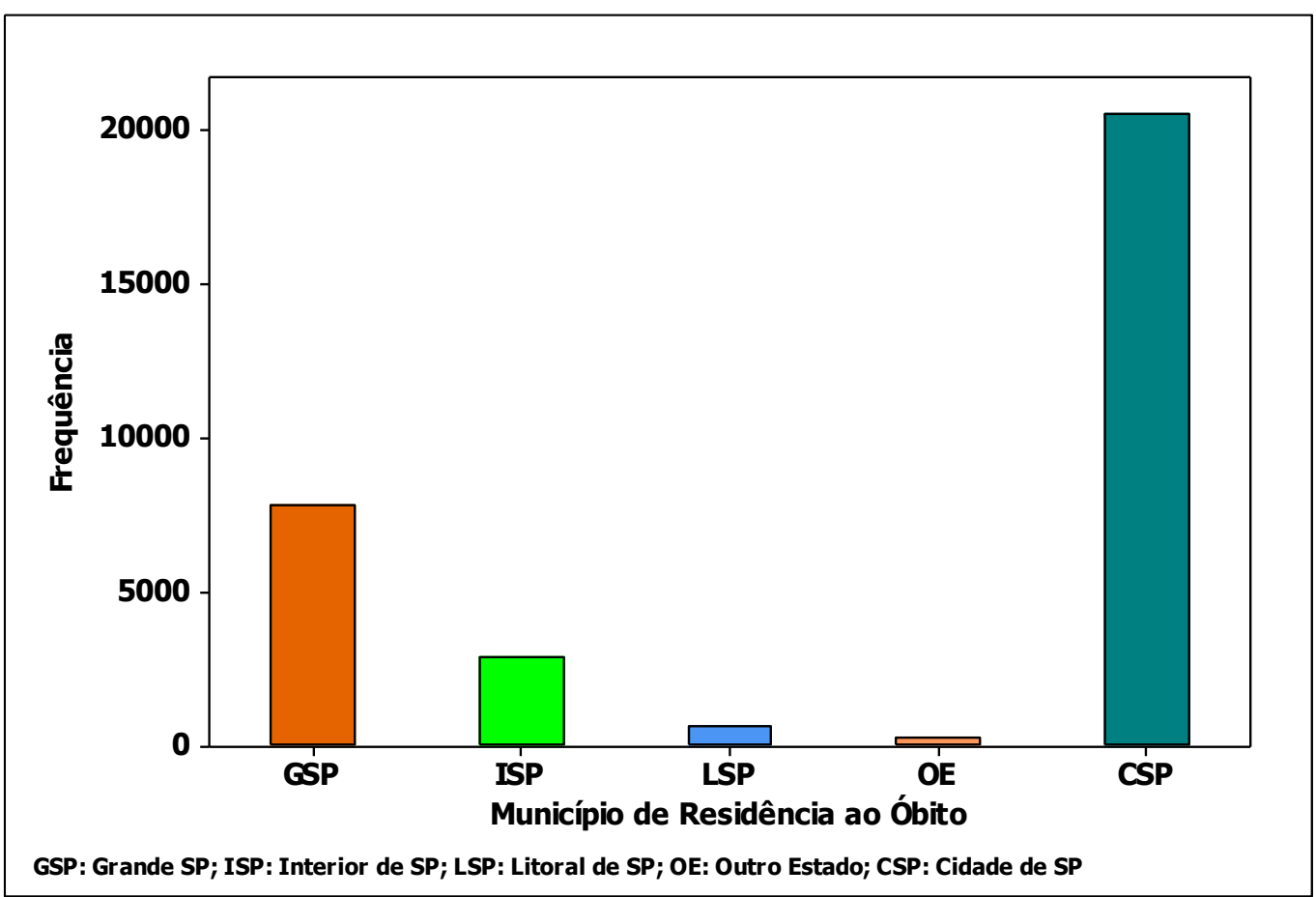

Figura 5. Distribuição de frequências do local de residência

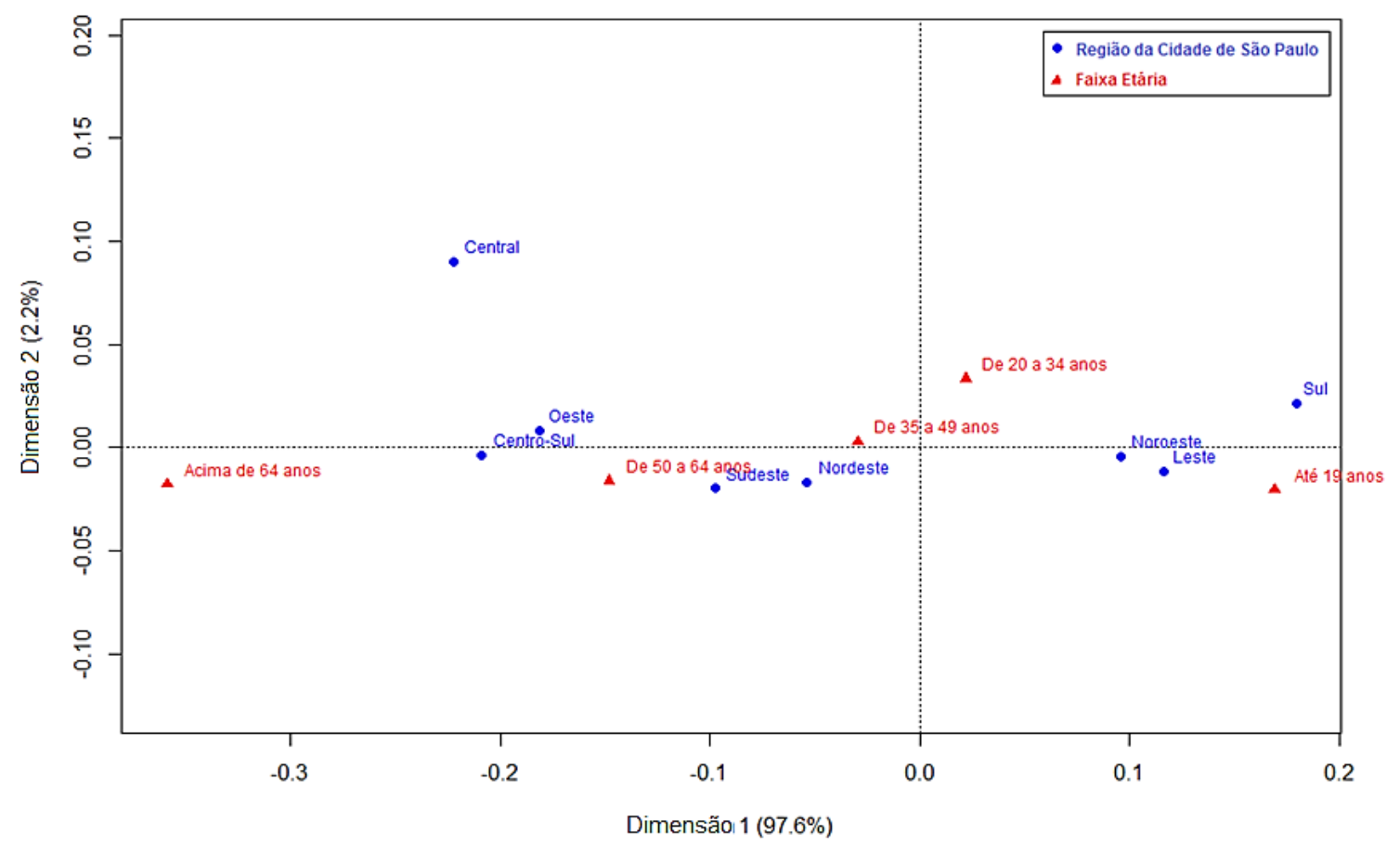

Figura 6. Análise de correspondência da população anual média por faixa etária, segundo região da cidade de São Paulo 


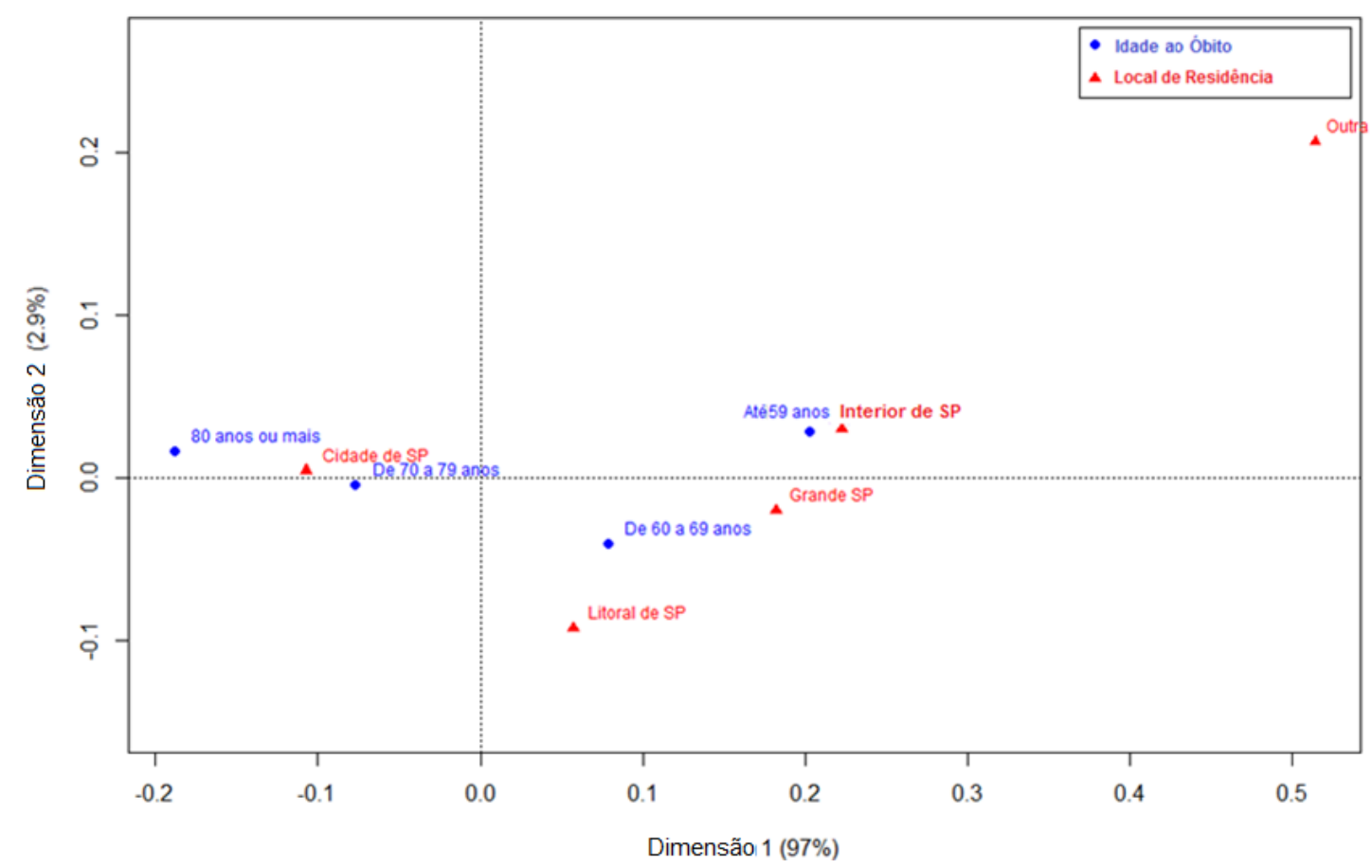

Figura 7. Análise de correspondência da idade do óbito e do local de residência

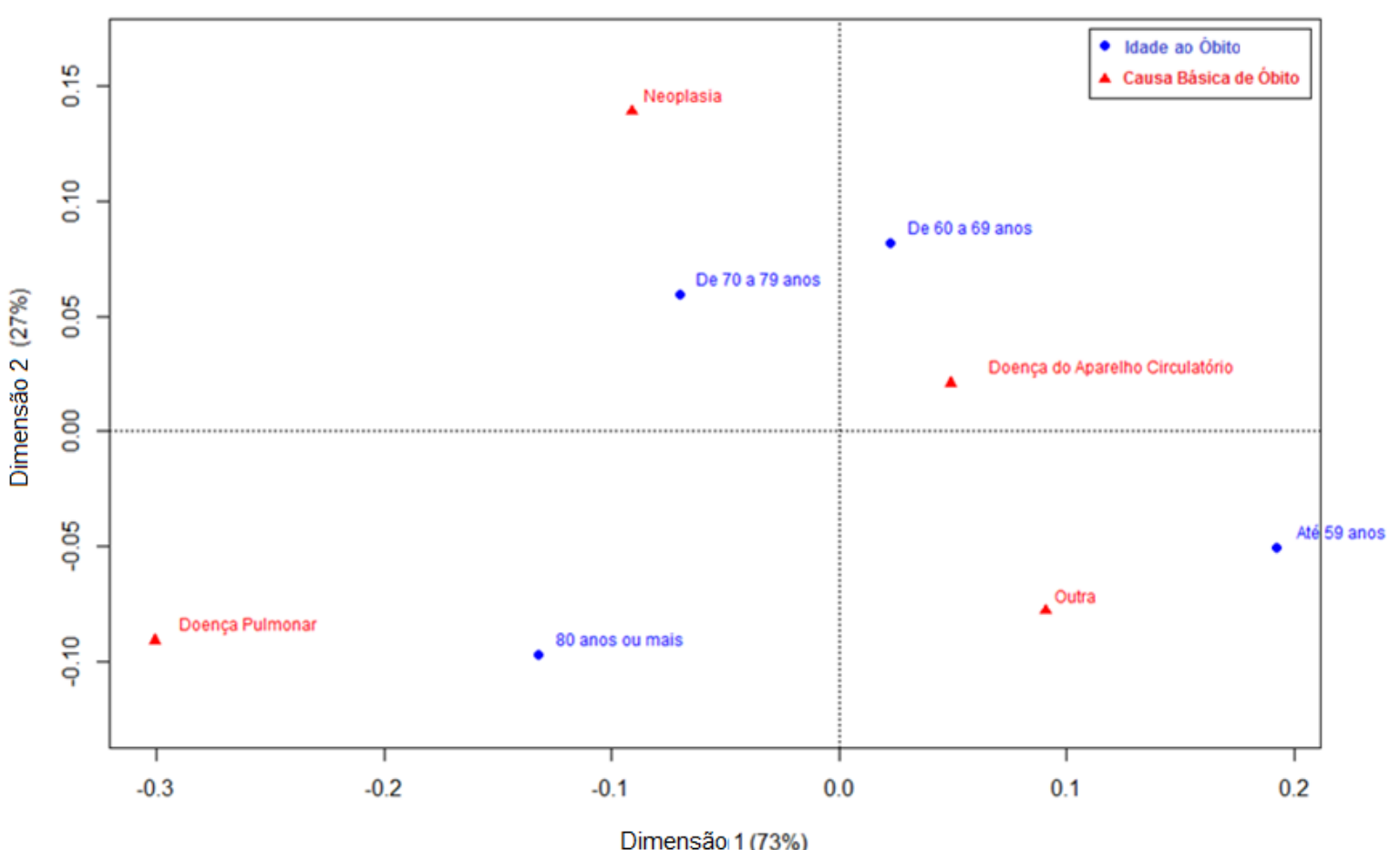

Figura 8. Análise de correspondência da idade do óbito e da causa básica do óbito 


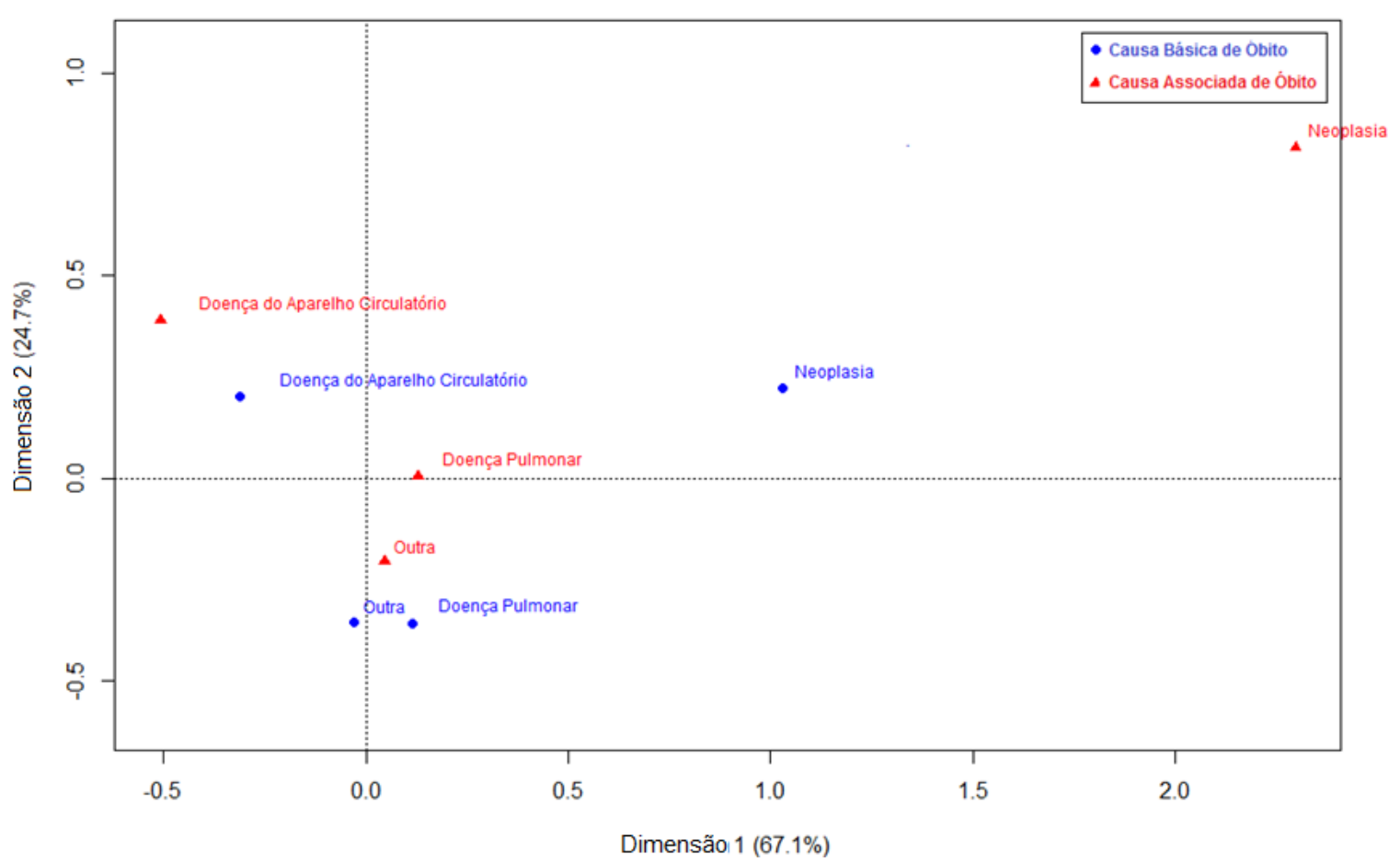

Figura 9. Análise de correspondência da causa básica e da causa associada de óbito (agrupamento 1)

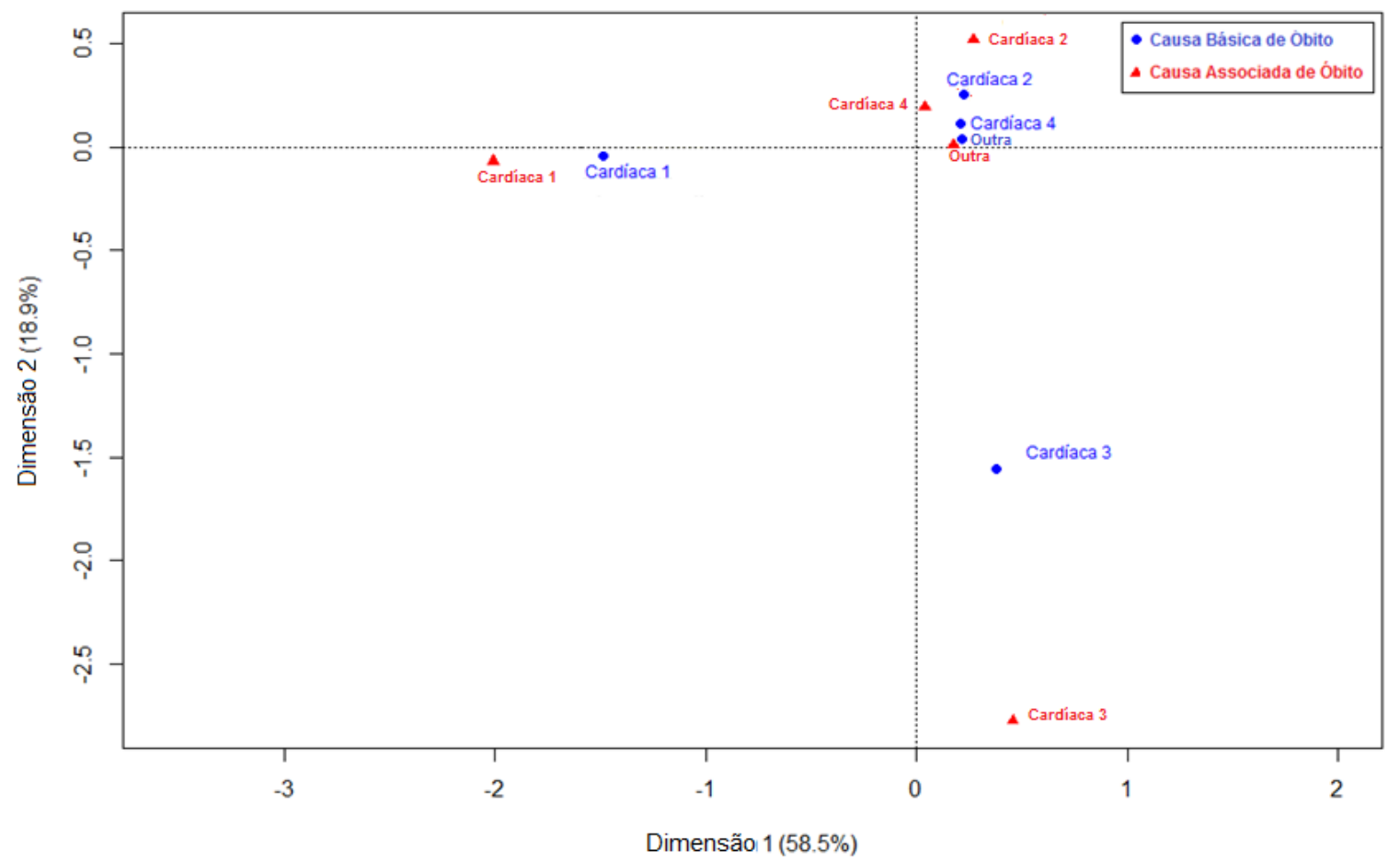

Figura 10. Análise de correspondência da causa básica e da causa associada de óbito (agrupamento 2) 


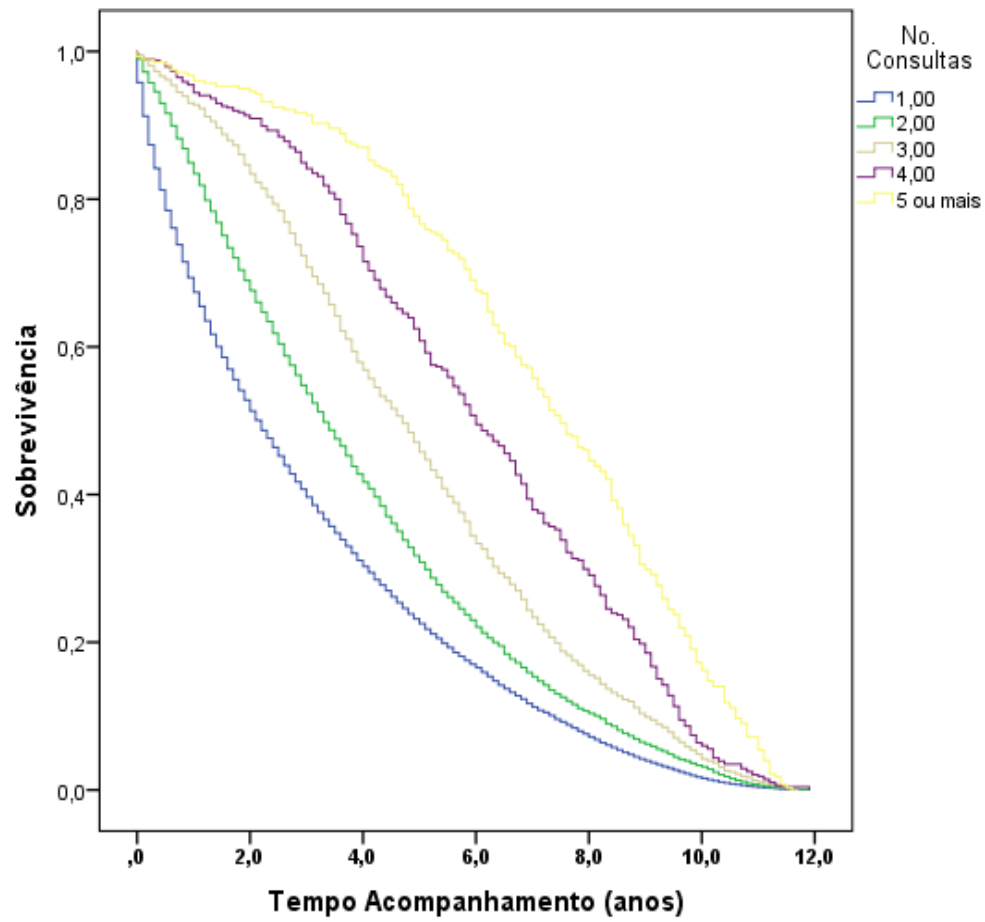

Figura 11. Probabilidade de sobrevida estimada (Kaplan-Meier) para tempo de acompanhamento agrupado por número de consultas (somente para os pacientes que faleceram)

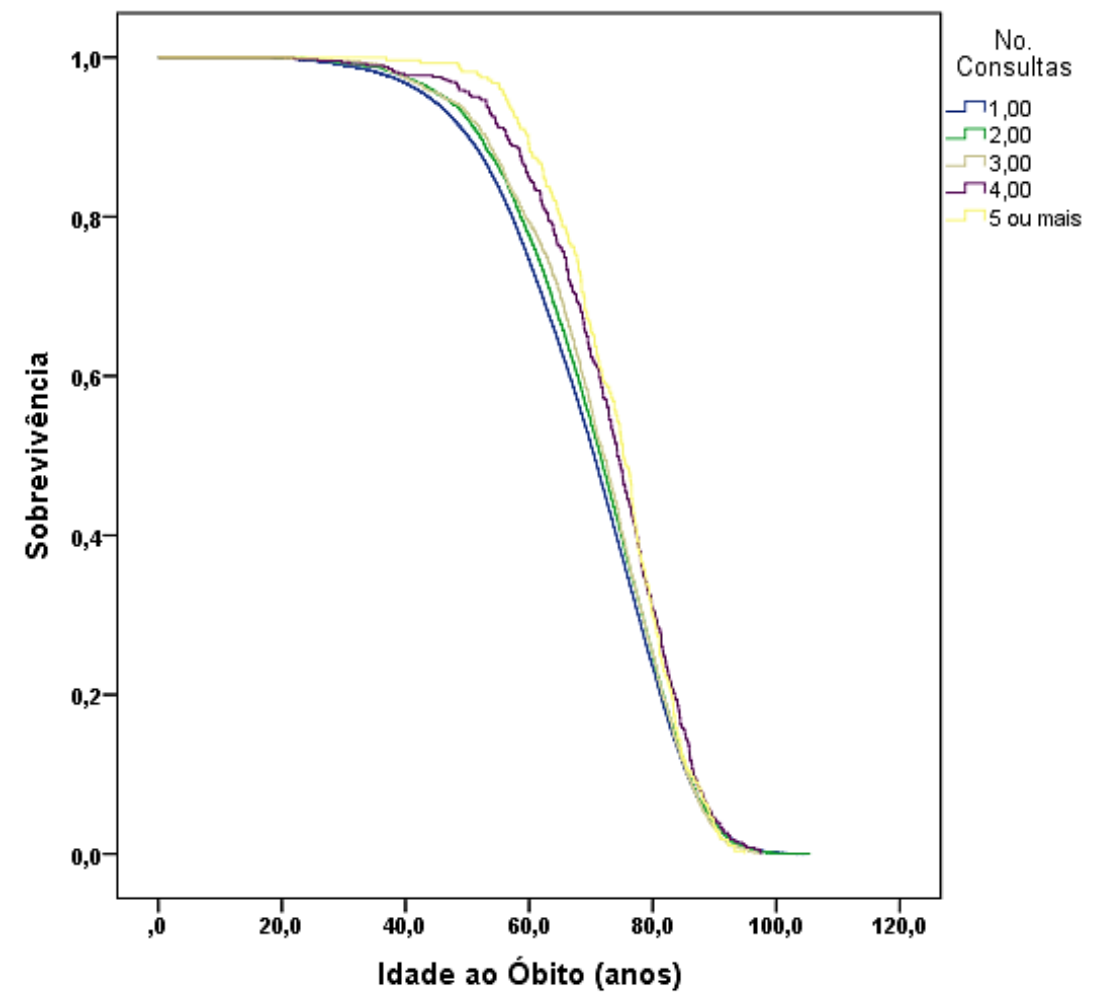

Figura 12. Probabilidade de sobrevida estimada (Kaplan-Meier) para tempo de acompanhamento de idade do óbito agrupado por número de consultas (somente para os pacientes que vieram a óbito) 


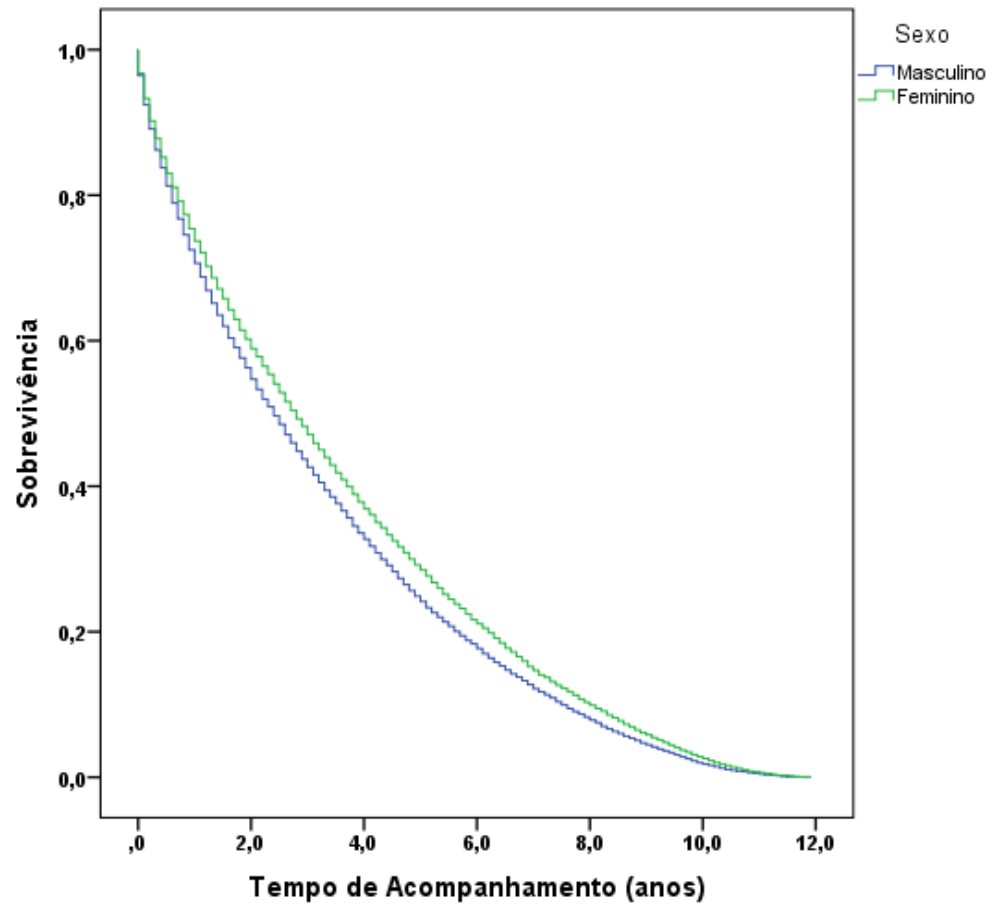

Figura 13. Probabilidade de sobrevida estimada (Kaplan-Meier) para tempo de acompanhamento agrupado por sexo (somente para os pacientes que vieram a óbito)

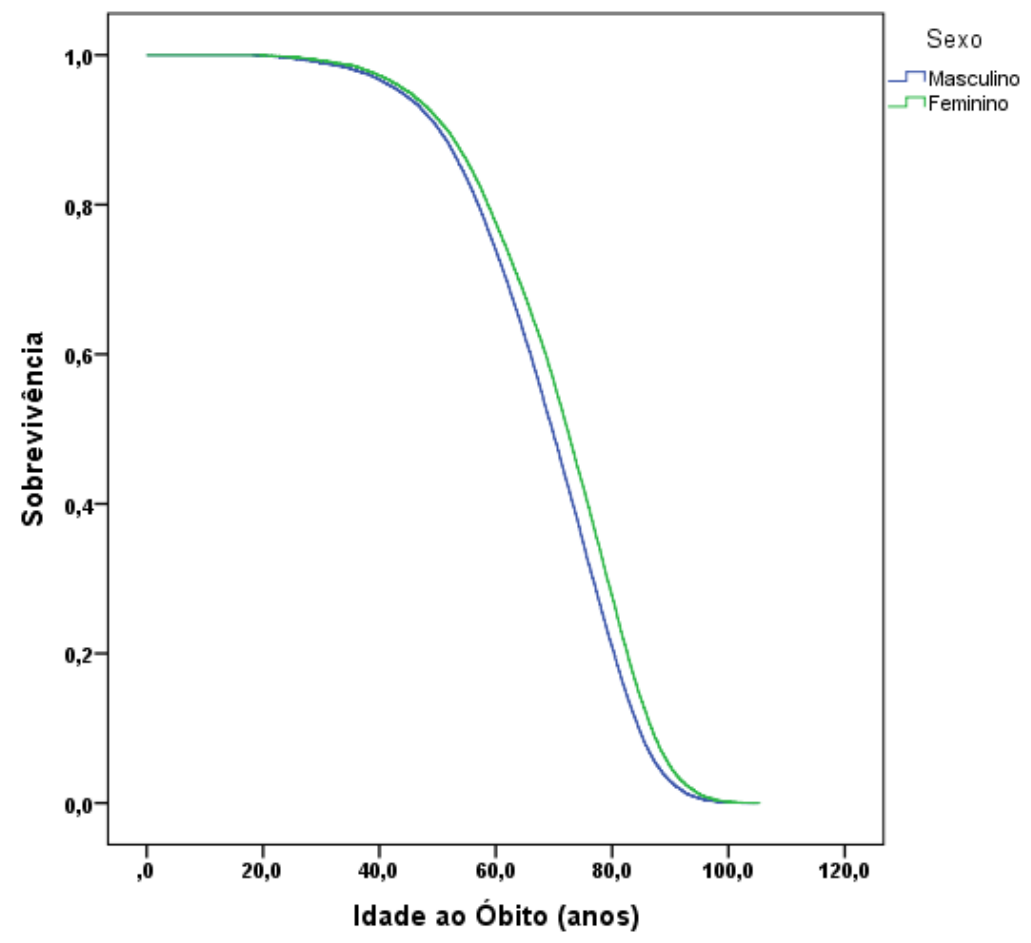

Figura 14. Probabilidade de sobrevida estimada (Kaplan-Meier) para idade ao óbito agrupado por sexo (somente para os pacientes que vieram a óbito) 


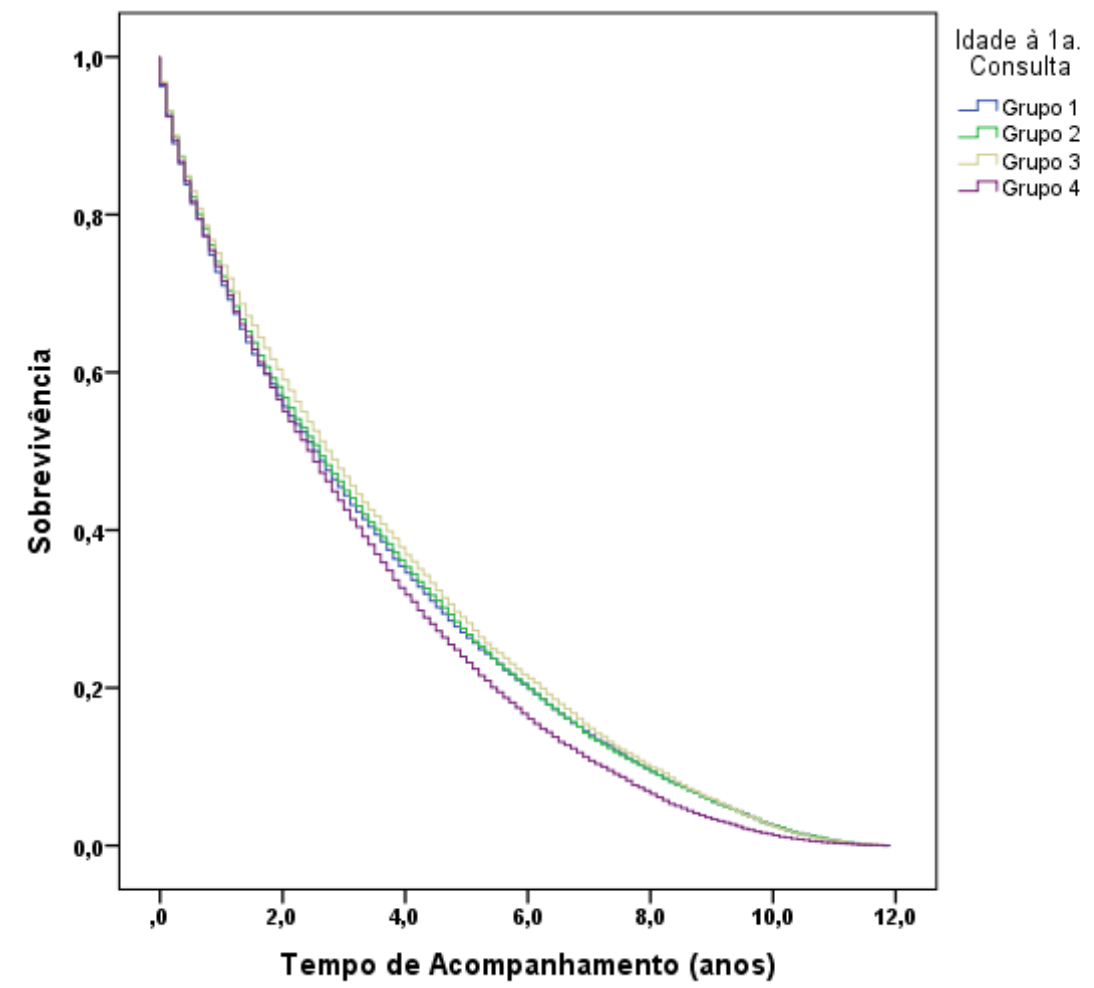

Figura 15. Probabilidade de sobrevida estimada (Kaplan-Meier) para tempo de acompanhamento agrupado por idade à primeira consulta (somente para os pacientes que vieram a óbito)

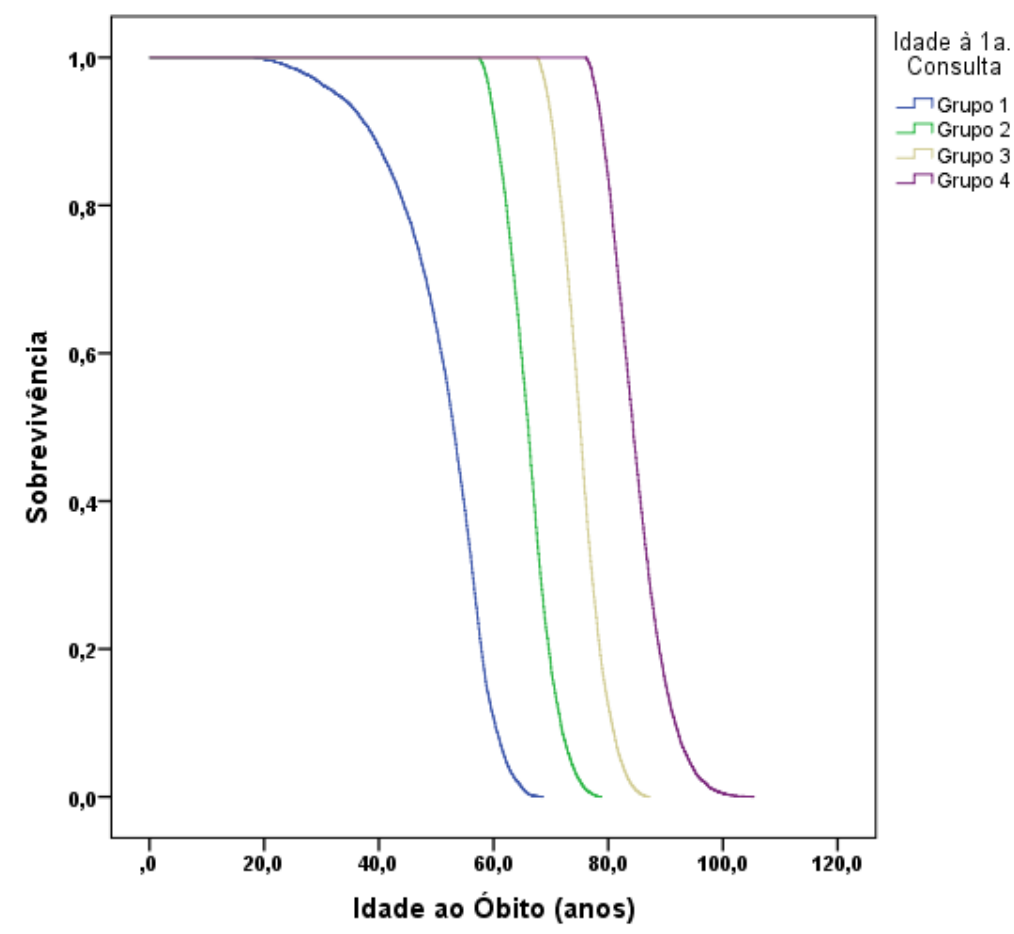

Figura 16. Probabilidade de sobrevida estimada (Kaplan-Meier) para idade ao óbito agrupado por idade à primeira consulta (somente para os pacientes que vieram a óbito) 


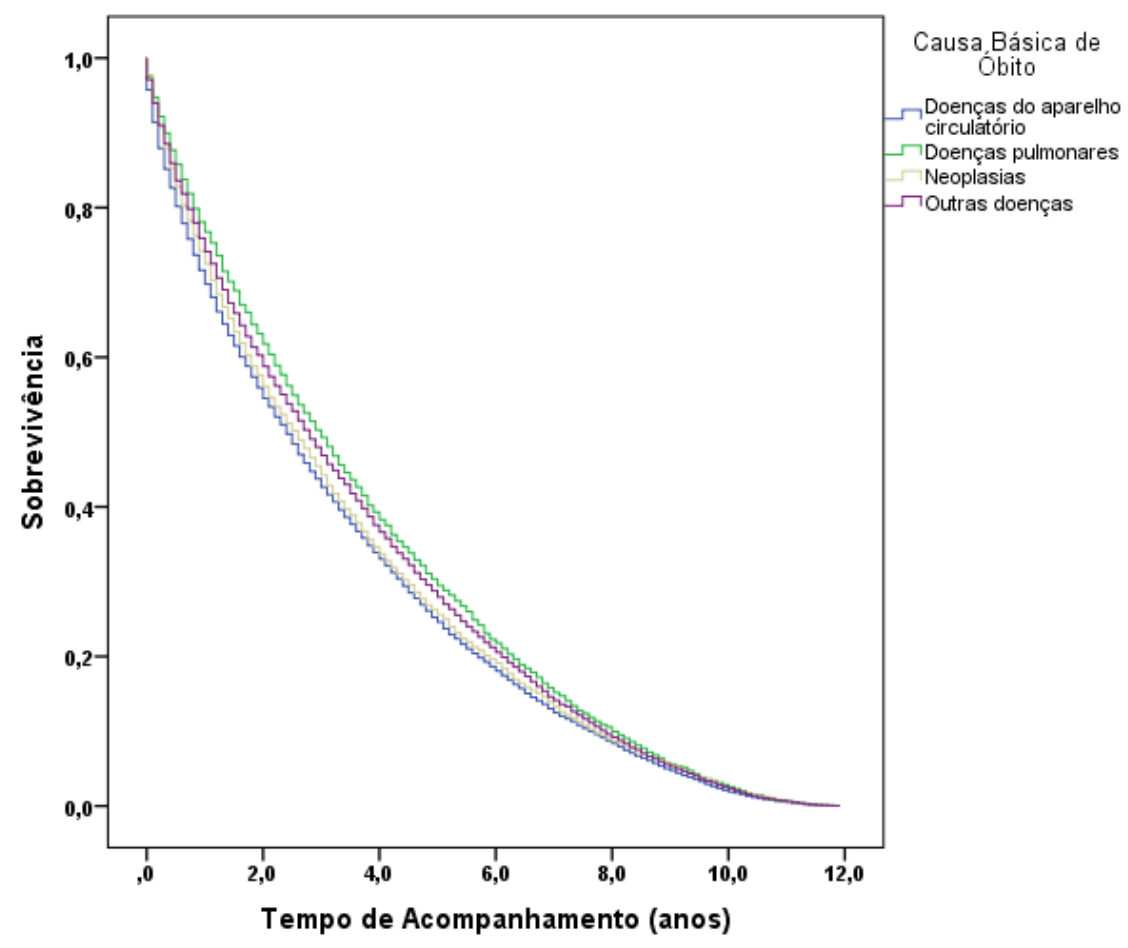

Figura 17. Probabilidade de sobrevida estimada (Kaplan-Meier) para tempo de acompanhamento agrupado por causa básica de óbito (somente para os pacientes que vieram a óbito)

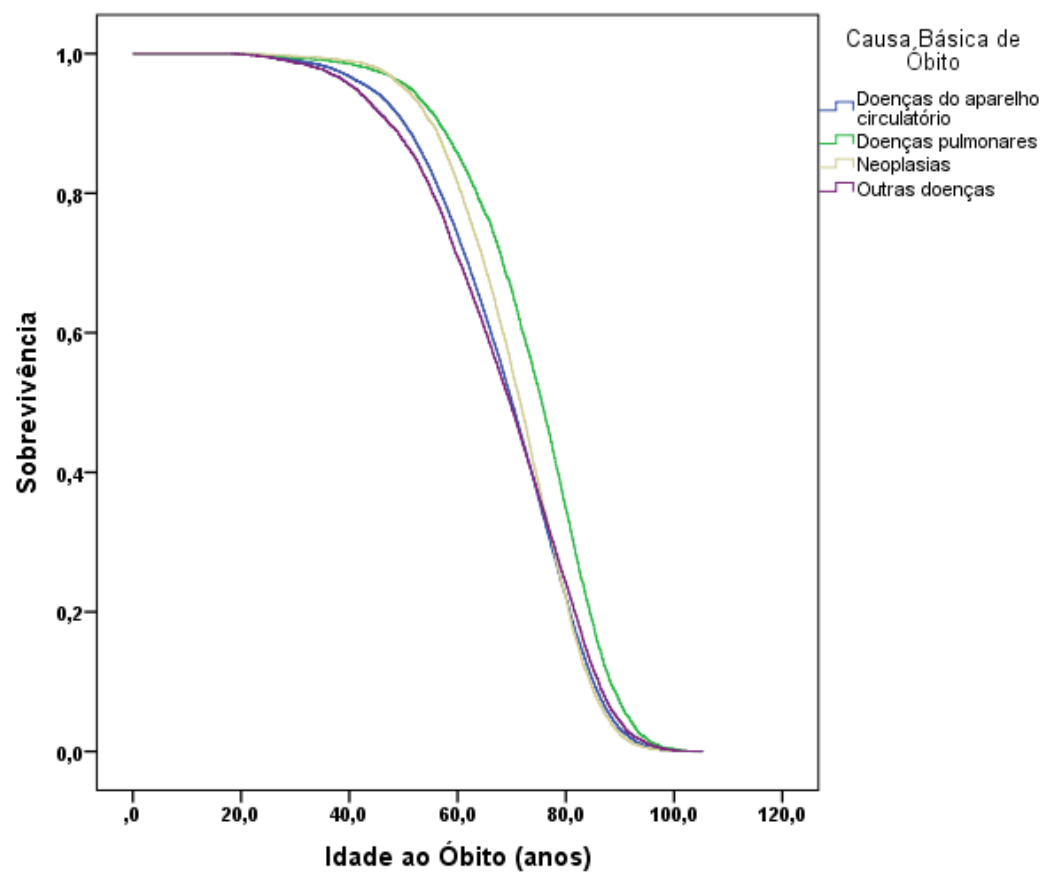

Figura 18. Probabilidade de sobrevida estimada (Kaplan-Meier) para idade ao óbito agrupado por causa básica de óbito (somente para os pacientes que vieram a óbito) 


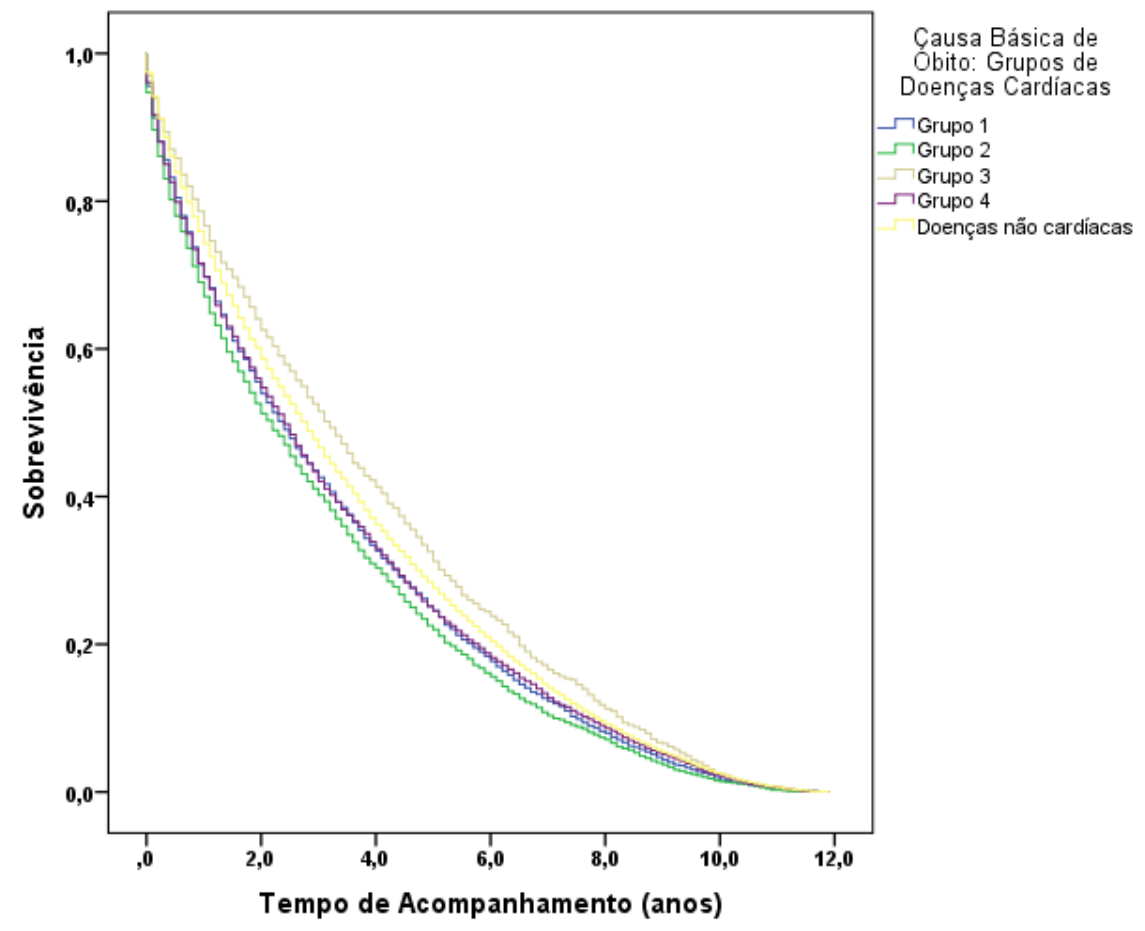

Figura 19. Probabilidade de sobrevida estimada (Kaplan-Meier) para tempo de acompanhamento agrupado por causa básica de óbito (somente para os pacientes que vieram a óbito)

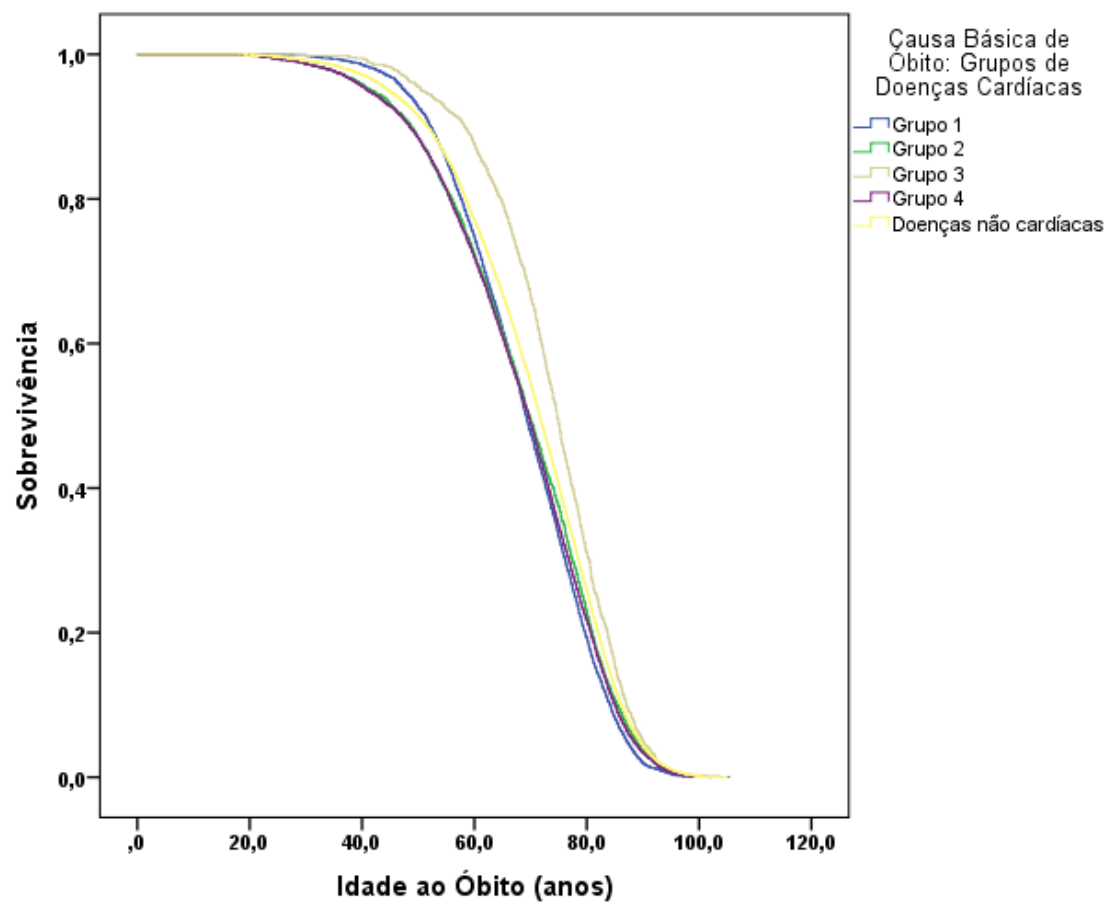

Figura 20. Probabilidade de sobrevida estimada (Kaplan-Meier) para idade ao óbito agrupado por causa básica de óbito (somente para os pacientes que vieram a óbito) - (Kaplan-Meier) 


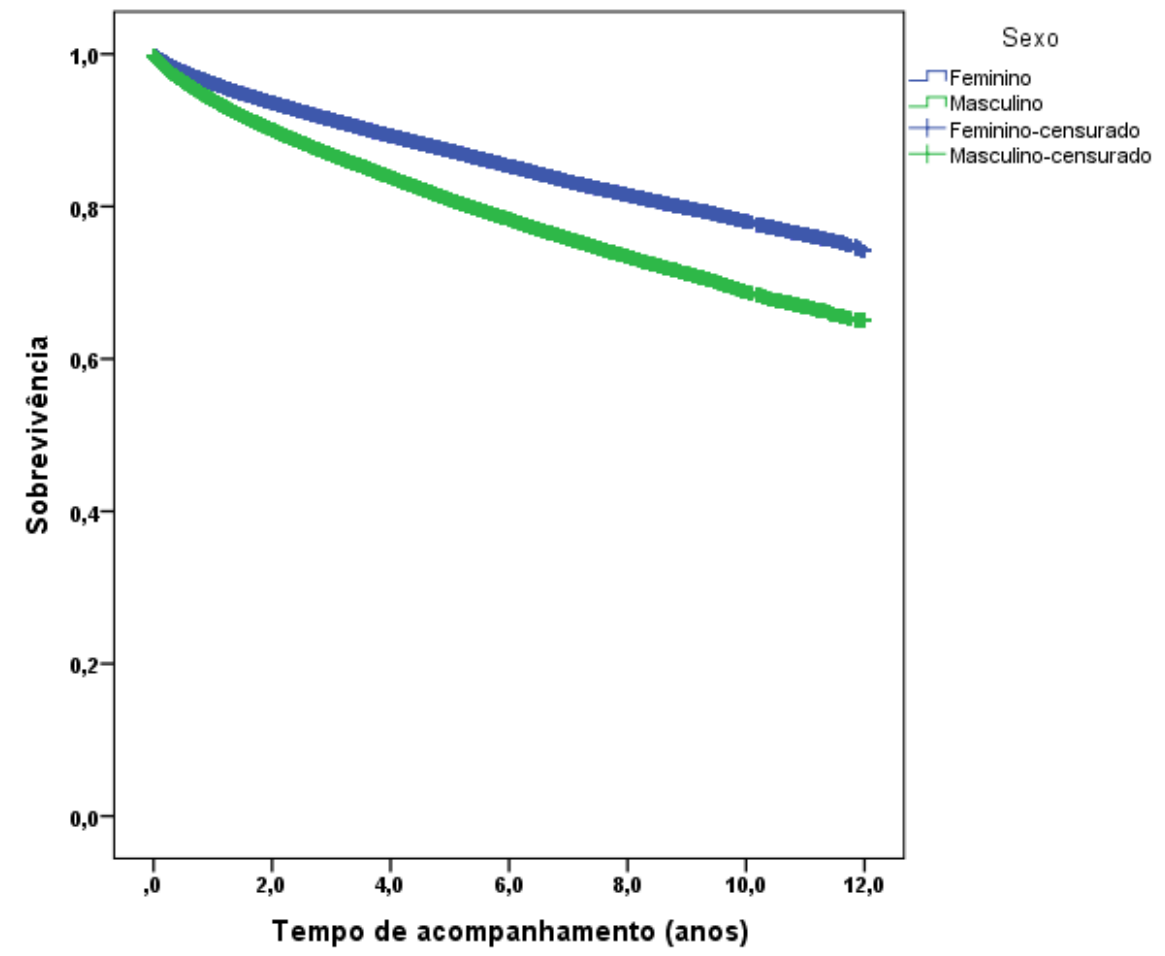

Figura 21. Probabilidade de sobrevida estimada (Kaplan-Meier) para tempo de acompanhamento agrupado por sexo (para todos os pacientes que passaram em consulta

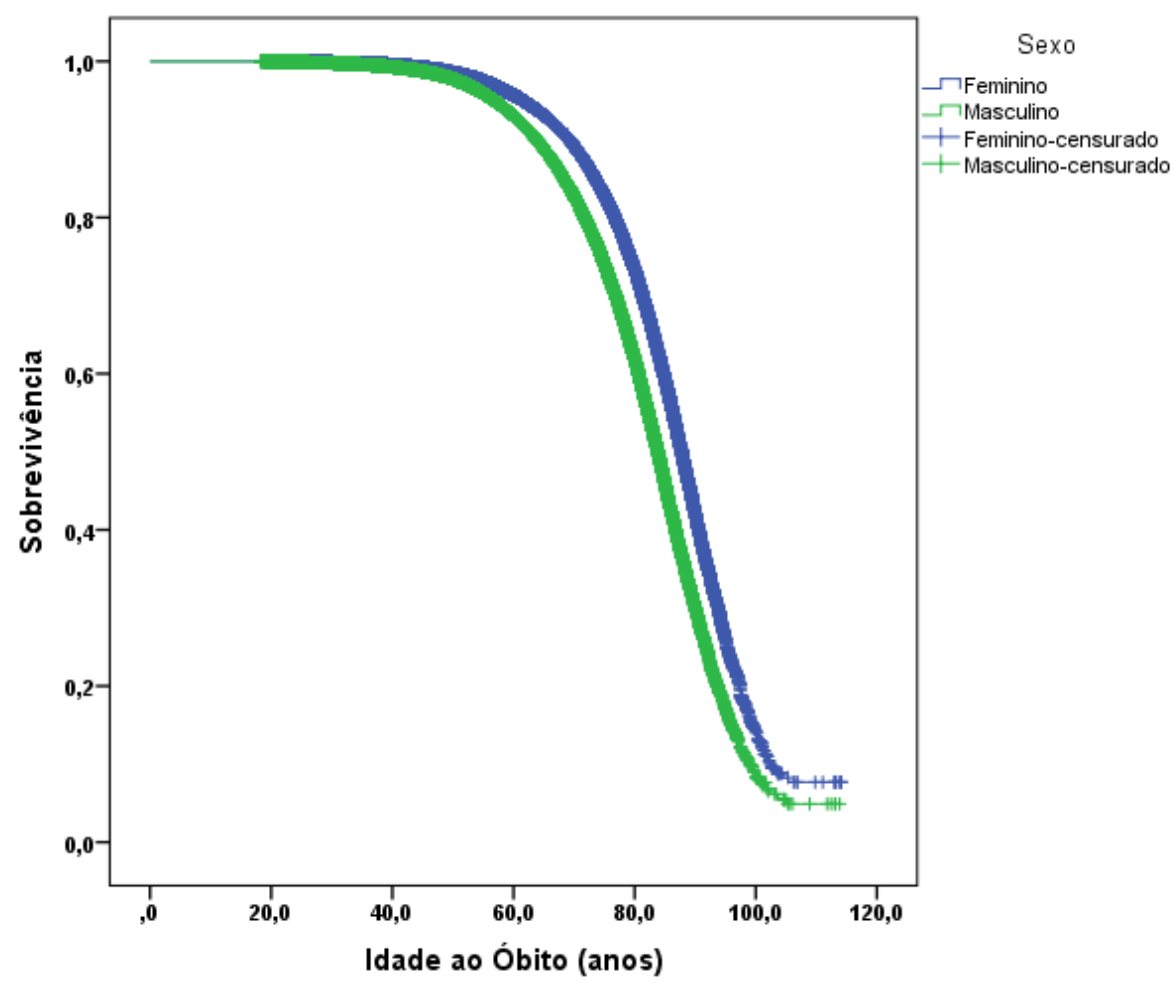

Figura 22. Probabilidade de sobrevida estimada (Kaplan-Meier) para idade ao óbito agrupado por sexo (para todos os pacientes que passaram em consulta) 


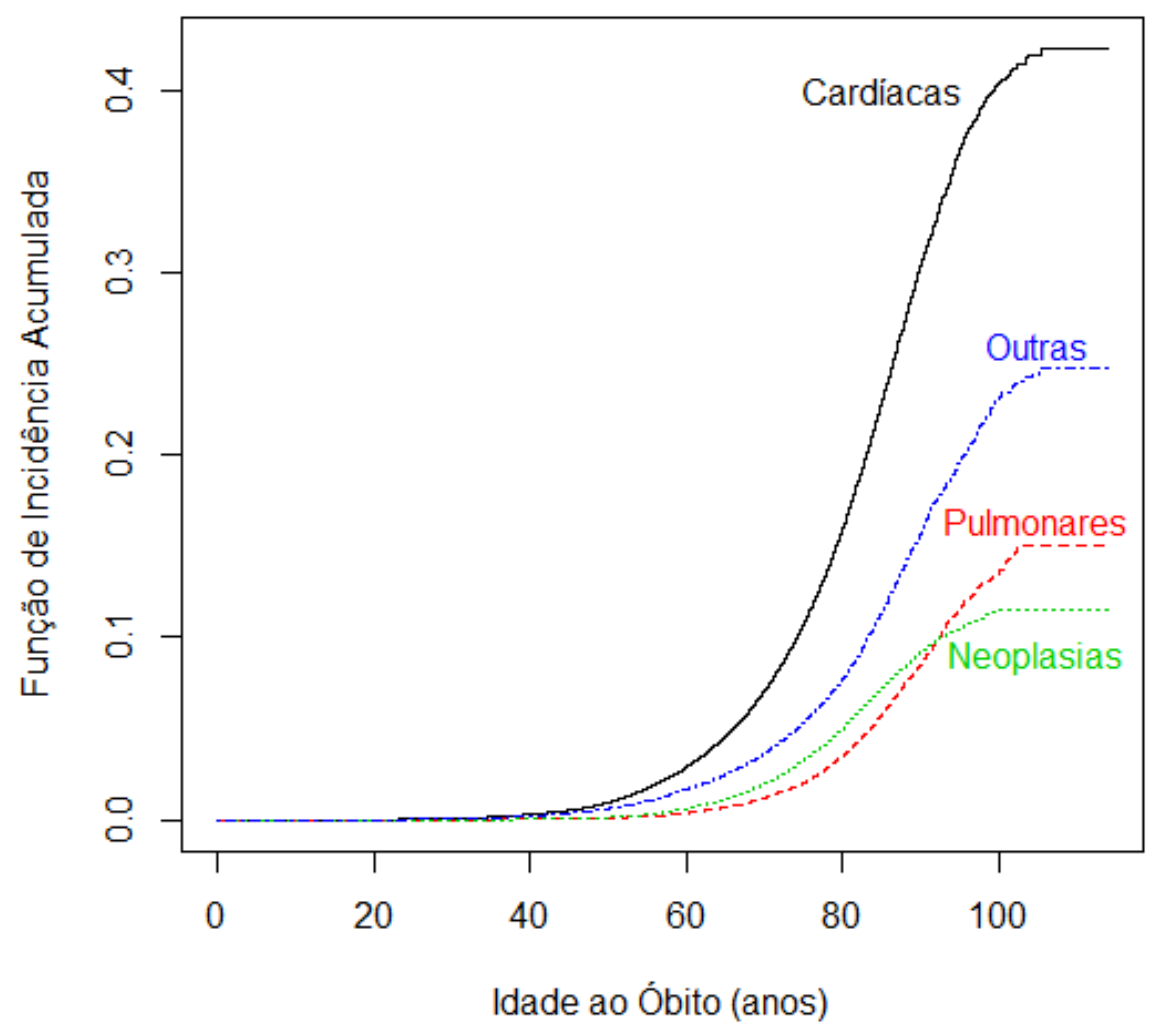

Figura 23. Função de Incidência Acumulada (FIA) para idade ao óbito modelado por risco competitivo de acordo com a causa básica de óbito (para todos os pacientes que passaram em consulta) 
Tabela 1 - Medidas-resumo de idade por sexo na primeira consulta (2002 - 2013)

\begin{tabular}{|c|c|c|c|c|c|c|c|c|}
\hline \multirow[b]{2}{*}{ Sexo } & \multirow[b]{2}{*}{$\mathrm{N}$} & \multicolumn{7}{|c|}{ Idade (anos) } \\
\hline & & Média & $\begin{array}{l}\text { Desvio } \\
\text { padrão }\end{array}$ & Mínimo & $\begin{array}{c}1^{0} \\
\text { quartil }\end{array}$ & Mediana & $\begin{array}{c}3^{0} \\
\text { quartil }\end{array}$ & Máximo \\
\hline Feminino & 98.786 & 56,8 & 15,5 & 18 & 47 & 58 & 68 & 109 \\
\hline Masculino & 82.143 & 56,7 & 15,5 & 18 & 47 & 58 & 68 & 108 \\
\hline Total & 180.929 & 56,8 & 15,5 & 18 & 47 & 58 & 68 & 109 \\
\hline
\end{tabular}

Tabela 2 - Distribuição de frequências do número de consultas por paciente, segundo o sexo

\begin{tabular}{|c|c|c|c|c|c|c|}
\hline \multirow{2}{*}{$\begin{array}{l}\text { Número de consultas } \\
\text { por paciente }\end{array}$} & \multicolumn{4}{|c|}{ Sexo } & \multirow{2}{*}{\multicolumn{2}{|c|}{ Total }} \\
\hline & \multicolumn{2}{|c|}{ Feminino } & \multicolumn{2}{|c|}{ Masculino } & & \\
\hline 1 & 75.933 & $(76,9 \%)$ & 63.356 & $(77,1 \%)$ & 139.289 & $(77,0 \%)$ \\
\hline 2 & 15.769 & $(16,0 \%)$ & 13.289 & $(16,2 \%)$ & 29.058 & $(16,1 \%)$ \\
\hline 3 & 4.383 & $(4,4 \%)$ & 3.552 & $(4,3 \%)$ & 7.935 & $(4,4 \%)$ \\
\hline 4 & 1.576 & $(1,6 \%)$ & 1.197 & $(1,5 \%)$ & 2.773 & $(1,5 \%)$ \\
\hline 5 & 625 & $(0,6 \%)$ & 435 & $(0,5 \%)$ & 1.060 & $(0,6 \%)$ \\
\hline 6 & 270 & $(0,3 \%)$ & 204 & $(0,2 \%)$ & 474 & $(0,3 \%)$ \\
\hline 7 & 127 & $(0,1 \%)$ & 64 & $(0,1 \%)$ & 191 & $(0,1 \%)$ \\
\hline 8 & 54 & $(0,1 \%)$ & 30 & $(0,04 \%)$ & 84 & $(0,05 \%)$ \\
\hline 9 & 28 & $(0,03 \%)$ & 9 & $(0,01 \%)$ & 37 & $(0,02 \%)$ \\
\hline 10 & 14 & $(0,01 \%)$ & 2 & $(0,002 \%)$ & 16 & $(0,01 \%)$ \\
\hline 11 & 1 & $(0,001 \%)$ & 4 & $(0,005 \%)$ & 5 & $(0,003 \%)$ \\
\hline 12 & 4 & $(0,004 \%)$ & 1 & $(0,001 \%)$ & 5 & $(0,003 \%)$ \\
\hline 13 & 1 & $(0,001 \%)$ & 0 & $(0,000 \%)$ & 1 & $(0,001 \%)$ \\
\hline 15 & 1 & $(0,001 \%)$ & 0 & $(0,000 \%)$ & 1 & $(0,001 \%)$ \\
\hline Total & 98.786 & $(100 \%)$ & 82.143 & $(100 \%)$ & 180.929 & $(100 \%)$ \\
\hline
\end{tabular}

$\%=$ por cento 
Tabela 3 - Distribuição de frequências de consultas por unidade federativa de residência

\begin{tabular}{|c|c|c|}
\hline Unidade Federativa de Residência & Frequência (N) & Porcentagem (\%) \\
\hline São Paulo & 159.413 & 97,3 \\
\hline Minas Gerais & 1.445 & 0,9 \\
\hline Bahia & 1.141 & 0,7 \\
\hline Rio de Janeiro & 316 & 0,2 \\
\hline Pernambuco & 208 & 0,1 \\
\hline Paraná & 187 & 0,1 \\
\hline Maranhão & 128 & 0,1 \\
\hline Amazonas & 122 & 0,1 \\
\hline Paraíba & 106 & 0,1 \\
\hline Alagoas & 97 & 0,1 \\
\hline Piauí & 96 & 0,1 \\
\hline Ceará & 86 & 0,1 \\
\hline Rondônia & 63 & $<0,1$ \\
\hline Mato Grosso & 62 & $<0,1$ \\
\hline Santa Catarina & 52 & $<0,1$ \\
\hline Goiás & 51 & $<0,1$ \\
\hline Mato Grosso do Sul & 49 & $<0,1$ \\
\hline Acre & 47 & $<0,1$ \\
\hline Espírito Santo & 45 & $<0,1$ \\
\hline Pará & 35 & $<0,1$ \\
\hline Rio Grande do Norte & 31 & $<0,1$ \\
\hline Distrito Federal & 30 & $<0,1$ \\
\hline Sergipe & 28 & $<0,1$ \\
\hline Rio Grande do Sul & 25 & $<0,1$ \\
\hline Roraima & 19 & $<0,1$ \\
\hline Amapá & 10 & $<0,1$ \\
\hline Tocantins & 8 & $<0,1$ \\
\hline Total & 163.900 & 100 \\
\hline
\end{tabular}

$\overline{\mathrm{N}}=$ número de consultas; $<$ = menor que; Observação: 17.029 dados faltantes 
Tabela 4 - Distribuição de frequências de consultas por município de residência Município de Residência Frequência (N) Porcentagem (\%)

\begin{tabular}{|c|c|c|}
\hline São Paulo & 111.943 & 68,8 \\
\hline Osasco & 5.339 & 3,3 \\
\hline Guarulhos & 5.046 & 3,1 \\
\hline Carapicuíba & 3.169 & 1,9 \\
\hline Taboão da Serra & 2.855 & 1,8 \\
\hline Embu das Artes & 1.972 & 1,2 \\
\hline Cotia & 1.650 & 1,0 \\
\hline São Bernardo do Campo & 1.589 & 1,0 \\
\hline Itaquaquecetuba & 1.140 & 0,7 \\
\hline Mauá & 1.135 & 0,7 \\
\hline Santo André & 1.115 & 0,7 \\
\hline Itapevi & 1.114 & 0,7 \\
\hline Francisco Morato & 1.048 & 0,6 \\
\hline Diadema & 1.037 & 0,6 \\
\hline Barueri & 1.001 & 0,6 \\
\hline Ferraz de Vasconcelos & 762 & 0,5 \\
\hline Jandira & 748 & 0,5 \\
\hline Franco da Rocha & 686 & 0,4 \\
\hline Suzano & 686 & 0,4 \\
\hline Mogi das Cruzes & 644 & 0,4 \\
\hline Outros & 17.978 & 11,1 \\
\hline Total & 162.657 & 100 \\
\hline
\end{tabular}


Tabela 5 - Distribuição de frequências de consultas por região de residência na cidade de São Paulo (2002 - 2013)

\begin{tabular}{lcc}
\hline $\begin{array}{l}\text { Região de Residência na } \\
\text { Cidade de São Paulo }\end{array}$ & Frequência (N) & Porcentagem (\%) \\
\hline Central & 5.932 & 6,5 \\
Centro-Sul & 15.417 & 16,9 \\
Leste & 15.805 & 17,3 \\
Nordeste & 14.213 & 15,6 \\
Noroeste & 11.422 & 12,5 \\
Oeste & 14.829 & 16,2 \\
Sudeste & 10.346 & 11,3 \\
Sul & 3.415 & 3,7 \\
\hline Total & 91.379 & 100 \\
\hline
\end{tabular}

$\mathrm{N}$ = número de consultas; Observação: 89.550 dados faltantes

Tabela 6 - População anual média e número de visitas anuais médias ao InCor por 100.000 habitantes (de 2002 a 2013) por região da cidade de São Paulo

\begin{tabular}{lcccc}
\hline $\begin{array}{l}\text { Região da cidade } \\
\text { de São Paulo }\end{array}$ & $\begin{array}{c}\text { População } \\
\text { anual média } \\
(\mathrm{N})\end{array}$ & $\begin{array}{c}\text { Porcentagem } \\
(\%)\end{array}$ & $\begin{array}{c}\text { Número de visitas anual } \\
\text { médio ao InCor por } \\
100.000 \text { habitantes }\end{array}$ & $\begin{array}{c}\text { Área } \\
\text { territorial } \\
\left(\mathrm{km}^{2}\right)\end{array}$ \\
\hline Central & 415.904 & 3,76 & 119 & 31 \\
Centro-Sul & 790.387 & 7,15 & 163 & 74 \\
Leste & 2.828 .587 & 25,60 & 47 & 209 \\
Nordeste & 1.218 .973 & 11,03 & 97 & 152 \\
Noroeste & 965.880 & 8,74 & 99 & 144 \\
Oeste & 996.251 & 9,02 & 124 & 128 \\
Sudeste & 1.586 .497 & 14,36 & 54 & 128 \\
Sul & 2.245 .020 & 20,32 & 13 & 607 \\
\hline Total & 11.047 .498 & 100 & 716 & 1.473 \\
\hline
\end{tabular}

$\mathrm{N}$ = número de pessoas (população); $\mathrm{km}^{2}$ = quilômetro quadrado 
Tabela 7 - Distribuição de frequências de consultas por distrito de residência na cidade de São Paulo

\begin{tabular}{|c|c|c|}
\hline Distrito de Residência na Cidade de São Paulo & Frequência (N) & Porcentagem (\%) \\
\hline Santo Amaro & 11.391 & 11,8 \\
\hline Butantã & 5.971 & 6,2 \\
\hline Itaquera & 4.635 & 4,8 \\
\hline Pirituba & 4.202 & 4,4 \\
\hline São Miguel Paulista & 4.004 & 4,2 \\
\hline Santana & 3.759 & 3,9 \\
\hline Tucuruvi & 3.543 & 3,7 \\
\hline Penha & 3.087 & 3,2 \\
\hline Pinheiros & 2.390 & 2,5 \\
\hline Guaianazes & 2.341 & 2,4 \\
\hline Lapa & 2.269 & 2,4 \\
\hline Vila Prudente & 2.208 & 2,3 \\
\hline Freguesia do Ó & 1.978 & 2,1 \\
\hline Cachoeirinha & 1.903 & 2,0 \\
\hline Ipiranga & 1.845 & 1,9 \\
\hline Perdizes & 1.797 & 1,9 \\
\hline Jabaquara & 1.758 & 1,8 \\
\hline Tatuapé & 1.625 & 1,7 \\
\hline Brasilândia & 1.573 & 1,6 \\
\hline Vila Maria & 1.567 & 1,6 \\
\hline Campo Limpo & 1.518 & 1,6 \\
\hline Casa Verde & 1.431 & 1,5 \\
\hline Ermelino Matarazzo & 1.377 & 1,4 \\
\hline Nossa Senhora do Ó & 1.368 & 1,4 \\
\hline São Mateus & 1.363 & 1,4 \\
\hline Itaim Paulista & 1.350 & 1,4 \\
\hline Bela Vista & 1.251 & 1,3 \\
\hline Santa Cecília & 1.153 & 1,2 \\
\hline Jaraguá & 1.110 & 1,2 \\
\hline Mooca & 1.084 & 1,1 \\
\hline Perus & 1.073 & 1,1 \\
\hline Vila Formosa & 1.072 & 1,1 \\
\hline Saúde & 970 & 1,0 \\
\hline Outros & 16.240 & 16,9 \\
\hline Total & 96.206 & 100 \\
\hline
\end{tabular}

$\overline{\mathrm{N}}=$ número de consultas; Observação: 84.723 dados faltantes 
Tabela 8 - Distribuição de frequências do ano de óbito

\begin{tabular}{ccc}
\hline Ano & Frequência $(\mathrm{N})$ & Porcentagem $(\%)$ \\
\hline 2002 & 435 & 1,4 \\
2003 & 1.102 & 3,4 \\
2004 & 1.587 & 5,0 \\
2005 & 1.785 & 5,6 \\
2006 & 2.143 & 6,7 \\
2007 & 2.328 & 7,3 \\
2008 & 2.826 & 8,8 \\
2009 & 3.295 & 10,3 \\
2010 & 3.611 & 11,3 \\
2011 & 3.893 & 12,2 \\
2012 & 4.228 & 13,2 \\
2013 & 4.723 & 14,8 \\
\hline Total & 31.956 & 100 \\
\hline
\end{tabular}

$\mathrm{N}$ = número de óbitos

Tabela 9 - Distribuição de frequências de óbito por sexo

\begin{tabular}{lcc}
\hline Sexo & Frequência $(\mathrm{N})$ & Porcentagem $(\%)$ \\
\hline Masculino & 17.244 & 54,0 \\
Feminino & 14.712 & 46,0 \\
\hline Total & 31.956 & 100 \\
\hline $\mathrm{N}=$ número de óbitos & &
\end{tabular}

Tabela 10 - Medidas-resumo de idade ao óbito

\begin{tabular}{lccccccc}
\hline \multicolumn{8}{c}{ Idade (anos) } \\
\hline N & Média & $\begin{array}{c}\text { Desvio } \\
\text { padrão }\end{array}$ & Mínimo & 1o quartil & Mediana & 3o quartil & Máximo \\
\hline 31.956 & 69,3 & 13,8 & 18,3 & 60,3 & 70,9 & 79,6 & 105,4 \\
\hline N = número de pacientes & & & & & &
\end{tabular}


Tabela 11 - Medidas-resumo da idade ao óbito por número de consultas

\begin{tabular}{|c|c|c|c|c|c|c|c|c|}
\hline \multirow{2}{*}{$\begin{array}{l}\text { Número de } \\
\text { consultas }\end{array}$} & \multirow{2}{*}{$\mathrm{N}$} & \multicolumn{7}{|c|}{ Idade ao óbito (anos) } \\
\hline & & Média & $\begin{array}{l}\text { Desvio } \\
\text { padrão }\end{array}$ & Mínimo & $1^{\circ}$ quartil & Mediana & $3^{\circ}$ quartil & Máximo \\
\hline 1 & 24.118 & 68,9 & 14,0 & 18,3 & 59,8 & 70,5 & 79,4 & 105,1 \\
\hline 2 & 5.555 & 70,0 & 13,3 & 19,3 & 61,4 & 71,6 & 80,0 & 105,4 \\
\hline 3 & 1.520 & 70,4 & 12,9 & 20,5 & 62,9 & 72,1 & 80,1 & 97,2 \\
\hline 4 & 485 & 72,8 & 12,4 & 22,0 & 65,8 & 74,3 & 81,8 & 97,6 \\
\hline 5 ou mais & 278 & 73,9 & 10,2 & 36,9 & 67,7 & 75,3 & 81,2 & 94,9 \\
\hline Total & 31.956 & 69,3 & 13,8 & 18,3 & 60,3 & 70,9 & 79,6 & 105,4 \\
\hline
\end{tabular}

$\mathrm{N}$ = número de pacientes

Tabela 12 - Medidas-resumo de idade ao óbito e medidas-resumo do tempo da primeira consulta até o óbito

\begin{tabular}{|c|c|c|c|c|c|c|c|}
\hline \multirow{2}{*}{$\mathrm{N}$} & \multicolumn{7}{|c|}{ Idade ao óbito (anos) } \\
\hline & Média & $\begin{array}{l}\text { Desvio } \\
\text { padrão }\end{array}$ & Mínimo & $1^{\circ}$ quartil & Mediana & 3q quartil & Máximo \\
\hline $\begin{array}{c}31.956 \\
\text { Idade ao } \\
\text { óbito }\end{array}$ & 69,3 & 13,8 & 18,3 & 60,3 & 70,9 & 79,6 & 105,4 \\
\hline $\begin{array}{l}31.956 \\
\text { Tempo da } 1 \underline{a} \\
\text { consulta até } \\
\text { o óbito }\end{array}$ & 3,3 & 2,9 & 0,0 & 0,9 & 2,6 & 5,2 & 11,9 \\
\hline
\end{tabular}


Tabela 13 - Distribuição de frequências de causa básica de óbito (por tipo de doença de acordo com CID 10)

Causa básica de óbito

Doenças do aparelho circulatório

Neoplasias

Doenças do aparelho respiratório

Doenças infecciosas e parasitárias

Doenças endócrinas, nutricionais e metabólicas

Doenças do aparelho digestório

Doenças do aparelho geniturinário

Causas externas de morbidade e mortalidade

Sintomas e sinais anormais clínicos e laboratoriais

Doenças do sistema nervoso

Doenças do sistema osteomuscular

Transtornos Mentais e Comportamentais

Doenças do sangue e sistema imune

Doenças da Pele

Malformações congênitas e cromossômicas

Gravidez, parto e puerpério

Doenças do Ouvido
Frequência (N)

Porcentagem (\%)

$15.676 \quad 49,0$

4.560

14,3

3.619

11,3

1.687

5,3

1.612

5,0

1.432

4,5

952

3,0

847

2,6

514

1,6

449

1,4

159

0,5

147

0,5

127

0,4

106

0,3

48

0,2

19

0,1

2

$<0,01$ 
Tabela 14 - Contagem de causa básica por letra do CID 10

\begin{tabular}{|c|c|c|}
\hline Causa Básica & Contagem & Porcentagem (\%) \\
\hline A & 410 & 1,28 \\
\hline B & 1.278 & 4,00 \\
\hline C & 4.464 & 13,97 \\
\hline $\mathrm{D}$ & 223 & 0,70 \\
\hline$E$ & 1.612 & 5,04 \\
\hline $\mathrm{F}$ & 147 & 0,46 \\
\hline G & 449 & 1,41 \\
\hline $\mathrm{H}$ & 2 & 0,01 \\
\hline 1 & 15.676 & 49,05 \\
\hline$J$ & 3.619 & 11,32 \\
\hline K & 1.432 & 4,48 \\
\hline L & 106 & 0,33 \\
\hline M & 159 & 0,50 \\
\hline N & 952 & 2,98 \\
\hline 0 & 19 & 0,06 \\
\hline Q & 48 & 0,15 \\
\hline $\mathrm{R}$ & 513 & 1,61 \\
\hline V & 165 & 0,52 \\
\hline W & 258 & 0,81 \\
\hline$x$ & 183 & 0,57 \\
\hline Y & 241 & 0,75 \\
\hline Total & 31.956 & 100,00 \\
\hline
\end{tabular}


Tabela 15 - Distribuição de frequências de causa básica de óbito (por grupo de doença do aparelho circulatório)

Causa Básica de Óbito

Frequência $(\mathrm{N})$

Porcentagem (\%)

\begin{tabular}{|c|c|c|}
\hline Grupo 1 & 4.128 & 12,9 \\
\hline Grupo 2 & 2.938 & 9,2 \\
\hline Grupo 3 & 1.269 & 4,0 \\
\hline Grupo 4 & 7.341 & 23,0 \\
\hline Outras doenças não cardíacas & 16.280 & 50,9 \\
\hline Total & 31.956 & 100 \\
\hline
\end{tabular}

Tabela 16 - Distribuição de frequências do número de consultas por causa básica de óbito (doenças do aparelho circulatório vs. outras doenças)

\begin{tabular}{lcccccc}
\hline \multirow{2}{*}{$\begin{array}{l}\text { Causa básica do } \\
\text { óbito }\end{array}$} & 1 & 2 & 3 & 4 & $\geq 5$ & \multirow{2}{*}{ Total } \\
\cline { 2 - 6 } & 11.675 & 2.820 & 785 & 245 & 151 & 15.676 \\
Doenças do & $(74,5 \%)$ & $(18,0 \%)$ & $(5,0 \%)$ & $(1,5 \%)$ & $(1,0 \%)$ & $(100 \%)$ \\
aparelho & circulatório & & & & \\
Outras doenças & 12.443 & 2.735 & 735 & 240 & 127 & 16.280 \\
& $(76,4 \%$ & $(16,8 \%)$ & $(4,5 \%)$ & $(1,5 \%)$ & $(0,8 \%)$ & $(100 \%)$ \\
\hline Total & 24.118 & 5.555 & 1.520 & 485 & 278 & 31.956 \\
& $(75,5 \%)$ & $(17,4 \%)$ & $(4,7 \%)$ & $(1,5 \%)$ & $(0,9 \%)$ & $(100 \%)$ \\
\hline
\end{tabular}

$\geq=$ maior ou igual $\mathrm{a} ; \%=$ por cento 
Tabela 17 - Distribuição de frequências do número de consultas por causa básica de óbito (tipo de doença agrupado)

\begin{tabular}{|c|c|c|c|c|c|c|}
\hline \multirow{2}{*}{ Causa básica de óbito } & \multicolumn{5}{|c|}{ Número de consultas } & \multirow{2}{*}{ Total } \\
\hline & 1 & 2 & 3 & 4 & $\geq 5$ & \\
\hline $\begin{array}{l}\text { Doenças do aparelho } \\
\text { circulatório }\end{array}$ & $\begin{array}{l}11.675 \\
(74,5 \%)\end{array}$ & $\begin{array}{c}2.820 \\
(18,0 \%)\end{array}$ & $\begin{array}{c}785 \\
(5,0 \%)\end{array}$ & $\begin{array}{c}245 \\
(1,5 \%)\end{array}$ & $\begin{array}{c}151 \\
(1,0 \%)\end{array}$ & $\begin{array}{l}15676 \\
(100 \%)\end{array}$ \\
\hline $\begin{array}{l}\text { Doenças do aparelho } \\
\text { respiratório }\end{array}$ & $\begin{array}{c}2.760 \\
(76,3 \%)\end{array}$ & $\begin{array}{c}602 \\
(16,6 \%)\end{array}$ & $\begin{array}{c}175 \\
(4,8 \%)\end{array}$ & $\begin{array}{c}55 \\
(1,5 \%)\end{array}$ & $\begin{array}{c}27 \\
(0,8 \%)\end{array}$ & $\begin{array}{c}3619 \\
(100 \%)\end{array}$ \\
\hline Neoplasias & $\begin{array}{c}3.528 \\
(77,3 \%)\end{array}$ & $\begin{array}{c}747 \\
(16,4 \%)\end{array}$ & $\begin{array}{c}195 \\
(4,3 \%)\end{array}$ & $\begin{array}{c}58 \\
(1,3 \%)\end{array}$ & $\begin{array}{c}32 \\
(0,7 \%)\end{array}$ & $\begin{array}{c}4560 \\
(100 \%)\end{array}$ \\
\hline Outras doenças & $\begin{array}{c}6.155 \\
(76,0 \%)\end{array}$ & $\begin{array}{c}1.386 \\
(17,1 \%)\end{array}$ & $\begin{array}{c}365 \\
(4,5 \%)\end{array}$ & $\begin{array}{c}127 \\
(1,6 \%)\end{array}$ & $\begin{array}{c}68 \\
(0,8 \%)\end{array}$ & $\begin{array}{c}8101 \\
(100 \%)\end{array}$ \\
\hline Total & $\begin{array}{l}24.118 \\
(75,5 \%)\end{array}$ & $\begin{array}{c}5.555 \\
(17,4 \%)\end{array}$ & $\begin{array}{l}1.520 \\
(4,7 \%)\end{array}$ & $\begin{array}{c}485 \\
(1,5 \%)\end{array}$ & $\begin{array}{c}278 \\
(0,9 \%)\end{array}$ & $\begin{array}{l}31956 \\
(100 \%)\end{array}$ \\
\hline
\end{tabular}

$\geq=$ maior ou igual $a ; \%=$ por cento 
Tabela 18 - Distribuição de frequências da causa básica de óbito por ano de óbito

\begin{tabular}{|c|c|c|c|c|c|}
\hline \multirow[b]{2}{*}{ Ano de Óbito } & \multicolumn{4}{|c|}{ Causa básica de óbito } & \multirow[b]{2}{*}{ Total } \\
\hline & $\begin{array}{c}\text { Doenças do } \\
\text { aparelho } \\
\text { circulatório }\end{array}$ & $\begin{array}{c}\text { Doenças do } \\
\text { aparelho } \\
\text { respiratório }\end{array}$ & Neoplasias & $\begin{array}{l}\text { Outras } \\
\text { doenças }\end{array}$ & \\
\hline \multirow{2}{*}{2002} & 253 & 42 & 57 & 83 & 435 \\
\hline & $(58,2 \%)$ & $(9,6 \%)$ & $(13,1 \%)$ & $(19,1 \%)$ & $(100 \%)$ \\
\hline \multirow{2}{*}{2003} & 603 & 98 & 166 & 235 & 1.102 \\
\hline & $(54,7 \%)$ & $(8,9 \%)$ & $(15,1 \%)$ & $(21,3 \%)$ & $(100 \%)$ \\
\hline \multirow{2}{*}{2004} & 800 & 163 & 244 & 380 & 1.587 \\
\hline & $(50,4 \%)$ & $(10,3 \%)$ & $(15,4 \%)$ & $(23,9 \%)$ & $(100 \%)$ \\
\hline \multirow{2}{*}{2005} & 927 & 168 & 286 & 404 & 1.785 \\
\hline & $(51,9 \%)$ & $(9,4 \%)$ & $(16,0 \%)$ & $(22,7 \%)$ & $(100 \%)$ \\
\hline \multirow{2}{*}{2006} & 1.101 & 213 & 309 & 520 & 2.143 \\
\hline & $(51,4 \%)$ & $(9,9 \%)$ & $(14,4 \%)$ & $(24,3 \%)$ & $(100 \%)$ \\
\hline \multirow{2}{*}{2007} & 1.170 & 226 & 351 & 581 & 2.328 \\
\hline & $(50,2 \%)$ & $(9,7 \%)$ & $(15,1 \%)$ & $(25,0 \%)$ & $(100 \%)$ \\
\hline \multirow{2}{*}{2008} & 1.375 & 294 & 433 & 724 & 2.826 \\
\hline & $(48,7 \%)$ & $(10,4 \%)$ & $(15,3 \%)$ & $(25,6 \%)$ & $(100 \%)$ \\
\hline \multirow{2}{*}{2009} & 1.535 & 367 & 521 & 872 & 3.295 \\
\hline & $(46,6 \%)$ & $(11,1 \%)$ & $(15,8 \%)$ & $(26,5 \%)$ & $(100 \%)$ \\
\hline \multirow{2}{*}{2010} & 1.730 & 428 & 485 & 968 & 3.611 \\
\hline & $(47,9 \%)$ & $(11,9 \%)$ & $(13,4 \%)$ & $(26,8 \%)$ & $(100 \%)$ \\
\hline \multirow{2}{*}{2011} & 1.860 & 485 & 548 & 1.000 & 3.893 \\
\hline & $(47,8 \%)$ & $(12,4 \%)$ & $(14,1 \%)$ & $(25,7 \%)$ & $(100 \%)$ \\
\hline \multirow{2}{*}{2012} & 1.987 & 525 & 560 & 1.156 & 4.228 \\
\hline & $(47,0 \%)$ & $(12,4 \%)$ & $(13,3 \%)$ & $(27,3 \%)$ & $(100 \%)$ \\
\hline \multirow{2}{*}{2013} & 2.335 & 610 & 600 & 1.178 & 4.723 \\
\hline & $(49,5 \%)$ & $(12,9 \%)$ & $(12,7 \%)$ & $(24,9 \%)$ & (100\%) \\
\hline \multirow{2}{*}{ Total } & 15.676 & 3.619 & 4.560 & 8.101 & 31.956 \\
\hline & $(49,1 \%)$ & $(11,3 \%)$ & $(14,3 \%)$ & $(25,3 \%)$ & (100\%) \\
\hline
\end{tabular}

$\%=$ por cento 
Tabela 19 - Medidas-resumo da idade à primeira consulta por causa básica de óbito (doenças do aparelho circulatório vs. outras doenças)

\begin{tabular}{lcccccccc}
\hline $\begin{array}{l}\text { Causa básica de } \\
\text { óbito }\end{array}$ & $\mathrm{N}$ & Média & $\begin{array}{l}\text { Desvio } \\
\text { padrão }\end{array}$ & Mínimo & $1^{\circ}$ quartil & Mediana & 30 quartil & Máximo \\
\hline $\begin{array}{l}\text { Doenças do } \\
\text { aparelho } \\
\text { circulatório }\end{array}$ & 15.676 & 65,4 & 13,6 & 18,1 & 56,5 & 66,8 & 75,6 & 101,4 \\
$\begin{array}{l}\text { Outras doenças } \\
\text { Total }\end{array}$ & 16.280 & 66,5 & 13,5 & 18,1 & 58,0 & 68,2 & 76,4 & 102,8 \\
\hline & 31.956 & 66,0 & 13,6 & 18,1 & 57,3 & 67,5 & 76,0 & 102,8 \\
\hline
\end{tabular}

$\mathrm{N}$ = número de óbitos

Tabela 20 - Distribuição de frequências da causa básica de óbito (doenças do aparelho circulatório vs. outras doenças) por sexo

\begin{tabular}{lccc}
\hline \multirow{2}{*}{ Sexo } & \multicolumn{2}{c}{ Causa básica de óbito } & \multirow{2}{*}{ Total } \\
\cline { 2 - 3 } & $\begin{array}{c}\text { Doenças do aparelho } \\
\text { circulatório }\end{array}$ & Outras Doenças & \\
\hline \multirow{2}{*}{ Masculino } & 8.496 & 8.748 & 17.244 \\
& $(49,3 \%)$ & $(50,7 \%)$ & $(100 \%)$ \\
Feminino & 7.180 & 7.532 & 14712 \\
& $(48,8 \%)$ & $(51,2 \%)$ & $(100 \%)$ \\
Total & 15.676 & 16.280 & 31.956 \\
& $(49,1 \%)$ & $(50,9 \%)$ & $(100 \%)$ \\
\hline
\end{tabular}

$\%=$ por cento 
Tabela 21 - Contagem de causa básica por agrupamento

\begin{tabular}{lcc}
\hline Causa básica & Contagem & Porcentagem (\%) \\
\hline Aterosclerose & 62 & 0,19 \\
Doença de Chagas & 986 & 3,09 \\
Câncer de mama & 358 & 1,12 \\
Câncer de próstata & 365 & 1,14 \\
Câncer de pulmão & 608 & 1,90 \\
Dislipidemia & 63 & 0,20 \\
Diabetes Mellitus & 1.333 & 4,17 \\
DPOC & 1.087 & 3,40 \\
Hipertensão arterial & 257 & 0,80 \\
Insuficiência cardíaca & 1.119 & 3,50 \\
Infarto agudo do miocárdio & 3.739 & 11,70 \\
Insuficiência renal crônica & 283 & 0,89 \\
Obesidade & 61 & 0,19 \\
Outras doenças & 21.635 & 67,70 \\
\hline Total & 31.956 & 100 \\
\hline
\end{tabular}


Tabela 22 - Contagem de causa imediata por letra do CID 10

\begin{tabular}{|c|c|c|}
\hline Causa Imediata & Contagem & Porcentual (\%) \\
\hline$A$ & 4.748 & 14,01 \\
\hline $\mathrm{B}$ & 51 & 0,15 \\
\hline C & 903 & 2,67 \\
\hline $\mathrm{D}$ & 103 & 0,30 \\
\hline$E$ & 258 & 0,76 \\
\hline $\mathrm{F}$ & 13 & 0,04 \\
\hline$G$ & 413 & 1,22 \\
\hline I & 7.336 & 21,65 \\
\hline$J$ & 7.381 & 21,78 \\
\hline K & 593 & 1,75 \\
\hline L & 14 & 0,04 \\
\hline$M$ & 4 & 0,01 \\
\hline $\mathrm{N}$ & 297 & 0,88 \\
\hline $\mathrm{O}$ & 5 & 0,01 \\
\hline $\mathrm{R}$ & 8.669 & 25,59 \\
\hline$S$ & 359 & 1,06 \\
\hline $\mathrm{T}$ & 2.386 & 7,04 \\
\hline V & 55 & 0,16 \\
\hline W & 114 & 0,34 \\
\hline$x$ & 71 & 0,21 \\
\hline $\mathrm{Y}$ & 109 & 0,32 \\
\hline
\end{tabular}

$\bar{A}$ e $B$ = algumas doenças infecciosas e parasitárias; $C$ = neoplasias; $D$ = doenças do sangue e dos órgãos hematopoéticos e alguns transtornos imunitários; $\mathrm{E}=$ doenças endócrinas, nutricionais e metabólicas; $\mathrm{F}=$ transtornos mentais e comportamentais; $\mathrm{G}=$ doenças do sistema nervoso; $\mathrm{H}$ = doenças dos olhos e anexos, do ouvido e da apófise mastoide; $\mathrm{I}=$ doenças do aparelho circulatório; $\mathrm{J}=$ doenças do aparelho respiratório; $\mathrm{K}=$ doenças do aparelho digestivo; $\mathrm{L}=$ doenças de pele e do tecido subcutâneo; $\mathrm{M}$ = doenças do sistema osteomuscular e do tecido conjuntivo; $\mathrm{N}=$ doenças do aparelho geniturinário; $\mathrm{O}=$ gravidez, parto $\mathrm{e}$ puerpério; $\mathrm{Q}=$ malformações congênitas, deformidades e anomalias cromossômica; $R$ = sintomas, sinais e achados anormais de exames clínicos e de laboratório, não classificados em outra parte; $\mathrm{V}, \mathrm{W}, \mathrm{X}, \mathrm{Y}=$ causas externas de morbidade e de mortalidade. 


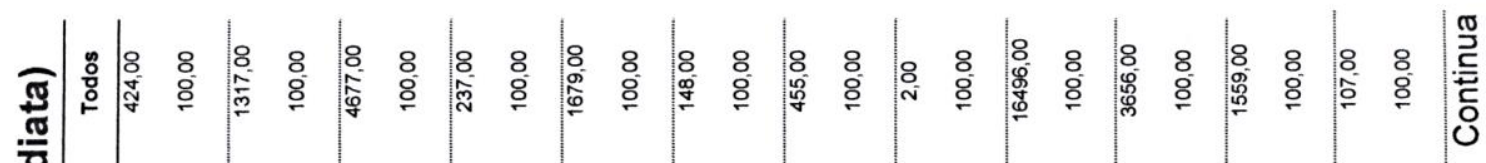

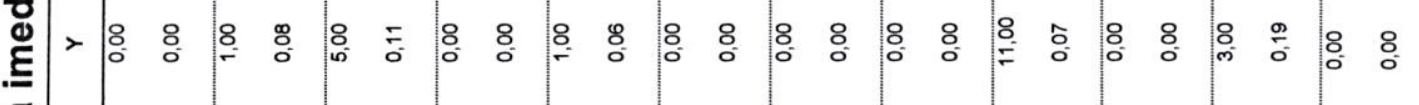

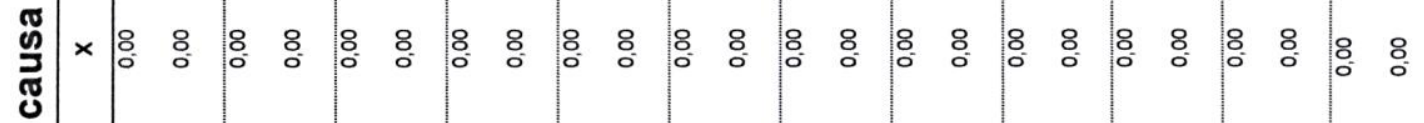

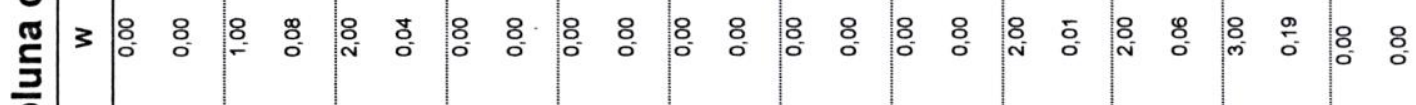

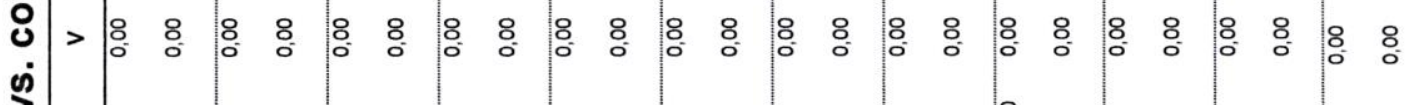

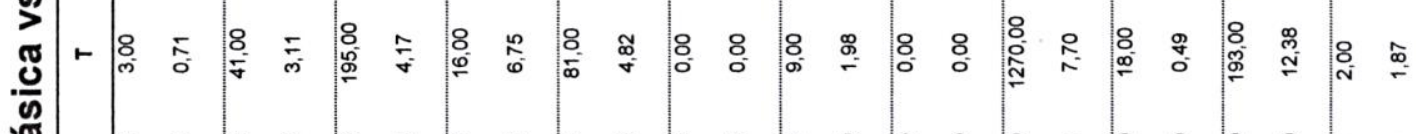
造

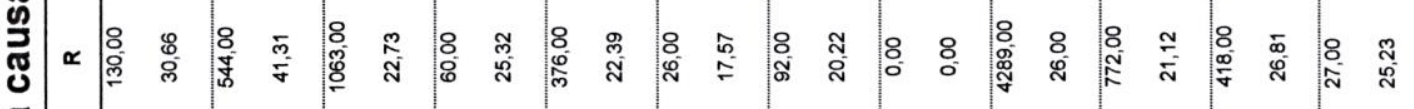
殼 은 일 = 焉

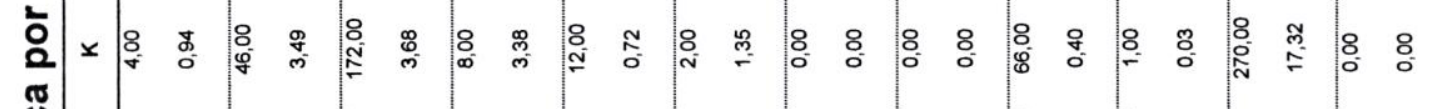

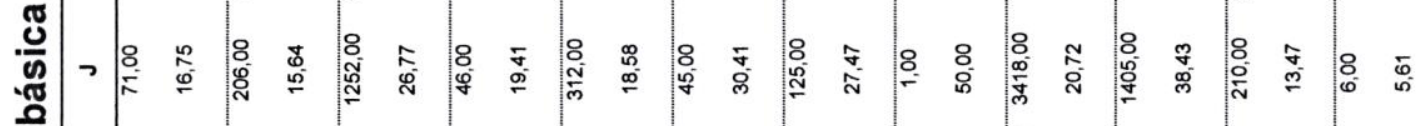
焉 西 0 ○ 岛

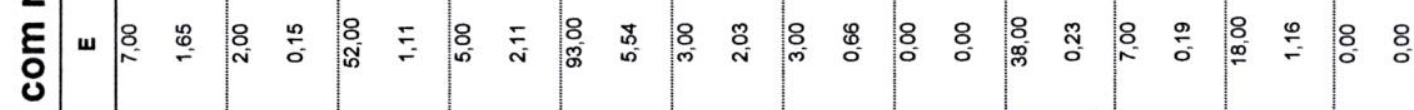

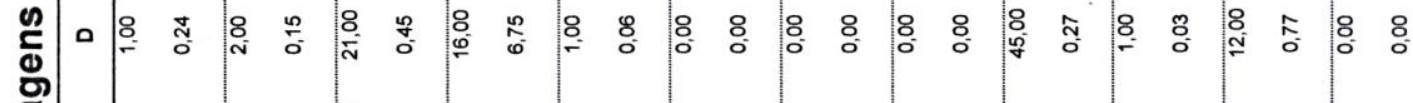

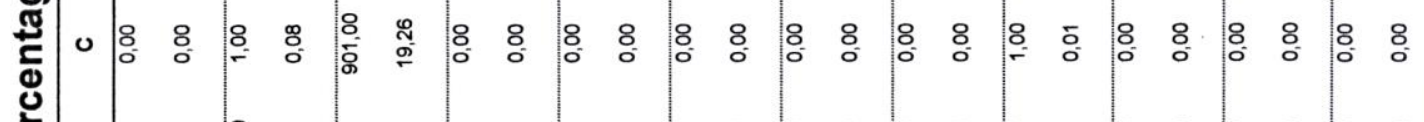
过 ๓ 空 


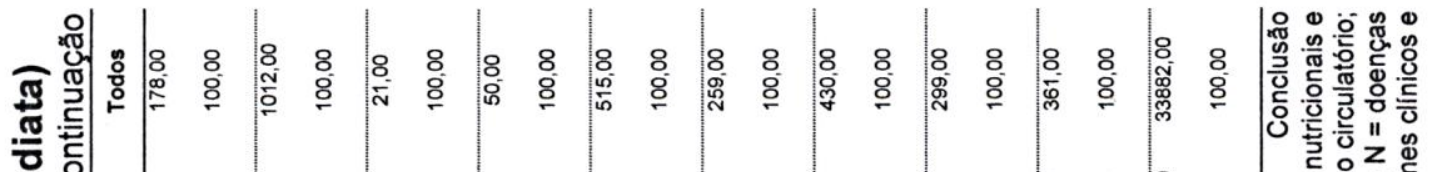
吾 急U > 疍

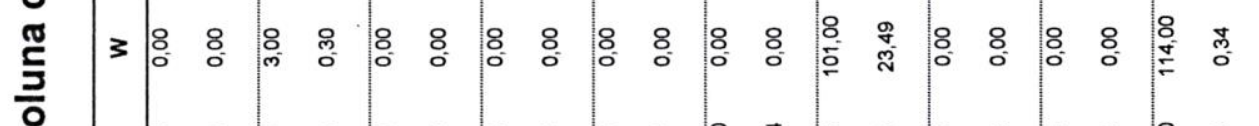

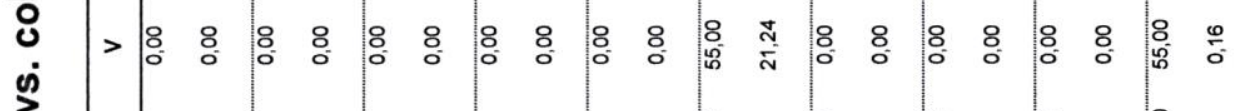

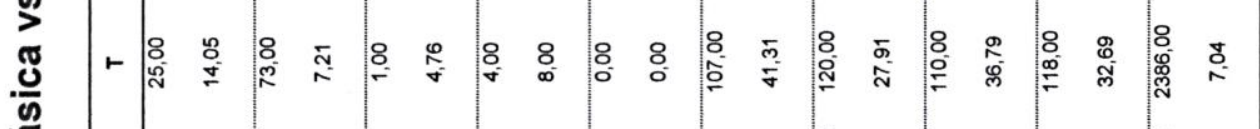

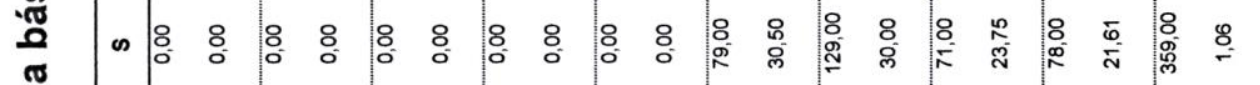

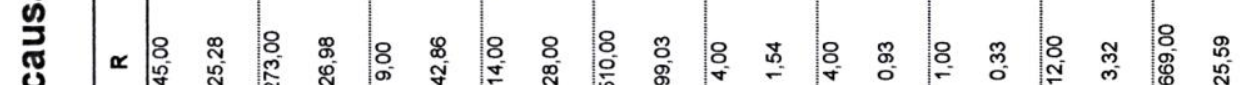

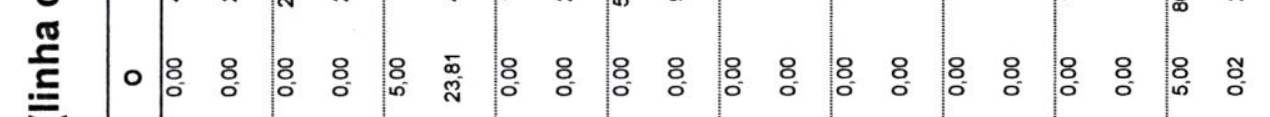

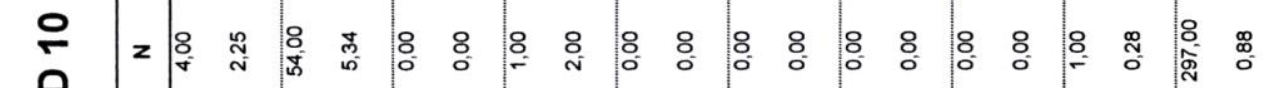
0
0
0 売 는

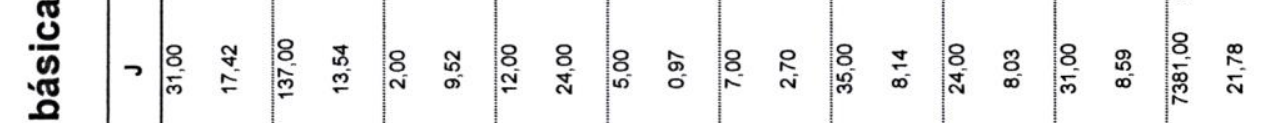

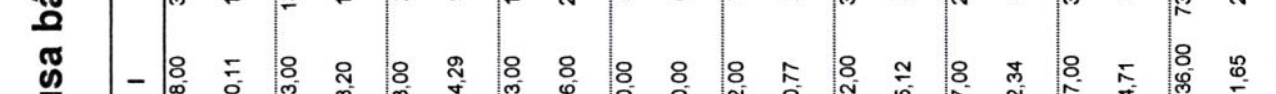

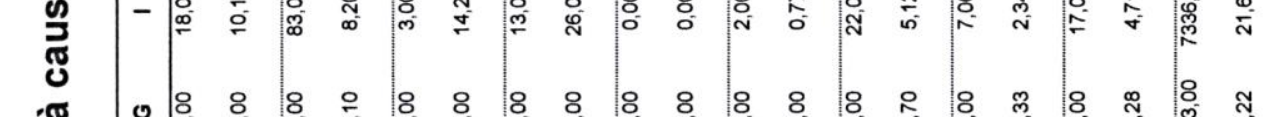

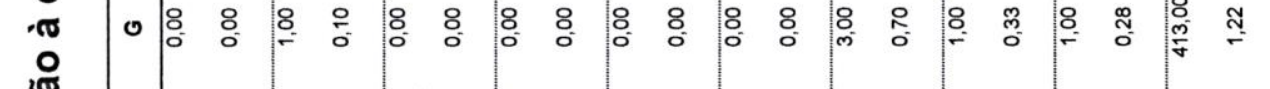

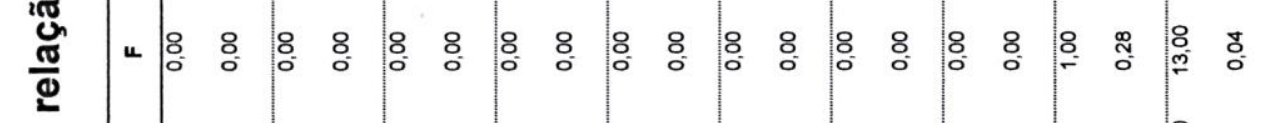

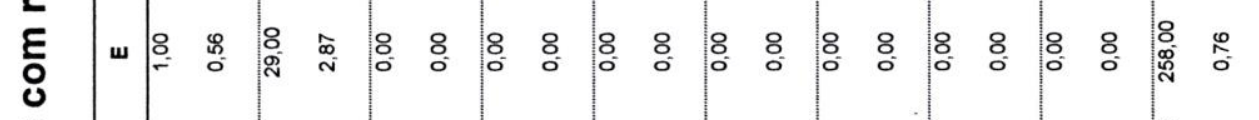

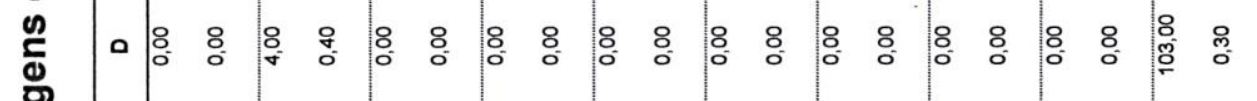
疍

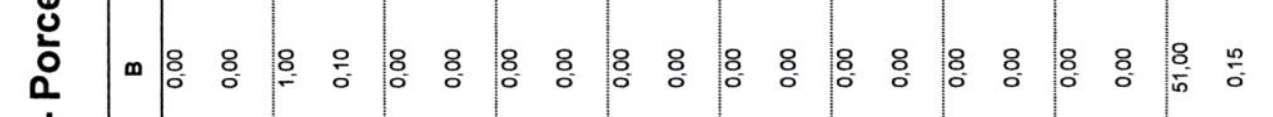

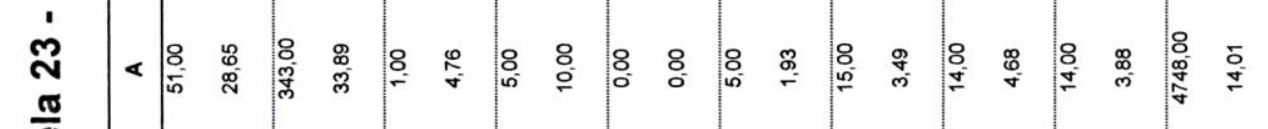

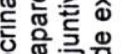
훈 응 응 $\frac{5}{\pi}$ 造 응 政 응 응 융 II 山.

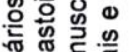
害 है

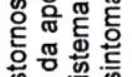
क्ष

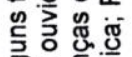
응응 행

in

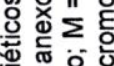
응

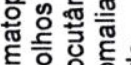
ब.

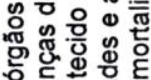
융융융흥 융

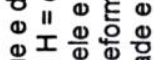
के o웡

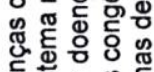

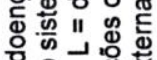
II 응 웛

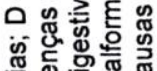
ญ 음 है 응 "응 “ II 0. 둔웡 3 惫 霓 ฮำ 잉 \&

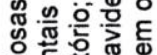
造 는 密 吾

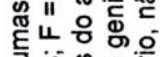

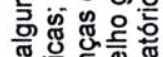
"I

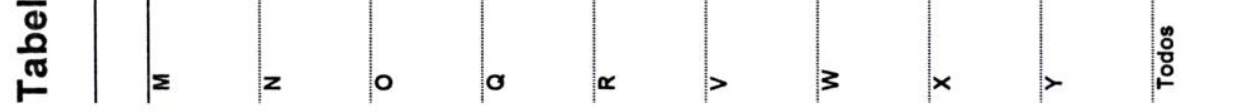




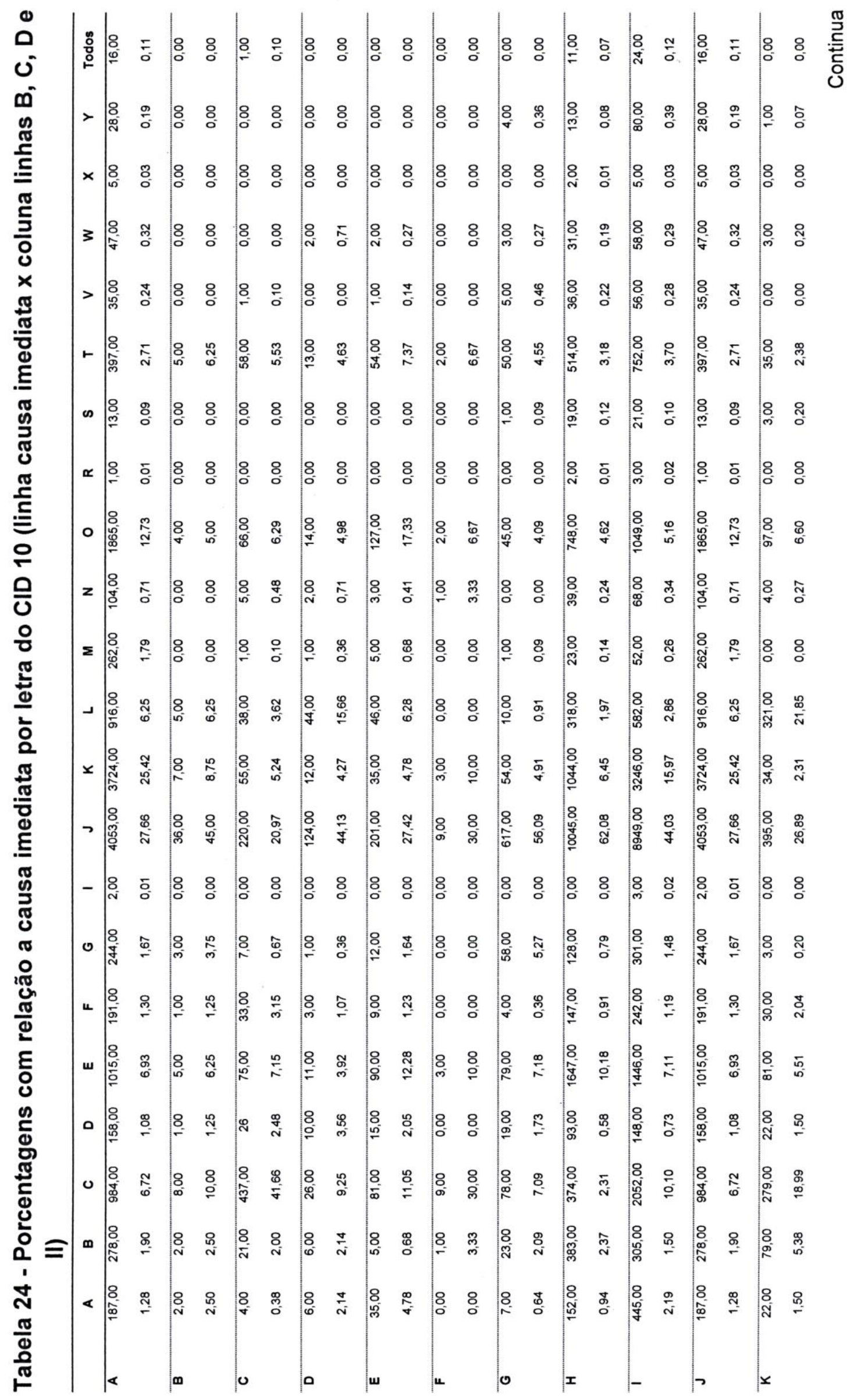




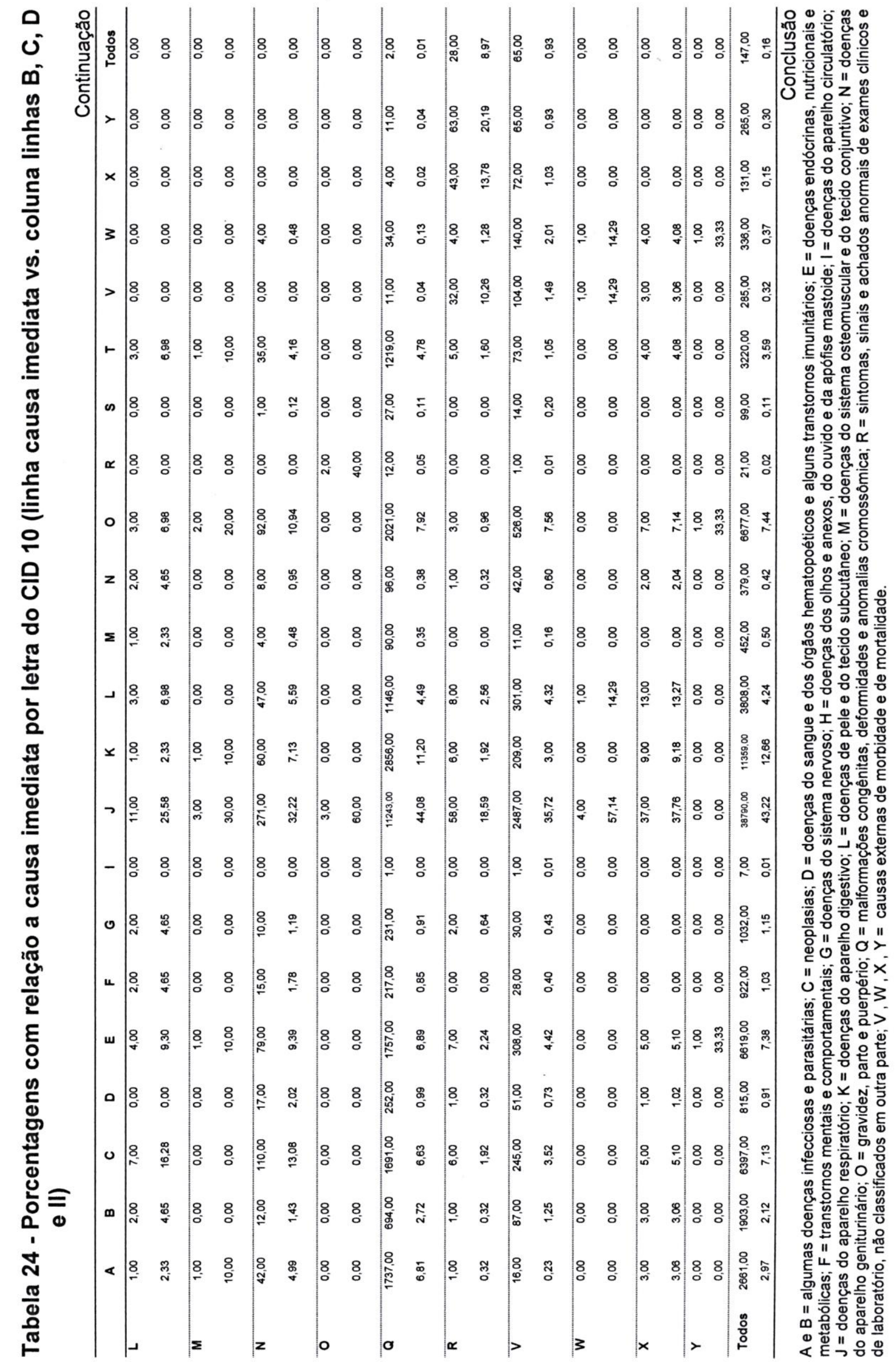


Tabela 25 - Contagem de causa imediata por agrupamento

\begin{tabular}{lcc}
\hline Causa imediata & Contagem & Porcentual (\%) \\
\hline Aterosclerose & 26 & 0,08 \\
Doença de Chagas & 37 & 0,11 \\
Câncer de mama & 44 & 0,13 \\
Câncer de próstata & 48 & 0,14 \\
Câncer de pulmão & 79 & 0,23 \\
Dislipidemia & 3 & 0,01 \\
Diabetes Mellitus & 46 & 0,14 \\
DPOC & 60 & 0,18 \\
Hipertensão arterial & 54 & 0,16 \\
Insuficiência cardíaca & 857 & 2,53 \\
Infarto & 2.374 & 7,01 \\
Insuficiência renal crônica & 69 & 0,20 \\
Obesidade & 1 & 80,01 \\
Outras doenças & 30.184 & 100,00 \\
\hline Total & 33.882 &
\end{tabular}




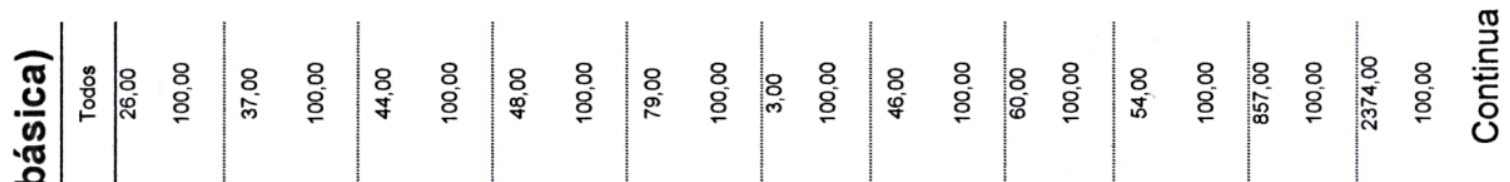

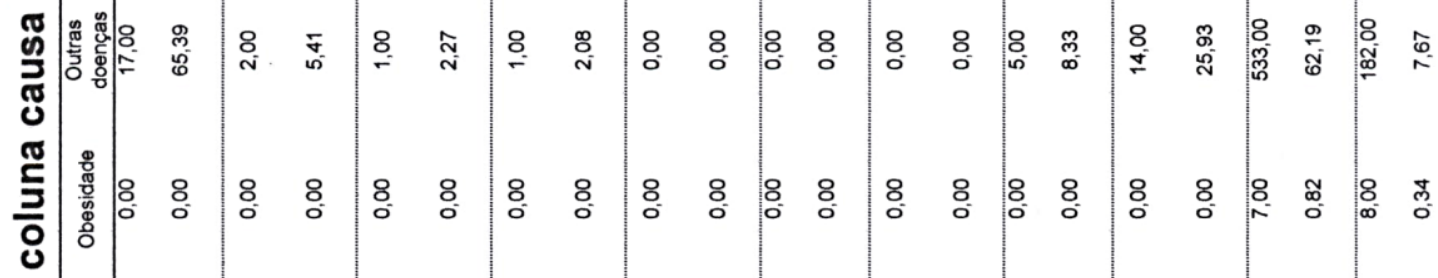

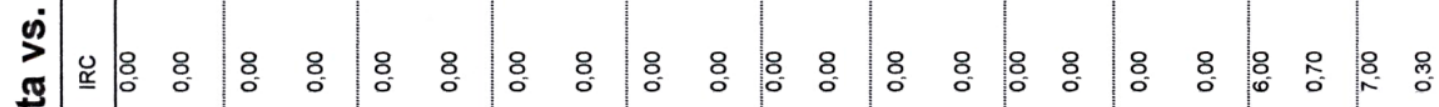

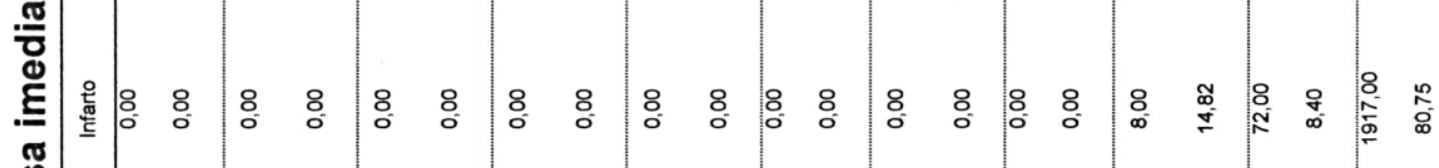
党

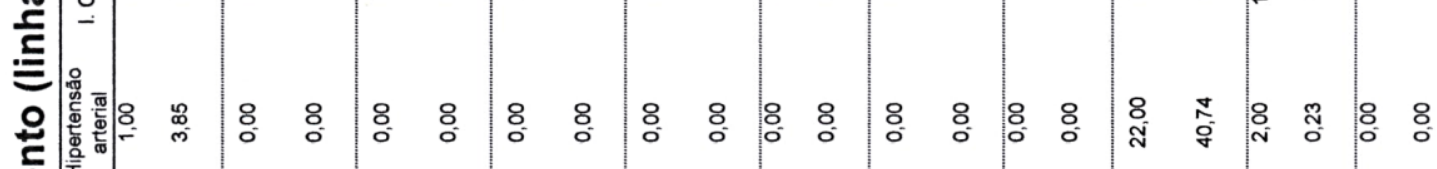

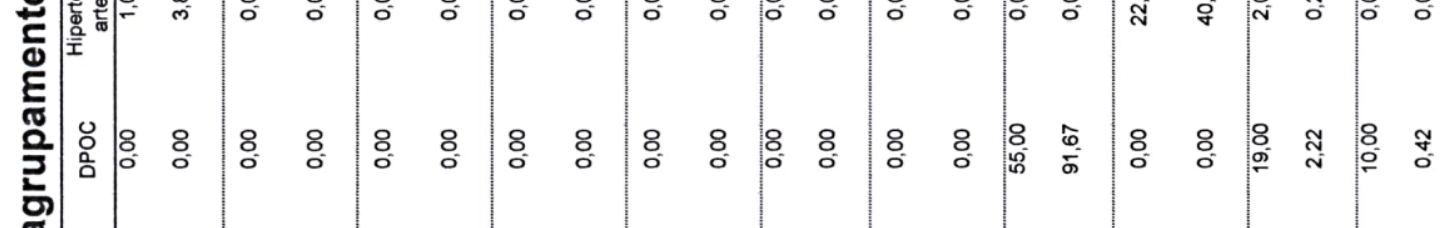

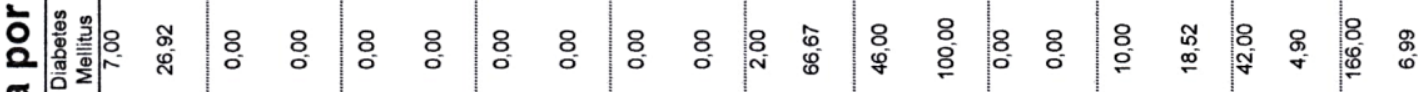

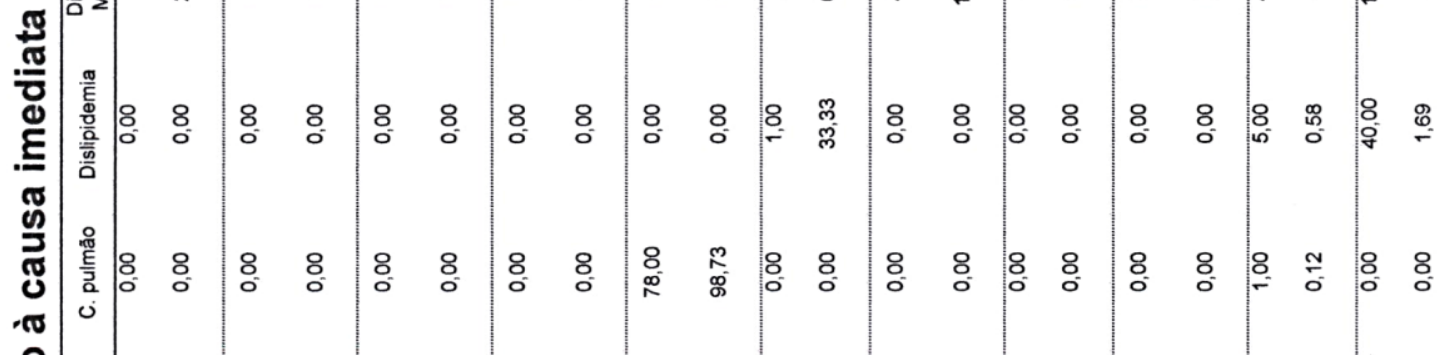
焉

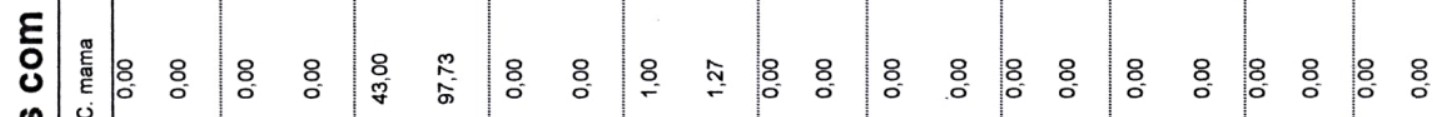

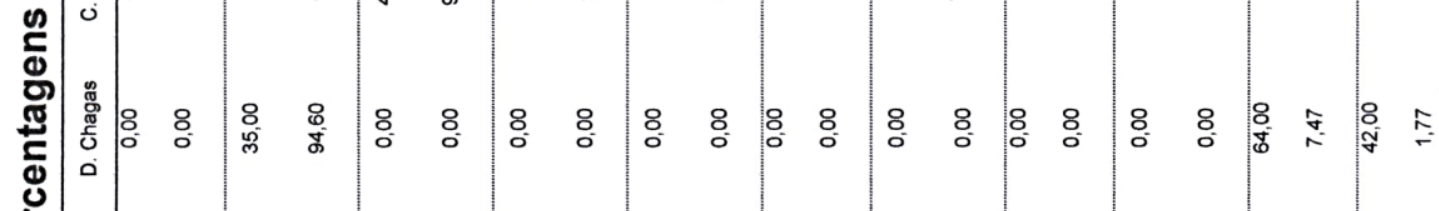

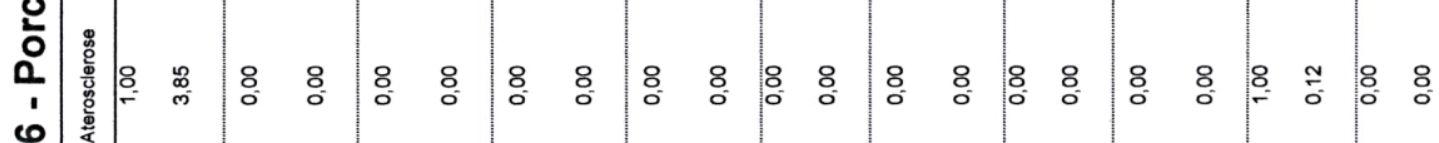

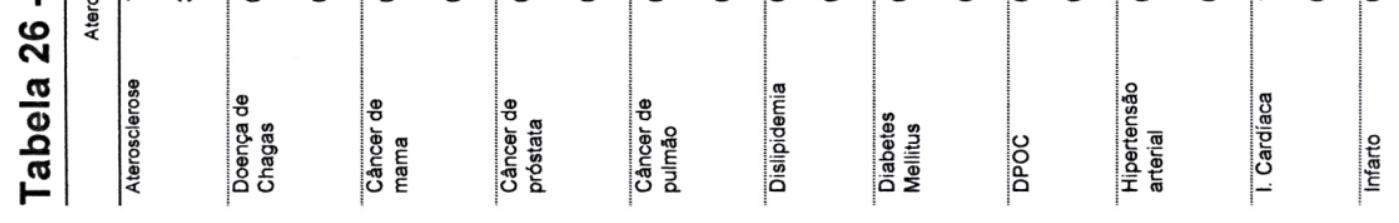




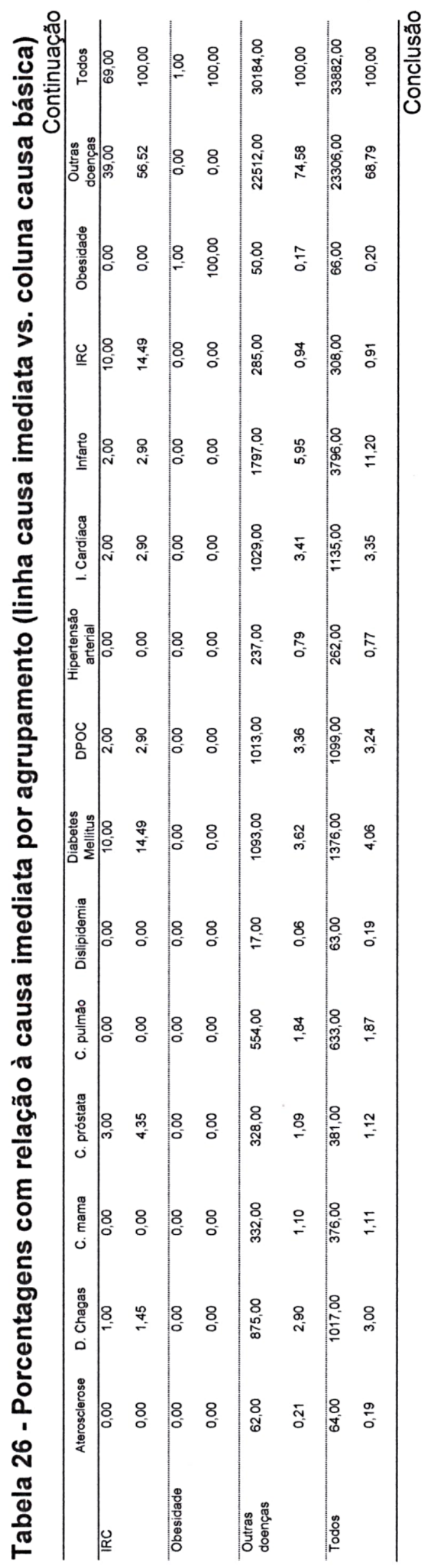




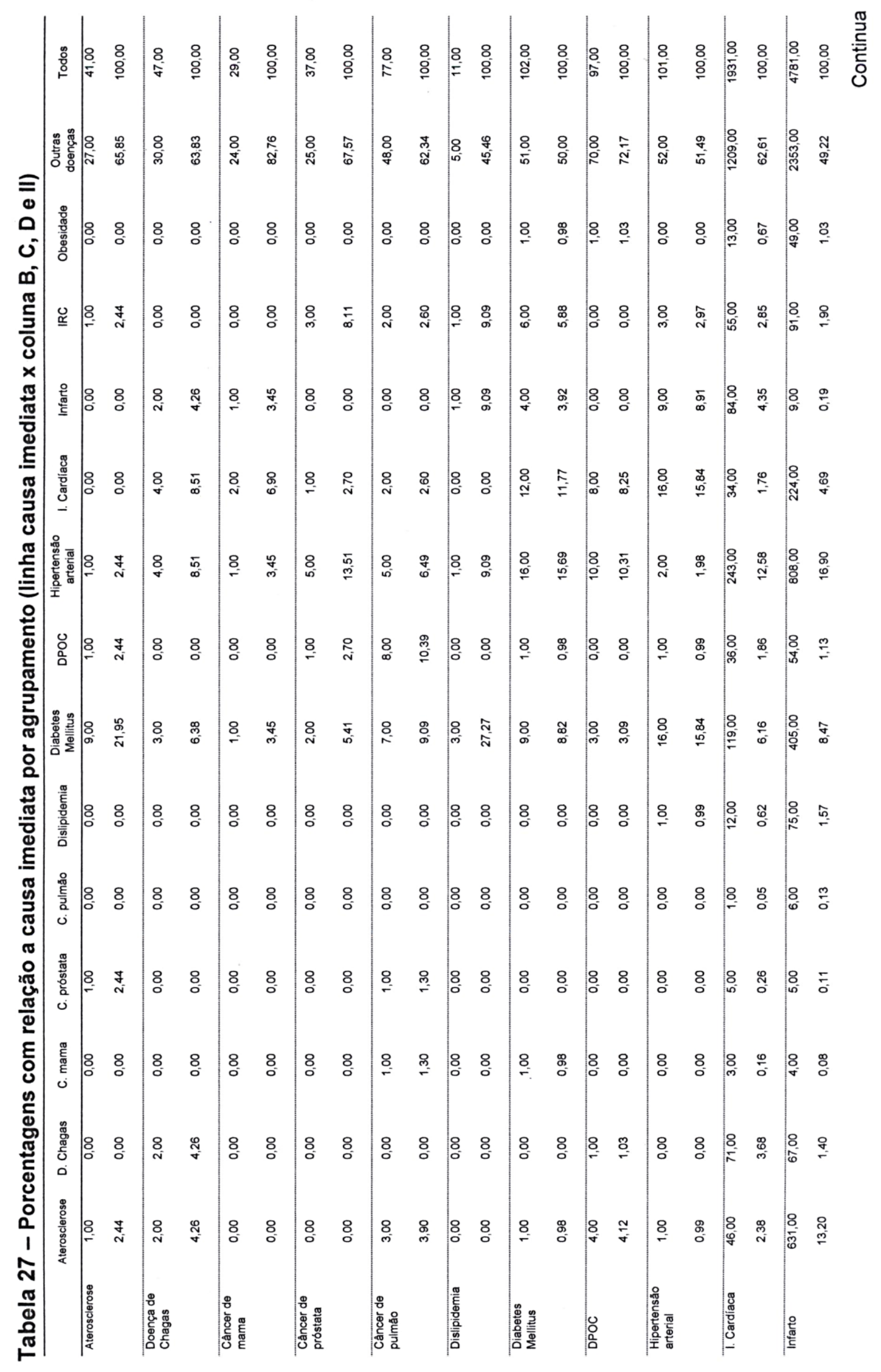




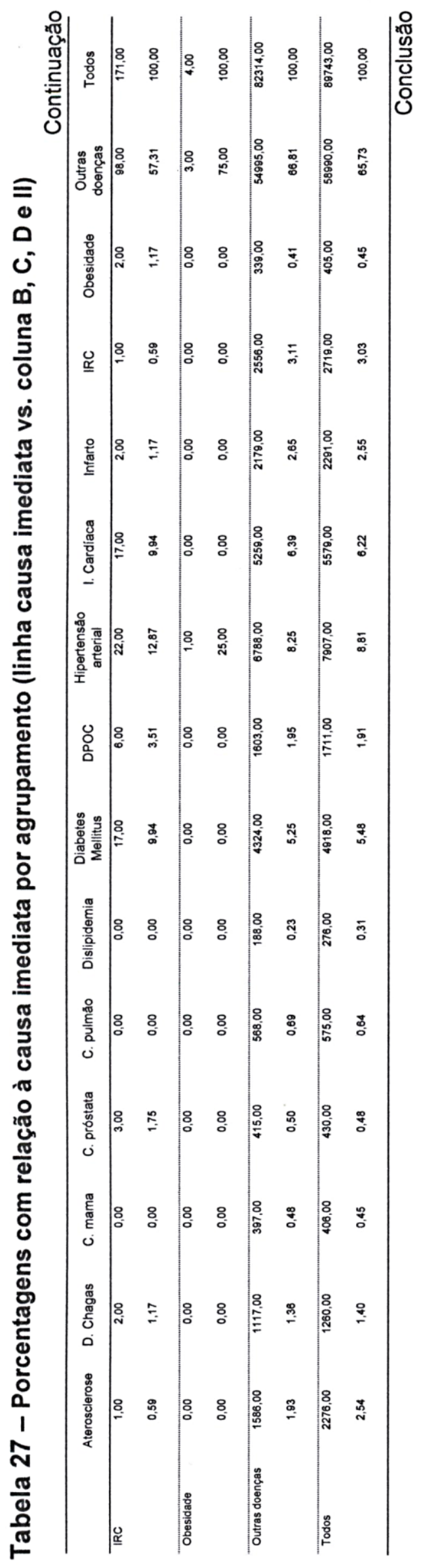


Tabela 28 - Todas as causas de óbitos listadas nas cinco linhas do atestado (causa imediata (A), causa básica, e outros diagnósticos das linhas B, C, D e II)

\begin{tabular}{lcc}
\hline Doenças & Causas listadas & Porcentagem (\%) \\
\hline Pneumonia & 8.667 & 5,7 \\
Infarto agudo do miocárdio & 8.375 & 5,54 \\
Hipertensão arterial & 8.006 & 5,3 \\
Insuficiência cardíaca & 7.410 & 4,9 \\
Septicemia & 7.272 & 4,81 \\
Doença isquêmica crônica do coração & 6.773 & 4,48 \\
Diabetes Mellitus & 5.698 & 3,77 \\
Choque & 4.771 & 3,15 \\
Insuficiência respiratória & 4.544 & 3 \\
Cardiomiopatias & 4.128 & 2,73 \\
Outras formas de doenças pulmonares obstrutivas & 3.142 & 2,08 \\
Outros sinais e sintomas normais & 3.114 & 2,06 \\
Insuficiência renal crônica & 2.926 & 1,93 \\
Edema pulmonar & 2.631 & 1,74 \\
Doença cardiovascular aterosclerótica & 2.537 & 1,67 \\
Aterosclerose & 2.329 & 1,54 \\
Doença de Chagas & 2.253 & 1,49 \\
Miocardiopatia Isquêmica & 1.917 & 1,26 \\
Doença cardíaca hipertensiva & 1.805 & 1,19 \\
Acidente vascular cerebral & 1.805 & 1,19 \\
Arritmias cardíacas & 1.766 & 1,16 \\
Doenças cerebrovasculares & 1.697 & 1,12 \\
Doença Isquêmica do Coração & 1.694 & 1,12 \\
Demais enfermidades com percentil < 1 & 37,07 \\
\hline Total & 58.778 & 100 \\
\hline & 151.038 & \\
\hline
\end{tabular}




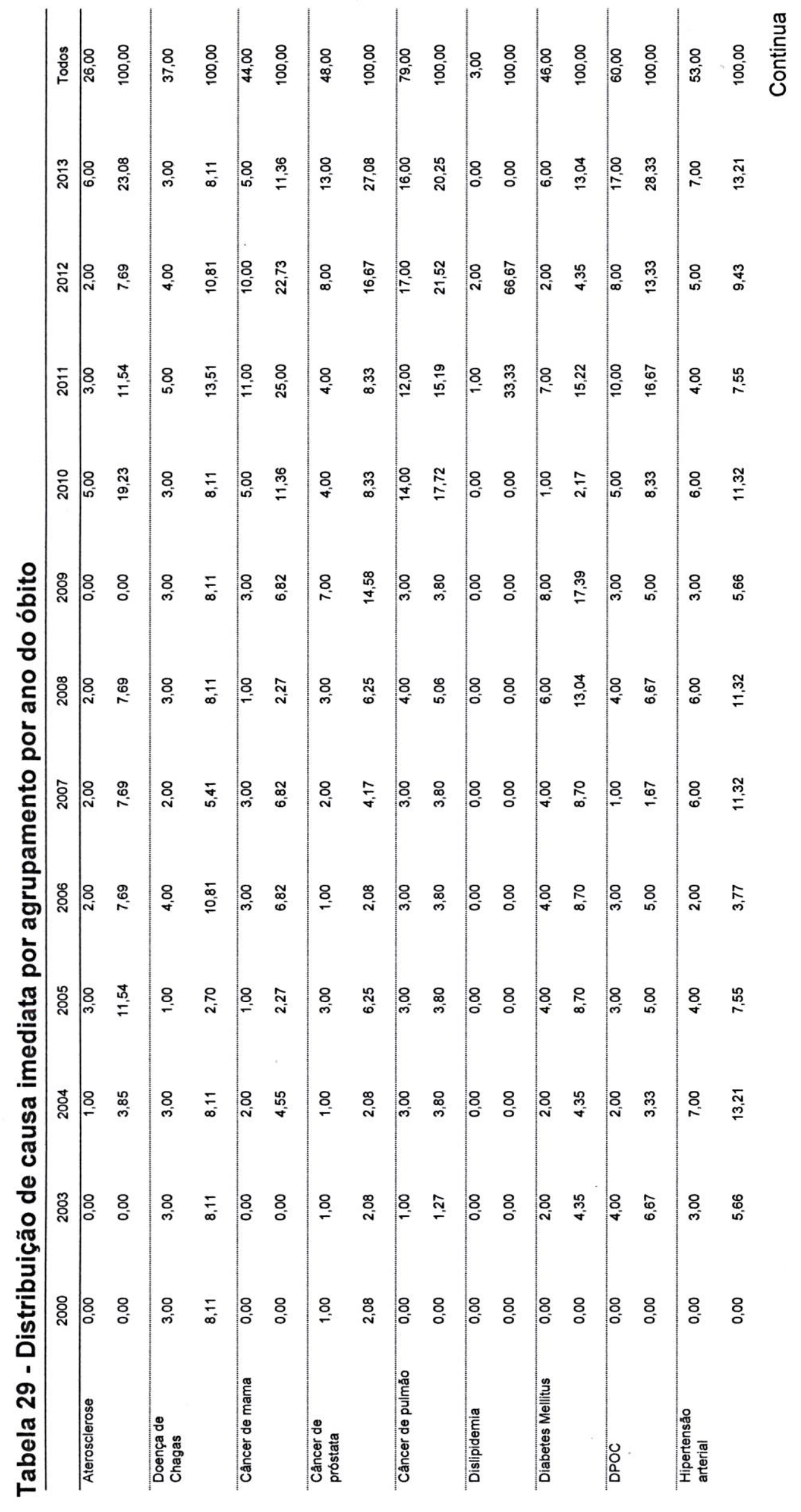




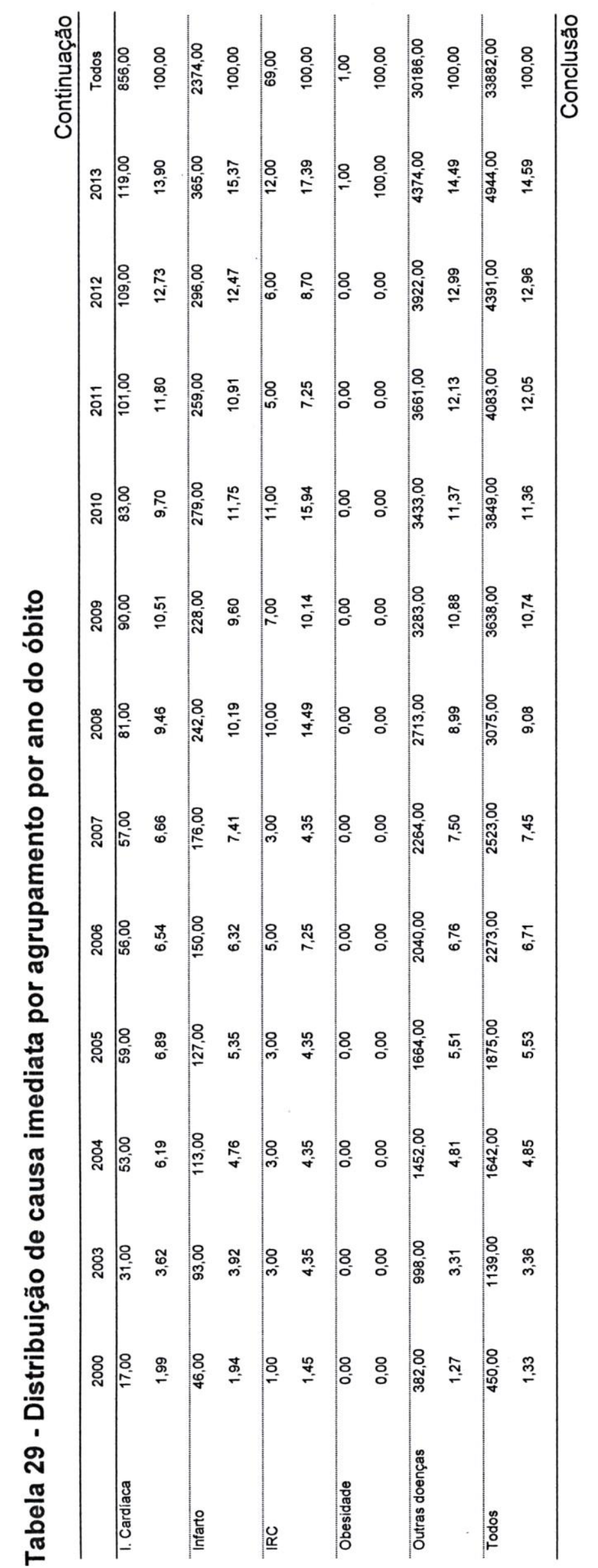




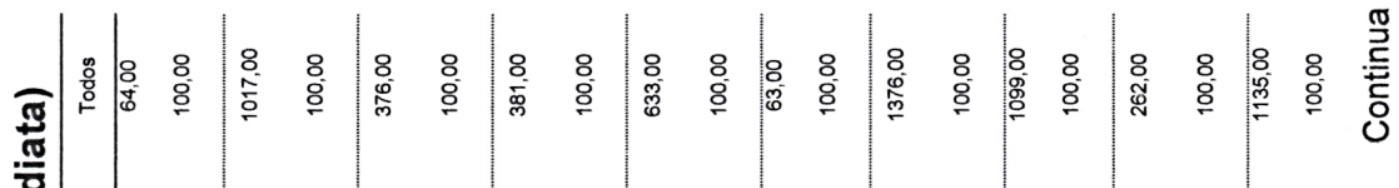

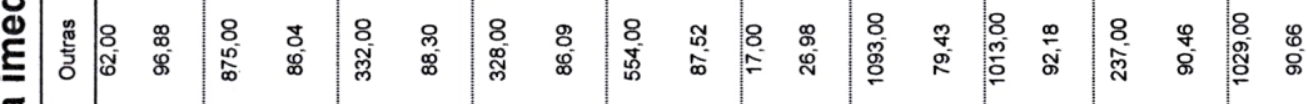

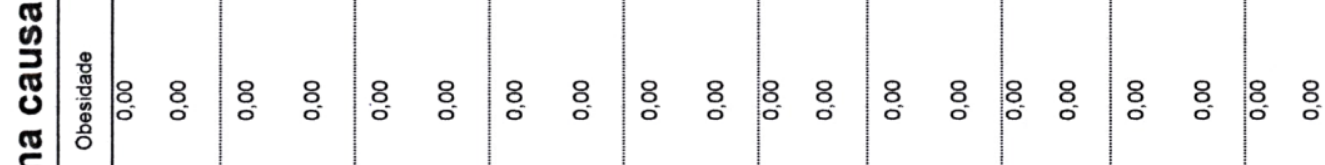

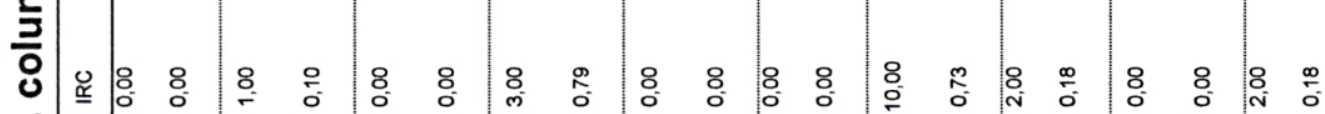

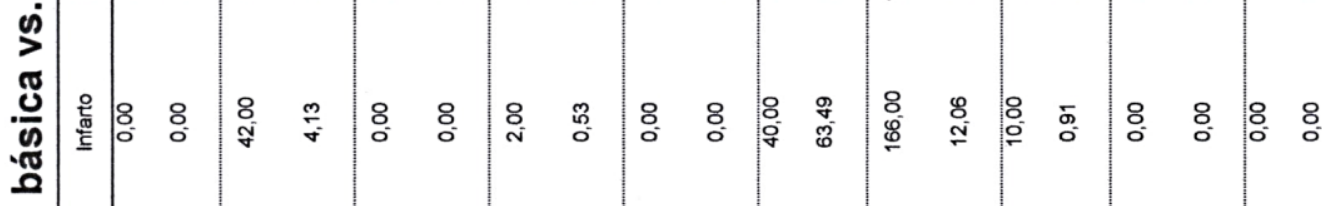

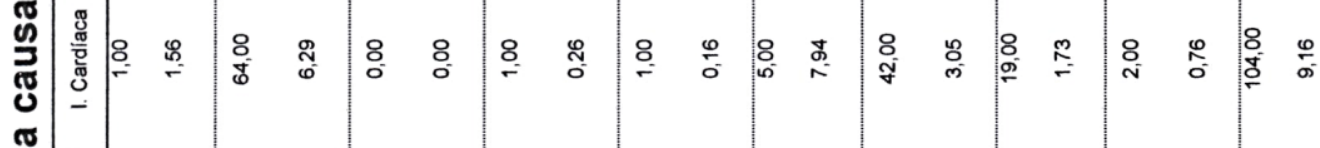

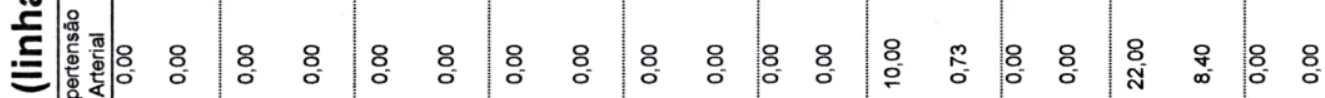

任|

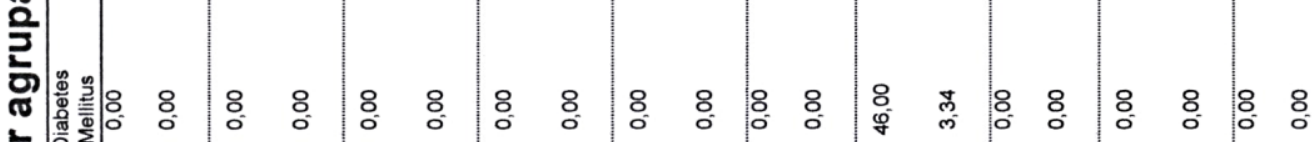

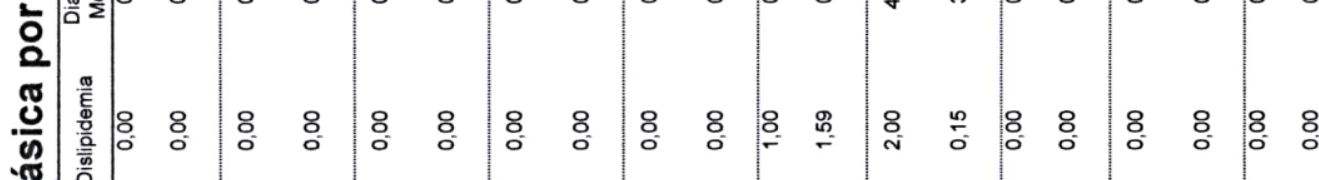

窇

宽

ป

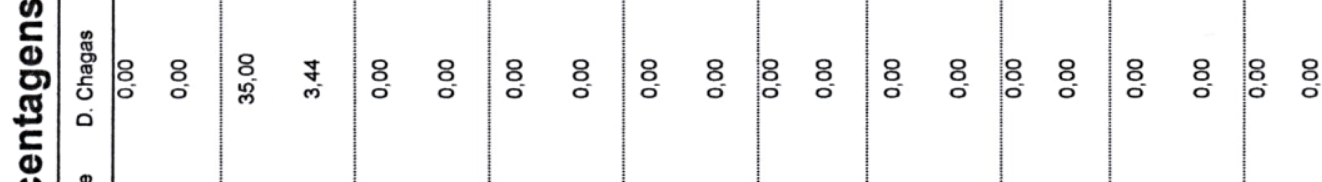

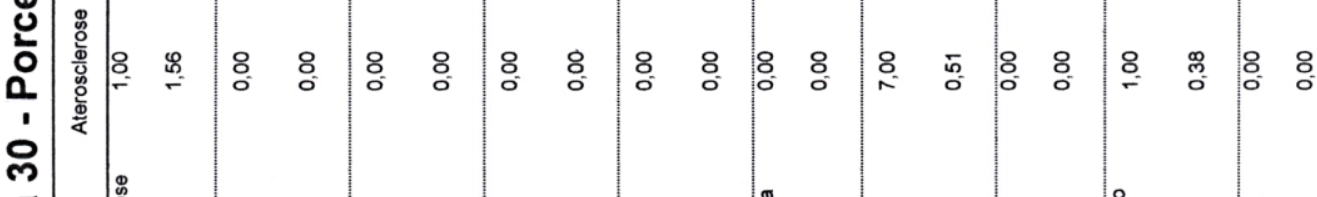

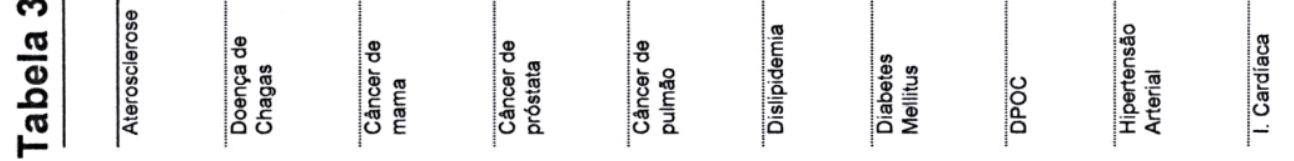




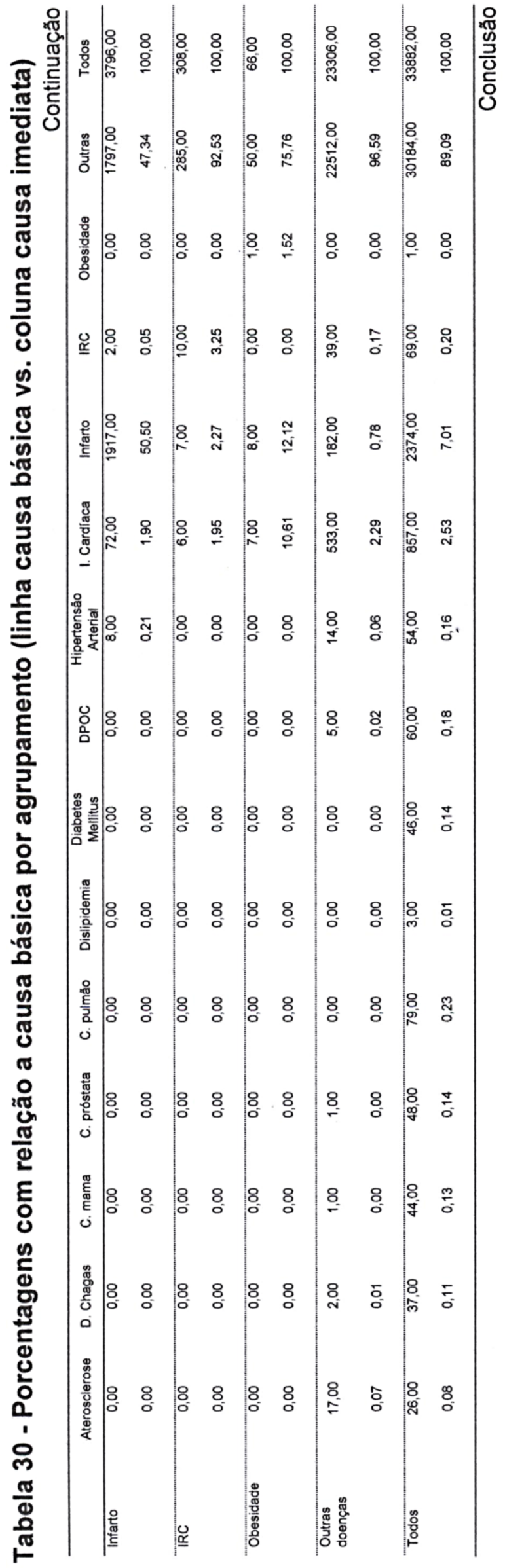




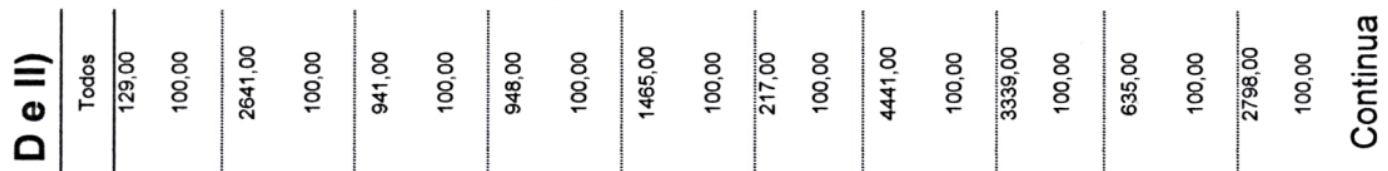

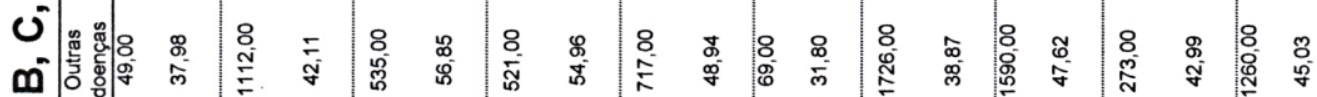

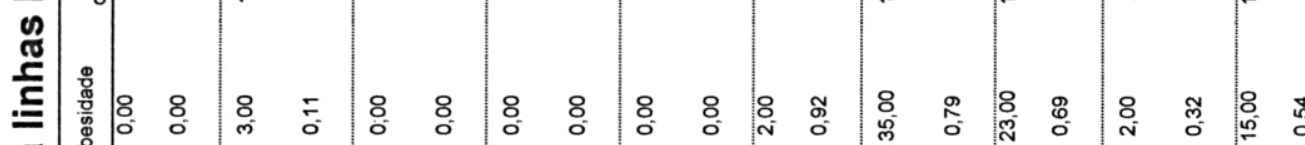

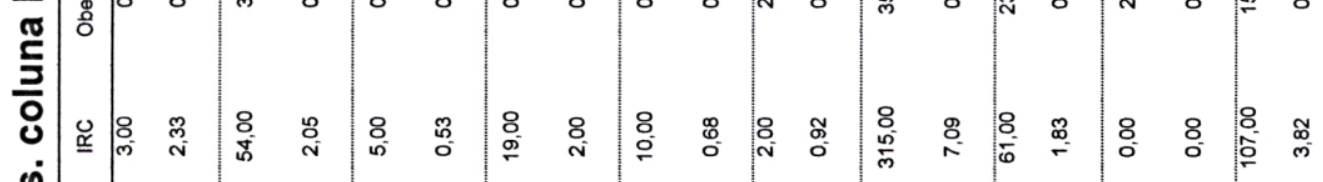

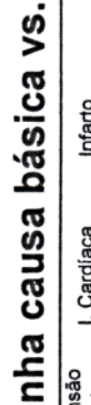

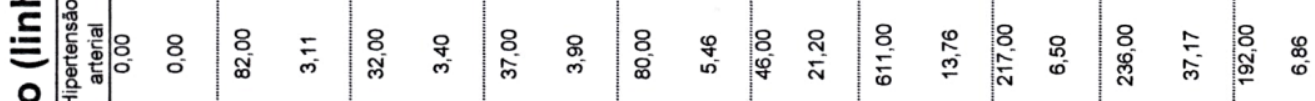

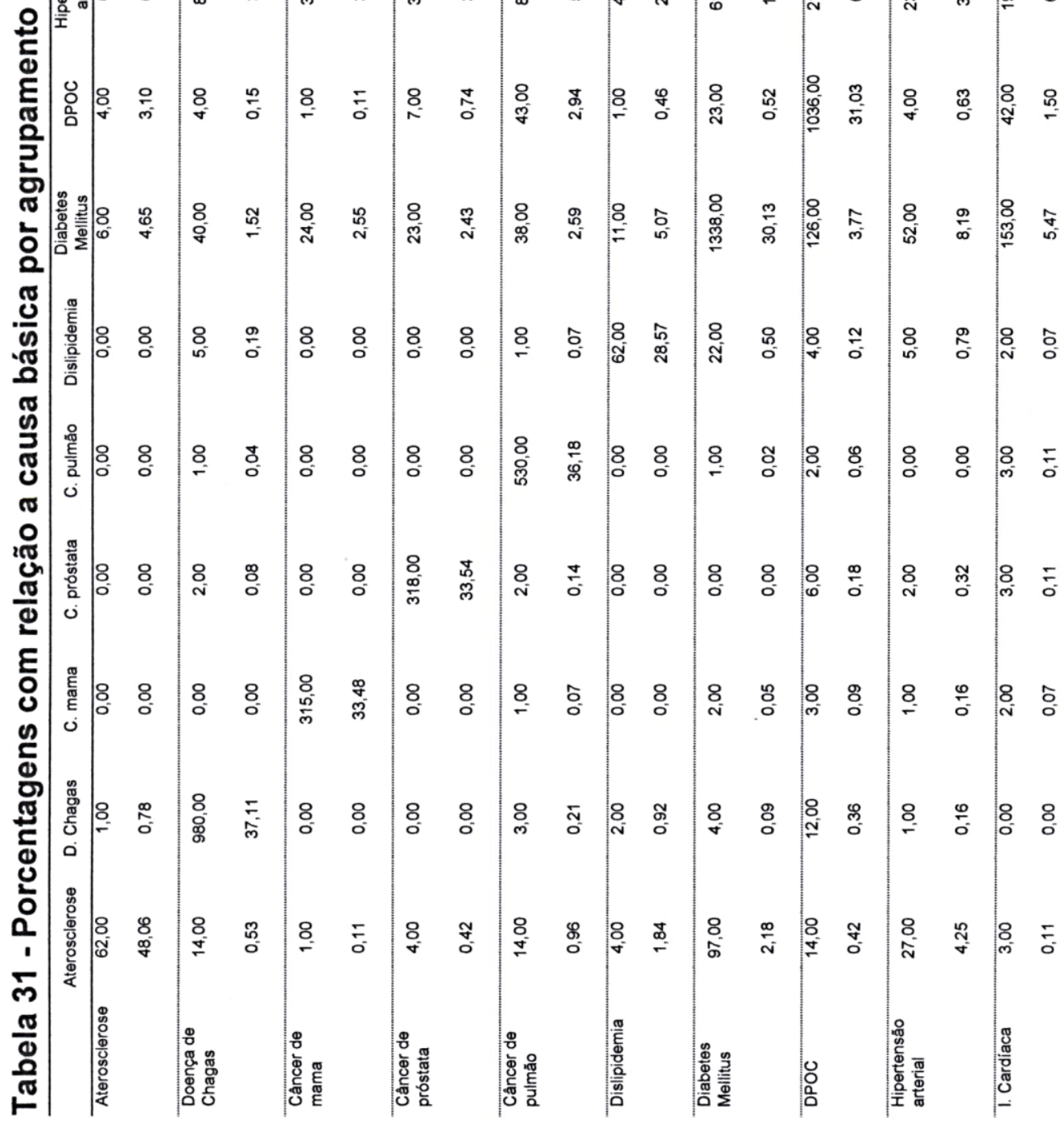




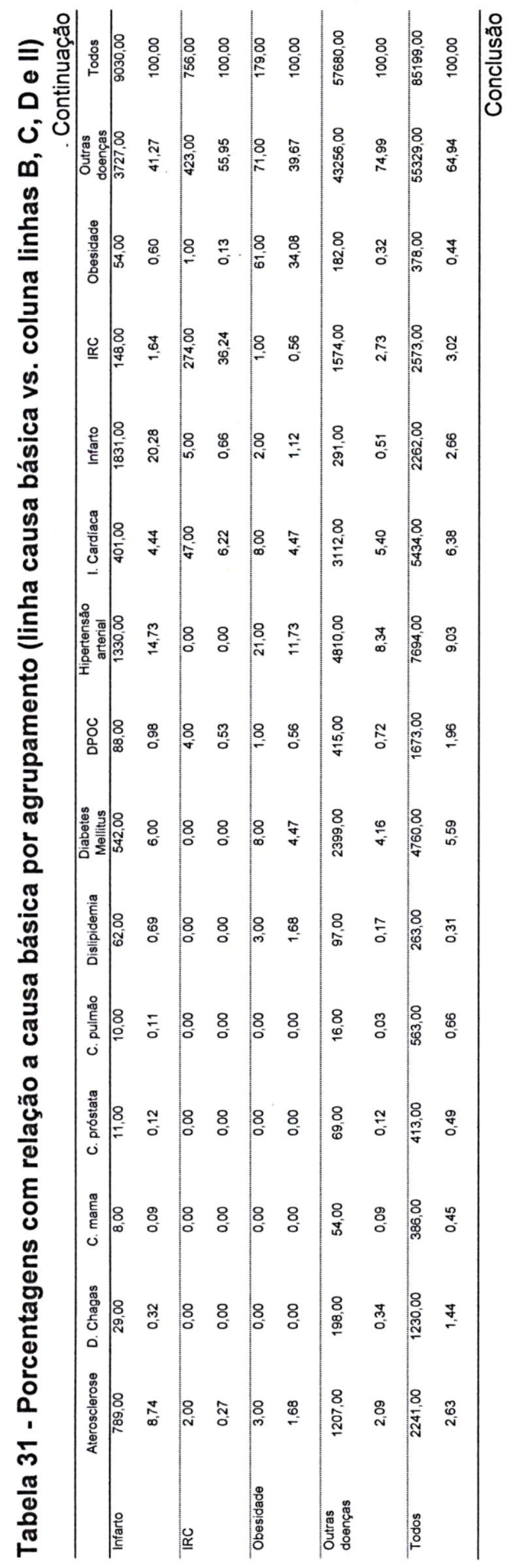




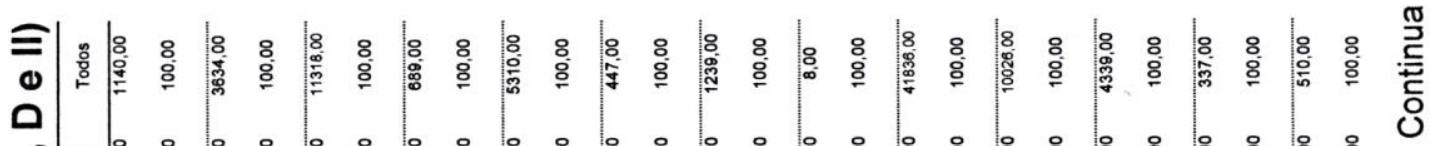
U

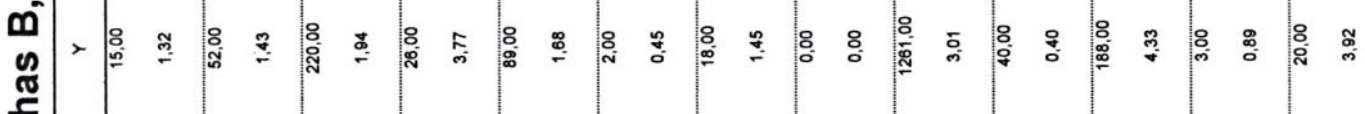

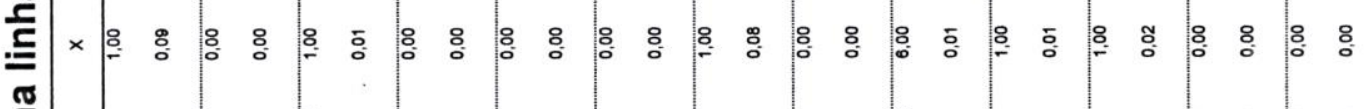
疍 3 ம் > 苟 西 苟 疍 은

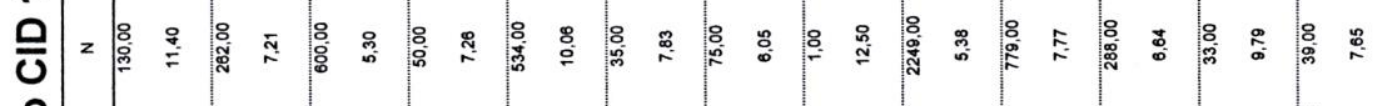
을 声 范 每 疍

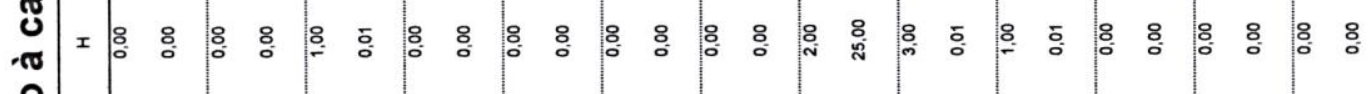

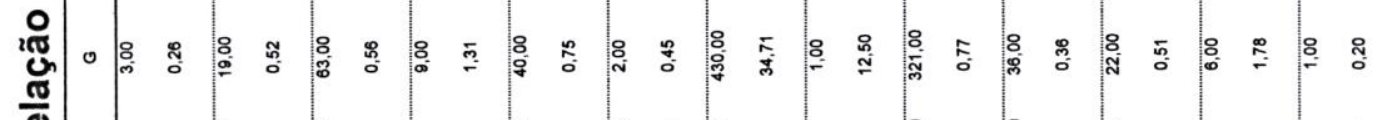
至

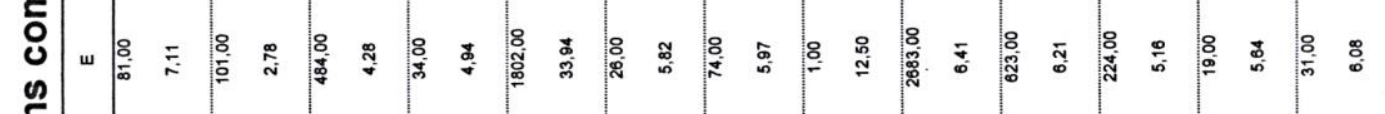
焉

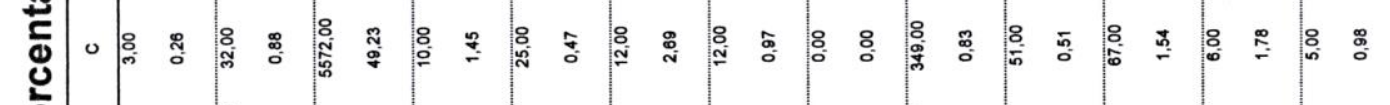
䒘 ๓ 攵 


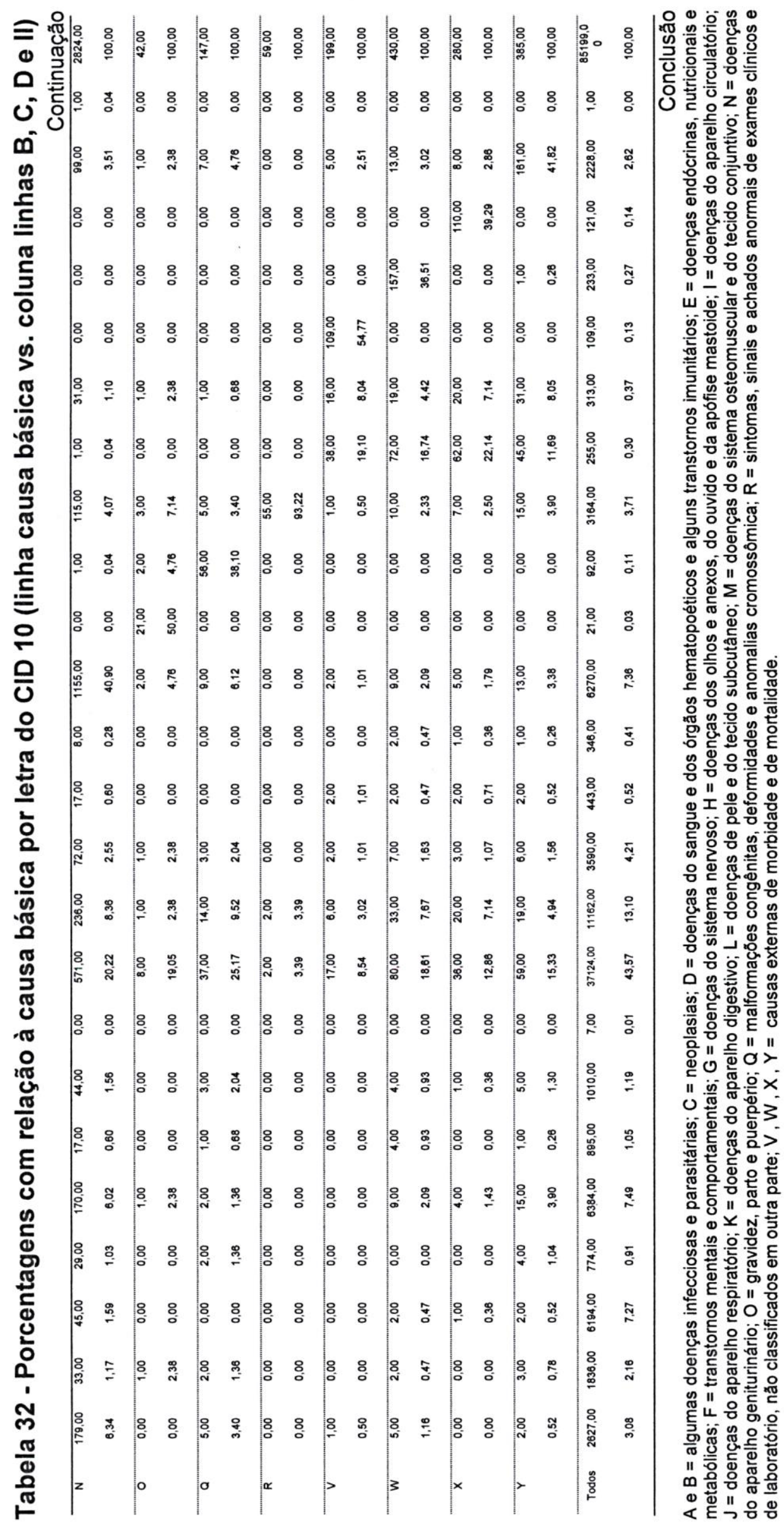


Tabela 33 - Medidas-resumo da idade ao óbito por ano de óbito

\begin{tabular}{|c|c|c|c|c|c|c|c|c|}
\hline \multirow{2}{*}{$\begin{array}{c}\text { Ano de } \\
\text { óbito }\end{array}$} & \multirow[b]{2}{*}{$\mathrm{N}$} & \multicolumn{7}{|c|}{ Idade (anos) } \\
\hline & & Média & $\begin{array}{l}\text { Desvio } \\
\text { padrão }\end{array}$ & Mínimo & $\begin{array}{c}1^{0} \\
\text { quartil }\end{array}$ & Mediana & $\begin{array}{c}3^{0} \\
\text { quartil }\end{array}$ & Máximo \\
\hline 2002 & 435 & 64,3 & 14,9 & 20,3 & 54,3 & 65,8 & 75,9 & 94,5 \\
\hline 2003 & 1.102 & 65,7 & 13,9 & 18,8 & 57,1 & 67,3 & 75,8 & 96,5 \\
\hline 2004 & 1.587 & 66,5 & 14,0 & 18,6 & 57,7 & 68,0 & 76,6 & 101,8 \\
\hline 2005 & 1.785 & 67,1 & 13,6 & 18,3 & 58,4 & 68,6 & 77,2 & 99,5 \\
\hline 2006 & 2.143 & 67,8 & 14,0 & 20,0 & 58,6 & 69,7 & 78,3 & 101,1 \\
\hline 2007 & 2.328 & 68,3 & 13,9 & 20,4 & 59,0 & 70,1 & 78,7 & 97,9 \\
\hline 2008 & 2.826 & 68,9 & 13,6 & 18,5 & 59,6 & 70,7 & 79,0 & 100,9 \\
\hline 2009 & 3.295 & 69,0 & 13,9 & 19,2 & 59,7 & 70,8 & 79,5 & 105,4 \\
\hline 2010 & 3.611 & 70,2 & 13,5 & 19,9 & 61,4 & 71,7 & 80,3 & 103,5 \\
\hline 2011 & 3.893 & 70,8 & 13,6 & 19,2 & 62,0 & 72,3 & 81,0 & 105,1 \\
\hline 2012 & 4.228 & 70,4 & 13,9 & 19,5 & 61,3 & 71,8 & 80,8 & 101,6 \\
\hline 2013 & 4.723 & 71,1 & 13,4 & 19,3 & 62,4 & 72,6 & 81,3 & 104,5 \\
\hline Total & 31.956 & 69,3 & 13,8 & 18,3 & 60,3 & 70,9 & 79,6 & 105,4 \\
\hline
\end{tabular}

$\mathrm{N}=$ número de óbitos 
Tabela 34 - Sobrevida estimada (Kaplan-Meier) para tempo de acompanhamento por número de consultas realizadas (apenas para os pacientes que vieram a óbito)

\begin{tabular}{ccccc}
\hline \multirow{2}{*}{${ }^{0}{ }^{0}$ de consultas } & & $\mathrm{N}$ & \multicolumn{2}{c}{ Tempo de acompanhamento (anos) } \\
\cline { 4 - 5 } & $\mathrm{N}$ & censurados & $\begin{array}{c}\text { Média } \\
\text { (Erro Padrão) }\end{array}$ & $\begin{array}{c}\text { IC 95\% para } \\
\text { Média }\end{array}$ \\
\hline 1 & 24.118 & - & $3,0(0,02)$ & $3,0-3,0$ \\
2 & 5.555 & - & $3,9(0,04)$ & $3,8-4,0$ \\
4 & 1.520 & - & $4,9(0,07)$ & $4,8-5,0$ \\
5 ou mais & 485 & - & $6,0(0,13)$ & $5,8-6,2$ \\
\hline Total & 278 & - & $7,2(0,17)$ & $6,9-7,5$ \\
\hline
\end{tabular}

$\mathrm{N}$ = número de óbitos IC 95\% = intervalo de confiança; - = nulo; Todas as médias apresentaram diferenças significantes entre si com $\mathrm{p}<0,001$ quando comparadas duas a duas (teste Log Rank de Mantel-Cox)

Tabela 35 - Estatísticas calculadas pelo método de Kaplan-Meier para idade ao óbito por número de consultas realizadas (apenas para os pacientes que vieram a óbito)

\begin{tabular}{|c|c|c|c|c|}
\hline \multirow[b]{2}{*}{$\mathrm{N} .{ }^{0}$ de consultas } & \multirow[b]{2}{*}{$\mathrm{N}$} & \multirow{2}{*}{$\begin{array}{c}\mathrm{N} \\
\text { censurados }\end{array}$} & \multicolumn{2}{|c|}{ Idade (anos) } \\
\hline & & & $\begin{array}{c}\text { Média } \\
\text { (Erro padrão) }\end{array}$ & $\begin{array}{c}\text { IC 95\% para } \\
\text { Média }\end{array}$ \\
\hline 1 & 24.118 & - & $68,9(0,1)$ & $68,7-69,1$ \\
\hline 2 & 5.555 & - & $70,0(0,2)$ & $69,6-70,4$ \\
\hline 3 & 1.520 & - & $70,4(0,3)$ & $69,8-71,0$ \\
\hline 4 & 485 & - & $72,8(0,6)$ & $71,6-73,9$ \\
\hline 5 ou mais & 278 & - & $73,9(0,6)$ & $72,7-75,1$ \\
\hline Total & 31.956 & - & $69,3(0,1)$ & $69,1-69,5$ \\
\hline
\end{tabular}


Tabela 36 - Estatísticas calculadas pelo método de Kaplan-Meier para tempo de acompanhamento por sexo (apenas para os pacientes que vieram a óbito)

\begin{tabular}{ccccc}
\hline \multirow{2}{*}{ Sexo } & \multirow{2}{*}{$\mathrm{N}$} & $\mathrm{N}$ & \multicolumn{2}{c}{ Tempo de acompanhamento (anos) } \\
\cline { 4 - 5 } & & censurados & $\begin{array}{c}\text { Média } \\
\text { (Erro Padrão) }\end{array}$ & $\begin{array}{c}\text { IC 95\% para } \\
\text { Média }\end{array}$ \\
\hline Masculino & 17.244 & - & $3,19(0,02)$ & $3,15-3,23$ \\
Feminino & 14.712 & - & $3,50(0,02)$ & $3,45-3,55$ \\
\hline Total & 31.956 & - & $3,33(0,02)$ & $3,30-3,36$
\end{tabular}

$\mathrm{N}=$ número de óbitos; IC 95\% = intervalo de confiança; - = nulo; Observação: teste Log Rank de Mantel-Cox com $p<0,001$

Tabela 37 - Estatísticas calculadas pelo método de Kaplan-Meier para idade ao óbito por sexo (apenas para os pacientes que vieram a óbito)

\begin{tabular}{ccccc}
\hline \multirow{2}{*}{ Sexo } & $\mathrm{N}$ & $\mathrm{N}$ & \multicolumn{2}{c}{ Idade ao óbito (anos) } \\
\cline { 4 - 5 } & & censurados & $\begin{array}{c}\text { Média } \\
\text { (Erro Padrão) }\end{array}$ & $\begin{array}{c}\text { IC 95\% para } \\
\text { Média }\end{array}$ \\
\hline Masculino & 17.244 & - & $68,3(0,1)$ & $68,1-68,5$ \\
Feminino & 14.712 & - & $70,5(0,1)$ & $70,3-70,7$ \\
\hline \multicolumn{1}{c}{ Total } & 31.956 & - & $69,3(0,1)$ & $69,1-69,5$ \\
\hline $\begin{array}{l}\mathrm{N}=\text { número de óbitos; IC 95\% } \\
\mathrm{p}<0,001\end{array}$ & intervalo de confiança; - = nulo Observação: teste Log Rank de Mantel-Cox com
\end{tabular}


Tabela 38 - Estatísticas calculadas pelo método de Kaplan-Meier para tempo de acompanhamento por faixa etária à primeira consulta (apenas para os pacientes que vieram a óbito)

\begin{tabular}{|c|c|c|c|c|}
\hline \multirow[b]{2}{*}{ Faixa Etária } & \multirow[b]{2}{*}{$\mathrm{N}$} & \multirow{2}{*}{$\begin{array}{c}\mathrm{N} \\
\text { censurados }\end{array}$} & \multicolumn{2}{|c|}{ Tempo de acompanhamento (anos) } \\
\hline & & & $\begin{array}{c}\text { Média } \\
\text { (Erro Padrão) }\end{array}$ & $\begin{array}{c}\text { IC 95\% para } \\
\text { Média }\end{array}$ \\
\hline Faixa 1 & 8.039 & - & $3,34(0,03)$ & $3,28-3,40$ \\
\hline Faixa 2 & 7.943 & - & $3,38(0,03)$ & $3,32-3,44$ \\
\hline Faixa 3 & 7.992 & - & $3,49(0,03)$ & $3,43-3,55$ \\
\hline Faixa 4 & 7.982 & - & $3,13(0,03)$ & $3,07-3,19$ \\
\hline Total & 31.956 & - & $3,33(0,02)$ & $3,30-3,36$ \\
\hline
\end{tabular}

Tabela 39 - Estatísticas calculadas pelo método de Kaplan-Meier para idade ao óbito por faixa etária à primeira consulta (apenas para os pacientes que vieram a óbito)

\begin{tabular}{ccccc}
\hline \multirow{2}{*}{ Faixa Etária } & $\mathrm{N}$ & $\mathrm{N}$ & \multicolumn{2}{c}{ ldade ao óbito (anos) } \\
\cline { 4 - 5 } & & censurados & $\begin{array}{c}\text { Média } \\
\text { (Erro Padrão) }\end{array}$ & $\begin{array}{c}\text { IC 95\% para } \\
\text { Média }\end{array}$ \\
\hline Faixa 1 & 8.039 & - & $51,0(0,10)$ & $50,8-51,2$ \\
Faixa 2 & 7.943 & - & $66,1(0,05)$ & $66,0-66,2$ \\
Faixa 3 & 7.992 & - & $75,3(0,04)$ & $75,2-75,4$ \\
Faixa 4 & 7.982 & - & $84,9(0,05)$ & $84,8-85,0$ \\
\hline Total & 31.956 & - & $69,3(0,1)$ & $69,1-69,5$
\end{tabular}

N = número de óbitos; IC 95\% = intervalo de confiança; - = nulo; Observação: teste Log Rank de Mantel-Cox: comparações múltiplas todas com $p<0,001$ 
Tabela 40 - Estatísticas calculadas pelo método de Kaplan-Meier para tempo de acompanhamento por causa básica de óbito (grandes grupos de doenças e apenas para os pacientes que vieram a óbito)

\begin{tabular}{|c|c|c|c|c|}
\hline \multirow[b]{2}{*}{ Causa Básica de Óbito } & \multirow[b]{2}{*}{$\mathrm{N}$} & \multirow{2}{*}{$\begin{array}{c}\mathrm{N} \\
\text { censurados }\end{array}$} & \multicolumn{2}{|c|}{ Tempo de acompanhamento (anos) } \\
\hline & & & $\begin{array}{c}\text { Média } \\
\text { (Erro Padrão) }\end{array}$ & $\begin{array}{l}\text { IC 95\% para } \\
\text { Média }\end{array}$ \\
\hline $\begin{array}{l}\text { Doenças do ap. } \\
\text { circulatório }\end{array}$ & 15.676 & - & $3,20(0,02)$ & $3,16-3,24$ \\
\hline Doenças pulmonares & 3.619 & - & $3,62(0,05)$ & $3,52-3,72$ \\
\hline Neoplasias & 4.560 & - & $3,32(0,04)$ & $3,24-3,40$ \\
\hline Outras doenças & 8.101 & - & $3,47(0,03)$ & $3,41-3,53$ \\
\hline Total & 31.956 & - & $3,33(0,02)$ & $3,30-3,36$ \\
\hline
\end{tabular}

Tabela 41 - Estatísticas calculadas pelo método de Kaplan-Meier para idade ao óbito por causa básica de óbito (grandes grupos de doenças e apenas para os pacientes que vieram a óbito)

\begin{tabular}{|c|c|c|c|c|}
\hline \multirow[b]{2}{*}{ Causa Básica de Óbito } & \multirow[b]{2}{*}{$\mathrm{N}$} & \multirow{2}{*}{$\begin{array}{c}\mathrm{N} \\
\text { censurados }\end{array}$} & \multicolumn{2}{|c|}{ Idade ao óbito (anos) } \\
\hline & & & $\begin{array}{c}\text { Média } \\
\text { (Erro Padrão) }\end{array}$ & $\begin{array}{l}\text { IC 95\% para } \\
\text { Média }\end{array}$ \\
\hline Doenças do ap. circulatório & 15.676 & - & $68,6(0,1)$ & $68,4-68,8$ \\
\hline Doenças pulmonares & 3.619 & - & $73,7(0,2)$ & $73,3-74,1$ \\
\hline Neoplasias & 4.560 & - & $70,5(0,2)$ & $70,1-70,9$ \\
\hline Outras doenças & 8.101 & - & $68,0(0,2)$ & $67,6-68,4$ \\
\hline Total & 31.956 & - & $69,3(0,1)$ & $69,1-69,5$ \\
\hline
\end{tabular}


Tabela 42 - Estatísticas calculadas pelo método de Kaplan-Meier para tempo de acompanhamento por causa básica de óbito (por grupos de doenças cardíacas e apenas para os pacientes que vieram a óbito)

\begin{tabular}{|c|c|c|c|c|}
\hline \multirow[b]{2}{*}{ Causa Básica de Óbito } & \multirow[b]{2}{*}{$\mathrm{N}$} & \multirow{2}{*}{$\begin{array}{c}\mathrm{N} \\
\text { censurados }\end{array}$} & \multicolumn{2}{|c|}{ Tempo de acompanhamento (anos) } \\
\hline & & & $\begin{array}{c}\text { Média } \\
\text { (Erro Padrão) }\end{array}$ & $\begin{array}{l}\text { IC 95\% para } \\
\text { Média }\end{array}$ \\
\hline Grupo 1 & 4.128 & - & $3,17(0,04)$ & $3,09-3,25$ \\
\hline Grupo 2 & 2.938 & - & $2,97(0,05)$ & $2,87-3,07$ \\
\hline Grupo 3 & 1.269 & - & $3,76(0,08)$ & $3,60-3,92$ \\
\hline Grupo 4 & 7.341 & - & $3,21(0,03)$ & $3,15-3,27$ \\
\hline Doenças não cardíacas & 16.280 & - & $3,46(0,02)$ & $3,42-3,50$ \\
\hline Total & 31.956 & - & $3,33(0,02)$ & $3,30-3,36$ \\
\hline
\end{tabular}

$\mathrm{N}$ = número de óbitos; IC 95\% = intervalo de confiança; - = nulo; Grupo 1 = Infarto agudo do miocárdio e outras formas de doença isquêmica do coração; Grupo 2 = cardiomiopatia dilatada, insuficiência cardíaca congestiva (ICC), cardiomiopatia isquêmica, doença cardíaca hipertensiva com insuficiência cardíaca; Grupo 3 = acidente vascular cerebral, outras doenças cerebrovasculares; Grupo 4 = doença aterosclerótica do coração, doença cardíaca hipertensiva sem insuficiência cardíaca, outras formas de doenças cardíacas; Observação: teste Log Rank de Mantel-Cox: Grupo 1 com Grupo 2: $p=0,004$; Grupo 1 com Grupo 4: $p=0,307$; Grupo 3 com Doenças não cardíacas: $p=0,004$; demais comparações múltiplas com $p<0,001$. 
Tabela 43 - Estatísticas calculadas pelo método de Kaplan-Meier para idade ao óbito por causa básica de óbito (por grupos de doenças cardíacas e apenas para os pacientes que vieram a óbito)

\begin{tabular}{|c|c|c|c|c|}
\hline \multirow[b]{2}{*}{ Causa Básica de Óbito } & \multirow[b]{2}{*}{$\mathrm{N}$} & \multirow{2}{*}{$\begin{array}{c}\mathrm{N} \\
\text { censurados }\end{array}$} & \multicolumn{2}{|c|}{ Idade ao óbito (anos) } \\
\hline & & & $\begin{array}{c}\text { Média } \\
\text { (Erro Padrão) }\end{array}$ & $\begin{array}{l}\text { IC 95\% para } \\
\text { Média }\end{array}$ \\
\hline Grupo 1 & 4128 & - & $68,6(0,2)$ & $68,2-69,0$ \\
\hline Grupo 2 & 2938 & - & $68,2(0,3)$ & $67,7-68,7$ \\
\hline Grupo 3 & 1269 & - & $73,5(0,3)$ & $72,9-74,1$ \\
\hline Grupo 4 & 7341 & - & $67,8(0,2)$ & $67,4-68,2$ \\
\hline Doenças não cardíacas & 16280 & - & $70,0(0,1)$ & $69,8-70,2$ \\
\hline Total & 31956 & - & $69,3(0,1)$ & $69,1-69,5$ \\
\hline \multicolumn{5}{|c|}{$\begin{array}{l}\mathrm{N} \text { = número de óbitos; IC 95\% = intervalo de confiança; - = nulo; Grupo } 1 \text { = Infarto agudo do miocárdio e outras } \\
\text { formas de doença isquêmica do coração; Grupo } 2 \text { = cardiomiopatia dilatada, insuficieincia cardíaca congestiva } \\
\text { (ICC), cardiomiopatia isquêmica, doença cardíaca hipertensiva com insuficiência cardíaca; Grupo } 3 \text { - acidente } \\
\text { vascular cerebral, outras doenças cerebrovasculares; Grupo } 4=\text { doença aterosclerótica do coração, doença } \\
\text { cardíaca hipertensiva sem insuficiência cardíaca, outras formas de doenças cardíacas. Observação: teste Log } \\
\text { Rank de Mantel-Cox: Grupo } 1 \text { com Grupo } 2: p=0,001 \text {; Grupo } 1 \text { com Grupo 4: } p=0,016 \text {; Grupo } 2 \text { com Grupo 4: } p \\
=0,152 \text {; demais comparações múltiplas com } p<0,001 \text {. }\end{array}$} \\
\hline
\end{tabular}




\section{REFERÊNCIAS BIBLIOGRÁFICAS}




\section{REFERÊNCIAS BIBLIOGRÁFICAS}

Benjamin EJ, Muntner P, Alonso A, Bittencourt MS, Callaway CW, Carson AP, et al. Heart Disease and Stroke Statistics-2019 Update: A Report From the American Heart Association. Circulation. 2019;139(10):e56-e528.

Brant LCC, Nascimento BR, Passos VMA, Duncan BB, Bensenor IJM, Malta DC, et al. Variações e diferenciais da mortalidade por doença cardiovascular no Brasil e em seus estados, em 1990 e 2015: estimativas do Estudo Carga Global de Doença [on-line]. Rev Bras Epidemiol [internet]. Maio 2017;20(Suppl1):116-28.

Camargo ABM. Idosos e mortalidade: preocupante relação com as causas externas. Fundação SEADE. Fev 2016. Disponível em: http://www.seade.gov.br/wpcontent/uploads/2016/03/Primeira_Analise_35_fev16.pdf

Ceccon RF, Borges DO, Paes LG, Klafke JZ, Viecili PRN. Mortalidade por doenças circulatórias e evolução da saúde da família no Brasil: um estudo ecológico [on-line]. Rev Arq Bras Cardiol. 2001;76:497-503.

Cesse EAP, Carvalho EF, Souza WV, Luna C. Tendência da mortalidade por doenças do aparelho circulatório no Brasil: 1950 a 2000. [on-line]. Arq Bras Cardiol. 2009;93(5):490-7.

Costa JSD, Facchini LA. Utilização de serviços ambulatoriais em Pelotas: onde a população consulta e com que frequência. Rev Saúde Púb. [Internet]. 1997;31(4):3609.

Czarnecki A, Chong A, Lee DS, Schull MJ, Tu JV, Lau C, Farkouh ME, Ko DT. Association between physician follow-up and outcomes of care after chest pain assessment in high-risk patients. Circulation. 2013;127(13):1386-94.

Dalton JE, Perzynski AT, Zidar DA, Rothberg MB, Coulton CJ, Milinovich AT, et al. Accuracy of cardiovascular risk prediction varies by neighborhood socioeconomic position: A retrospective cohort study [on-line]. Ann Intern Med. 2017;167(7):456-64.

Dilélio AS, Tomasi E, Thumé E, Silveira DS, Siqueira FCV, Piccini RX et al. Padrões de utilização de atendimento médico-ambulatorial no Brasil entre usuários do Sistema Único de Saúde, da saúde suplementar e de serviços privados. Cad Saúde Púb. [Internet]. 2014;30(12):2594-606.

Farias N, Souza JMP, Laurenti R, Alencar SM. Mortalidade cardiovascular por sexo e faixa etária em São Paulo, Brasil: 1996 a 1998 e 2003 a 2005. Arq Bras Cardiol. [Internet]. 2009;93(5):498-505.

Ferreira CEC e Lopes LLC. Sobrevivência e esperança de vida em São Paulo. In: Primeira Análise, n.28, Fundação SEADE, São Paulo, 2015. Disponível em: https://www.seade.gov.br/wp-content/uploads/2015/10/primeira_Analise_28_jul.pdf; 
Giordani NE. Riscos competitivos: uma aplicação na sobrevida de pacientes com câncer [dissertação]. Porto Alegre: Universidade Federal do Rio Grande do Sul, Faculdade de Medicina, 2015. Disponível em: https://www.lume.ufrgs.br/bitstream/ handle/10183/132143/000982160.pdf?sequence $=1$

Gomes R, Nascimento EF, Araújo FC. Por que os homens buscam menos os serviços de saúde do que as mulheres? As explicações de homens com baixa escolaridade e homens com ensino superior. Cad Saúde Púb [Internet]. 2007;23(3):565-74.

Greenacre M. Theory and applications for correspondence analysis. London: Academic Press; 1984. Disponível em: http://www.carme-n.org/?sec=books5

IBGE. Instituto Brasileiro de Geografia e Estatística [on-line]. Projeção da População do Brasil e das Unidades Federativas. Brasília. 2018. Disponível em: https://www.ibge.gov.br/apps/populacao/projecao

Kaplan EL, Meier P. Nonparametric estimation from incomplete observations. J Am Stat Assoc. 1958;53(282):457-481.

Krumholz HM, Lin Z, Keenan PS, Chen J, Ross JS, Drye EE, Bernheim SM, Wang Y, Bradley EH, Han LF, Normand SL. Relationship between hospital readmission and mortality rates for patients hospitalized with acute myocardial infarction, heart failure, or pneumonia. J Am Med Assoc. 2013;309(6):587-93.

Lebrão ML. O envelhecimento no Brasil: aspectos da transição demográfica e epidemiológica. [on-line]. Rev Saúde Colet. 2007;04(17):165-40.

Mendoza-Sassi R, Béria JU. Utilización de los servicios de salud: una revisión sistemática sobre los factores relacionados. Cad. Saúde Pública [Internet]. 2001; 17(4):819-32.

Ministério da Saúde - MS. Princípios do SUS. 2019. Disponível em: http://www.saude.gov.br/sistema-unico-de-saude/principios-do-sus

Ministério da Saúde - MS. DATASUS. Indicadores e Dados Básicos - Brasil, 2012. Disponível em: http://www.datasus.gov.br/idb

Ministério da Saúde - MS. Diretrizes para o cuidado das pessoas com doenças crônicas nas redes de atenção à saúde e nas linhas de cuidado prioritárias. [on-line].1 $1^{a}$ edição. Brasília: 2013. Disponível em: http://bvsms.saude.gov.br/bvs/ publicacoes/diretrizes\%20_cuidado_pessoas\%20_doencas_cronicas.pdf

Monteiro CA, Levy RB, Claro RM, de Castro IR, Cannon G. Increasing consumption of ultra-processed foods and likely impact on human health: evidence from Brazil. Pub Health Nutr. 2011;14:5-13.

Organização Pan-Americana de Saúde - OPAS [on-line]. Doenças cardiovasculares. Brasília, DF. Revisado em 2017. Disponível em: https://www.paho.org/bra/index.php? option=com_content\& view=article\&id=5253:doencas-cardiovasculares\&ltemid=839 
Pinheiro RS, Viacava F, Travassos C, Brito AS. Gênero, morbidade, acesso e utilização de serviços de saúde no Brasil [on-line]. Rev Cien Saúde Colet. 2002;7(4):687-707.

Ribeiro MCSA, Barata RB, Almeida MF, da Silva ZP. Perfil sóciodemográfico e padrão de utilização de serviços de saúde para usuários e não-usuários do SUS - PNAD 2003. Ciênc Saúde Colet [Internet]. 2016;11(4):1011-22. Disponível em: http://www.scielo.br/scielo.php?script=sci_arttext\&pid=S1413-81232006000400022\& Ing=en.

Ribeiro ALP, Duncan BB, Brant LCC, Lotufo PA, Mill JG, Barreto SM. Cardiovascular Health in Brazil trends and perspectives. Circulation. 2016;133(4):422-33.

Schmidt MI, Duncan BB, Azevedo e Silva G, Menezes AM, Monteiro CA, Barreto SM, Chor D, Menezes PR. Chronic non-communicable diseases in Brazil: burden and current challenges. Lancet. 2011;377:1949-61.

SEADE. Fundação Sistema Estadual de Análise de Dados. Estatísticas do registro civil: mais um século de informações para o estado de São Paulo. Edição SP Demográfico - Resenha de estatísticas vitais do estado de São Paulo. Out 2018. Disponível em: http://www.seade.gov.br/produtos/midia/2018/10/SPDemografico _Num\%2003_out2018_Divulgacao31102018.pdf

SEADE. Fundação Sistema Estadual de Análise de Dados. Perfil da mortalidade da população no Estado de São Paulo - Resenha de Estatísticas Vitais do Estado de São Paulo. [on-line]. Edição 3. São Paulo; Julho 2014. Disponível em: https://www.seade.gov.br/perfil-da-mortalidade-da-populacao-no-estado-de-saopaulo

SEADE. Fundação Sistema Estadual de Análise de Dados. Portal de estatísticas do estado de São Paulo. 2013. Disponível em: http://produtos.seade.gov.br/produtos/ projpop/index.php

Shurlock B. The Mayo Clinic, Rochester: 'Only the Best need apply'. Eur Heart J [online]. 2009;(9):1017-9.

Sposito AC, Caramelli B, Fonseca FAH, Bertolami MC, Afiune NA, Souza AD et al. IV Diretriz Brasileira sobre dislipidemias e prevenção da aterosclerose: Departamento de Aterosclerose da Sociedade Brasileira de Cardiologia. Arq Bras Cardiol. 2007;88(Suppl1):2-19.

Stevens B, Pezzullo L, Verdian L, Tomlinson J, George A, Bacal F. Os Custos das Doenças Cardíacas no Brasil. Arq Bras Cardiol. 2018;111(1):29-36.

Thumé E, Facchini LA, Wyshak G, Campbell P. The utilization of home care by the elderly in Brazil's primary health care system. Am J Public Health 2011;101:868-74. 
Travassos C, Viacava F, Pinheiro R, Brito A. Utilização dos serviços de saúde no Brasil: gênero, características familiares e condição social. Rev Panam Salud Pública. 2002;11:365-73. Disponível em: https://www.scielosp.org/pdf/rpsp/2002.v11n5-6/365$373 / \mathrm{pt}$

Turci MA, Lima-Costa MF, Proietti FA, Cesar CC, Macinko J. Intraurban differences in the use of ambulatory health services in a large Brazilian city. J Urban Health. 2010;87(6):994-1006.

Veloso DLC, Peres VC, Lopes JSOC, Guimarães JV, Alvim MAP e Veloso FLC. Saúde da mulher trabalhadora no Brasil: Uma revisão integrativa. Brasília Med. 2014;51(3.4):245-54.

Waldvogel BC, Morais LCC, Perdigão ML, Teixeira MP, Freitas RMV, Aranha VJ. Experiência da Fundação SEADE com a aplicação da metodologia de vinculação determinística de bases de dados. Ensaio \& Conjuntura. Fundação SEADE, mar 2019. Disponível em: http://www.seade.gov.br/produtos/midia/2019/04/Ensaio_ conjuntura _Vinculacao.pdf

World Heart Federation - WHF. Cardiovascular diseases (CVDs) - Global facts and figures. Maio, 2017. Disponível em: https://www.world-heart-federation.org/resources/ cardiovascular-diseases-cvds-global-facts-figures

Xavier HT, Izar MC, Faria Neto JR, Assad MH, Rocha VZ, Sposito AC et al. V Diretriz brasileira de dislipidemias e prevenção da aterosclerose. Arq Bras Cardiol. [Internet]. 2013;101(4Suppl1):1-20.

Xavier SS, Sousa AS, Moreno AH. Aplicação da nova Classificação da Insuficiência Cardíaca (ACC/AHA) na Cardiopatia Chagásica Crônica: Análise crítica das curvas de sobrevida. Rev SOCERJ. 2005;18(3):227-32. Disponível em: http://sociedades. cardiol.br/socerj/revista/2005_03/a2005_v18_n03_art06.pdf

Yamada AT, Mansur AJ, Chizzola PR, Hofmann W, Bellotti G. Pileggi, F. Atendimento cardiológico ambulatorial: comparação entre pacientes atendidos em hospital de referência e em centro de saúde comunitário. Arq Bras Cardiol. 1990;55(3):181-7. Disponível em: https://www.researchgate.net/publication/21059755 